\title{
ACUTE LYMPHOBLASTIC LEUKEMIA IN ADOLESCENTS AND YOUNG ADULTS IN FINLAND
}

\author{
Anu Usvasalo
}

ACADEMIC DISSERTATION

To be presented, with the permission of the Faculty of Medicine, University of Helsinki, for public examination in the Niilo Hallman Auditorium,

Hospital for Children and Adolescents, on March $26^{\text {th }}, 2010$, at 12 noon. 


\section{Supervised by}

Professor Ulla M. Pihkala, MD, PhD

Division of Hematology-Oncology and Stem Cell Transplantation

Hospital for Children and Adolescents

University of Helsinki

Helsinki, Finland

Docent Erkki Elonen, MD, PhD

Division of Hematology

Department of Medicine

Helsinki University Central Hospital

Helsinki, Finland

Reviewed by

Docent Veli Kairisto, MD, PhD

TYKSLAB

Turku University Hospital

Turku, Finland

Docent Anne Mäkipernaa, MD, PhD

Coagulation Disorders Unit, Division of Hematology

Department of Medicine

Helsinki University Central Hospital

Helsinki, Finland

Official opponent Docent Tarja-Terttu Pelliniemi, MD, PhD

Department of Clinical Chemistry

University of Turku

Turku, Finland

Cover design Jouko Raudasoja

ISBN 978-952-92-6794-1 (paperback)

ISBN 978-952-10-6052-6 (PDF)

http://ethesis.helsinki.fi

Helsinki University Print

Helsinki 2010 



\section{TABLE OF CONTENTS}

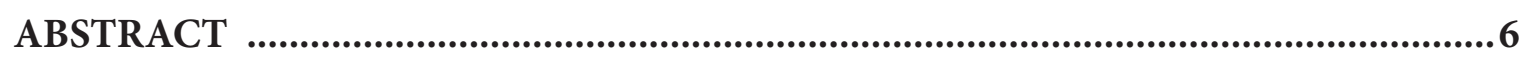

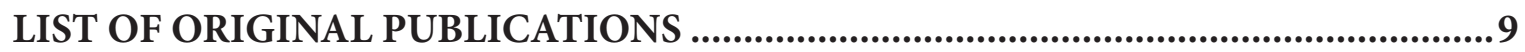

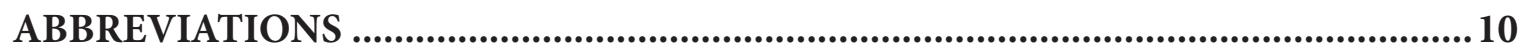

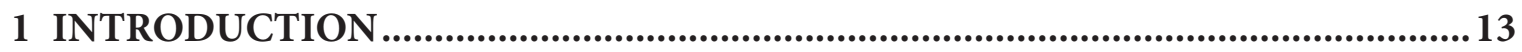

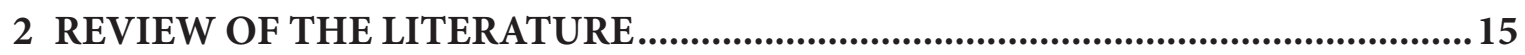

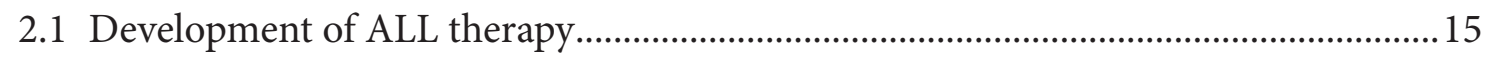

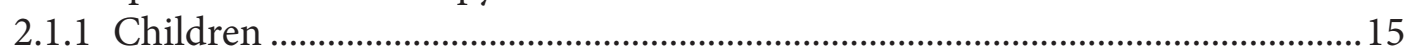

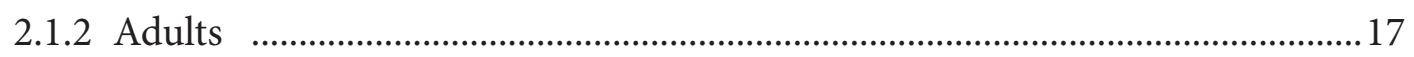

2.2 Adolescents and young adults with acute lymphoblastic leukemia .............................18

2.2.1 Special considerations for adolescents and young adults as ALL patients .....20

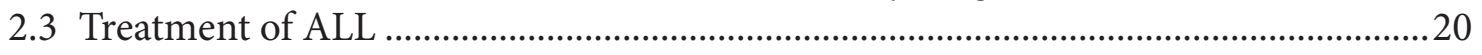

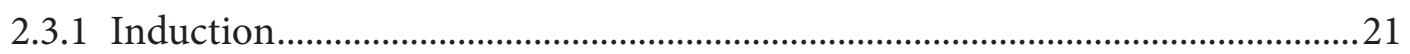

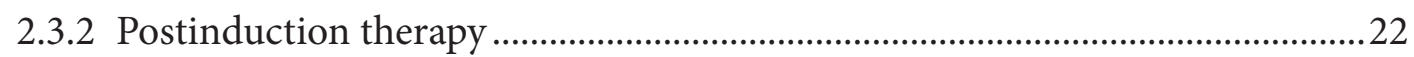

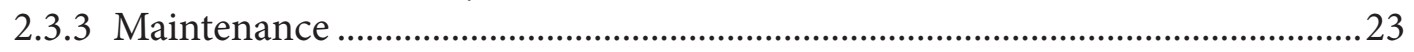

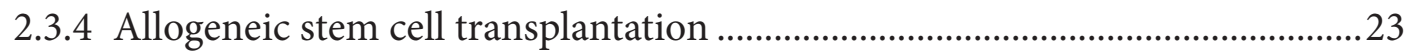

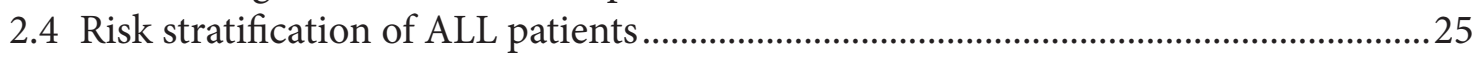

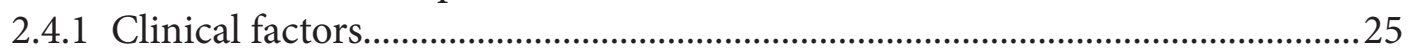

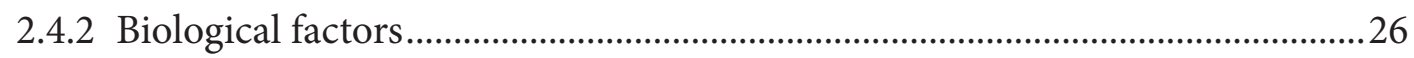

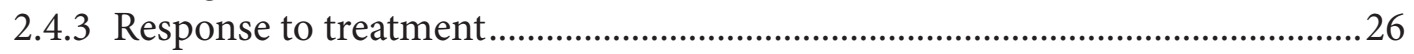

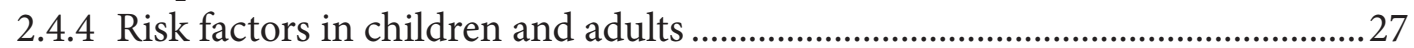

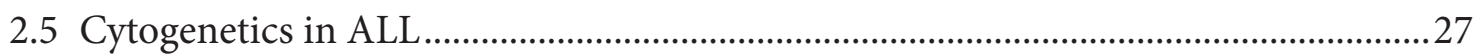

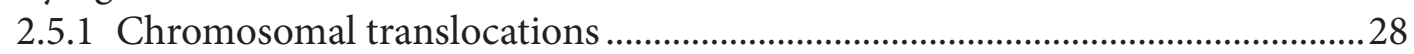

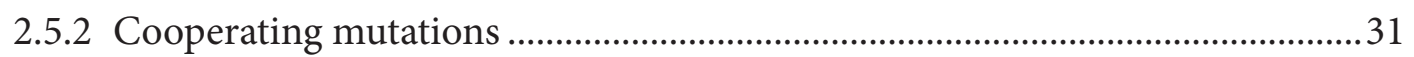

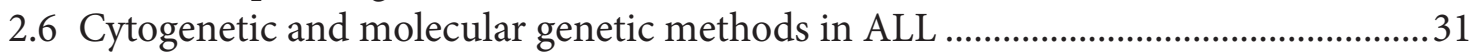

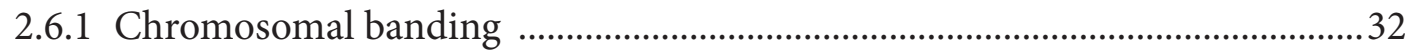

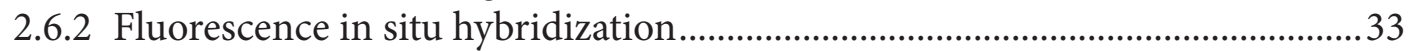

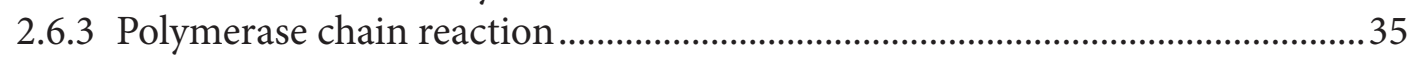

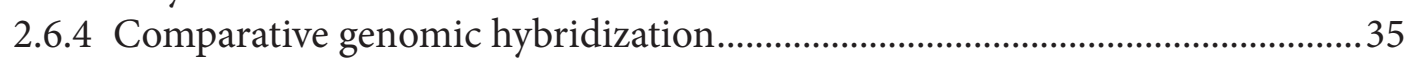

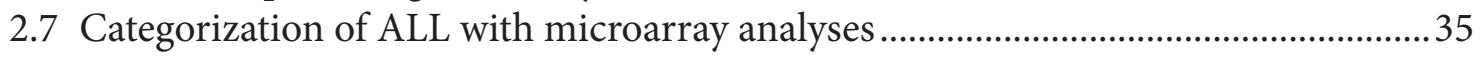

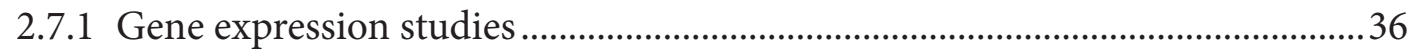

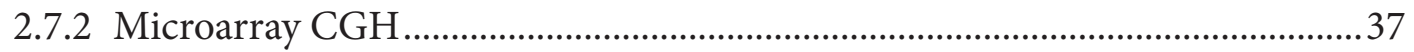

2.7.3 Single-nucleotide polymorphism arrays.............................................................. 38

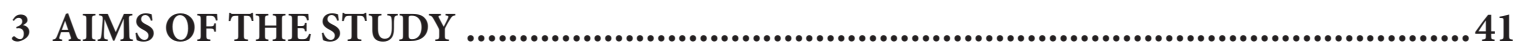




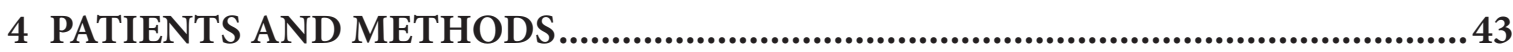

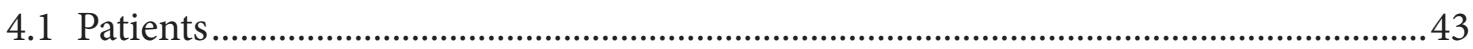

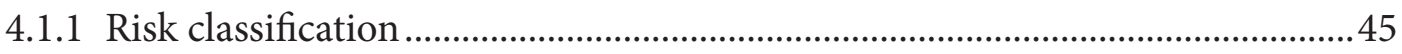

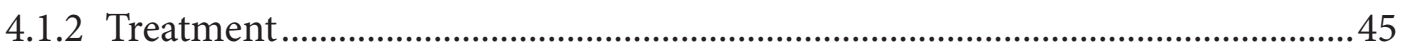

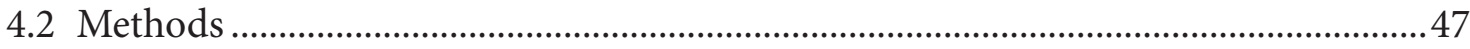

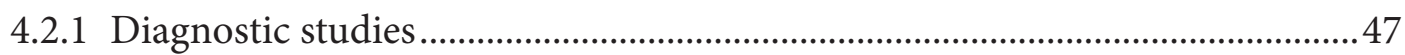

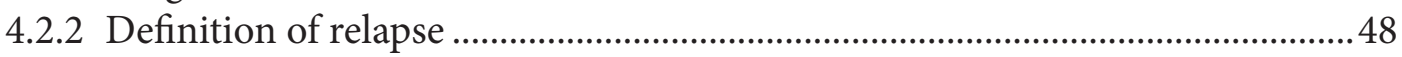

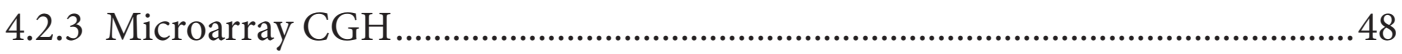

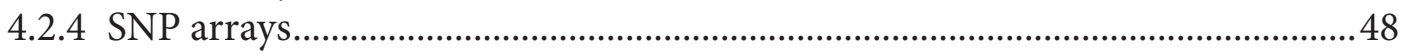

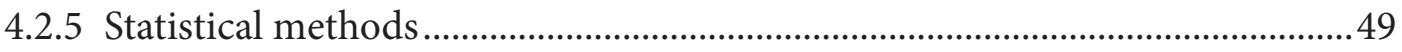

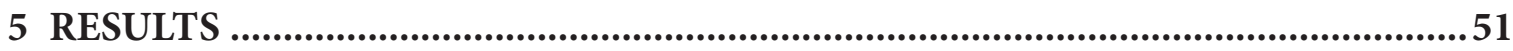

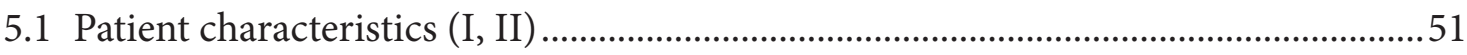

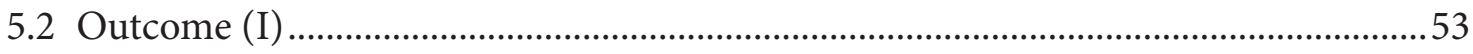

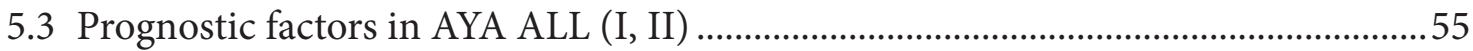

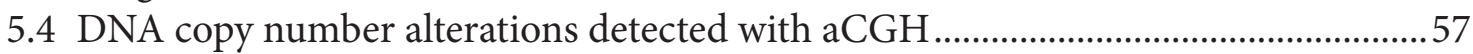

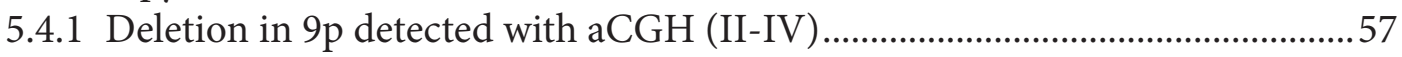

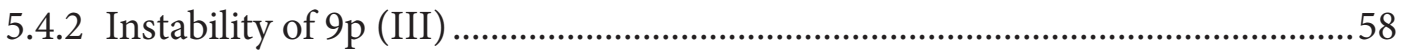

5.4.3 Copy number alterations in patients with initially normal karyotype (IV)....59

5.5 Prognostic classifier of ALL patients based on aCGH data (V) ...................................60

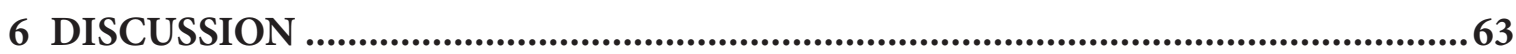

6.1 Adolescents and young adults as a group of ALL patients (I) ....................................63

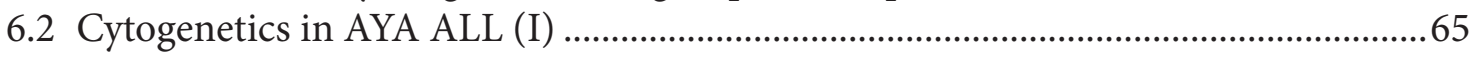

6.3 Copy number alterations in AYA ALL patients detected by aCGH.............................66

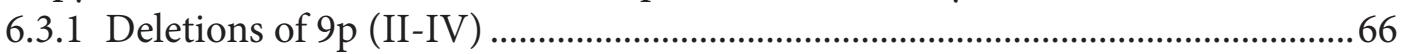

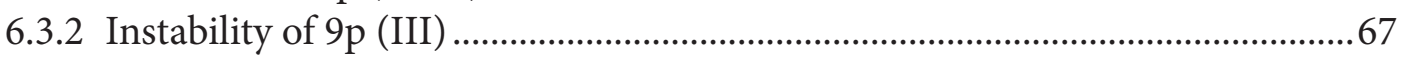

6.3.3 aCGH analysis for patients with initially normal karyotype (IV) ....................6

6.4 Prognostic classification of ALL based on aCGH analysis (V) ..................................69

6.5 Possible differences in the etiology of ALL in children and adults ..............................70

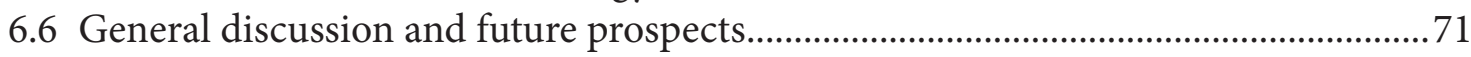

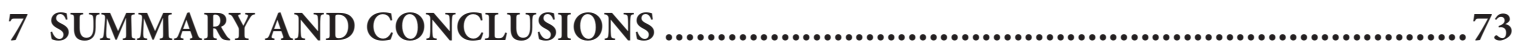

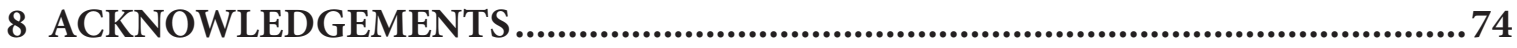

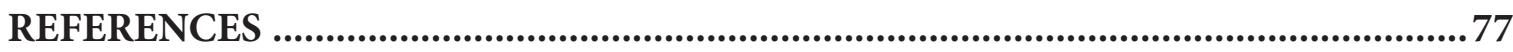




\section{ABSTRACT}

The prognosis of acute lymphoblastic leukemia (ALL) in adolescents and young adults (AYA) is poorer than in children. Older adults have the worst prognosis. In recent reports, AYA patients have had a better outcome with pediatric treatment than with adult protocols. ALL can be classified into biologic subgroups according to immunophenotype and cytogenetic changes, with different clinical characteristics and outcome. The proportions of the subgroups are different in children and adults. ALL subtypes in AYA patients are less well characterized.

In this study, we retrospectively analyzed the treatment and outcome of ALL in AYA patients aged 10-25 years in Finland on pediatric and adult protocols. In total, 245 patients were included. The proportions of biologic subgroups in different age groups were determined. We also elucidated the DNA copy number changes of blast cells in AYA ALL patients at diagnosis with oligonucleotide microarray-based comparative genomic hybridization (aCGH). Deletions and instability of chromosome 9p were screened in 54 AYA patients and in 140 patients from all age groups, respectively. In addition, 107 patients with other hematologic malignancies were screened for $9 p$ instability. Patients with initially normal or failed karyotype $(n=27)$ were examined with aCGH to reveal previously undetected changes of the blast cell genome. aCGH data were also used to determine a gene set that classifies AYA patients $(n=60)$ at diagnosis according to their risk of relapse. Receiver operating characteristic analysis was used to assess the value of the set of genes as prognostic classifiers. Naïve Bayes classifier was applied to categorical (loss-normal-gain) array data. For continuous log-ratio data, a linear regression model was applied.

The outcomes of AYA patients were not significantly different between pediatric and adult protocols, the 5 -year event-free survival being $67 \%$ and $60 \%(p=0.30)$, respectively. This result is clearly different from previous reports from other countries. White blood cell count over $100 \times 10^{9} / 1$ was associated with poor prognosis in the AYA group; 5-year eventfree survival was $27 \%$ compared with $69 \%(\mathrm{p}<0.05)$ in patients with a lower white blood cell count. Patients treated with pediatric protocols and assigned to an intermediate-risk group fared significantly better than those of the pediatric high-risk or adult treatment groups. 
Deletions of $9 \mathrm{p}$ were detected in $46 \%$ of AYA ALL patients. The chromosomal region 9p21.3 was always affected, and the CDKN2A gene was always deleted. In about $15 \%$ of AYA patients, the 9 p21.3 deletion was $<200 \mathrm{~kb}$ in size, and therefore, probably undetectable with conventional methods. Deletion of $9 \mathrm{p}$ was the most common aberration of AYA ALL patients with initially normal karyotype. Of ALL patients aged 2-65 years, $41 \%$ had a deletion or instability of chromosome $9 \mathrm{p}$. This abnormality was restricted to ALL; none of the patients with other hematologic malignancies had the aberration. Instability of $9 p$, defined as multiple separate areas of copy number loss or homozygous loss within a larger heterozygous area in 9p, was detected in 19\% $(n=27)$ of ALL patients. In 5 patients, the $9 p$ instability was the only copy number alteration detected.

The prognostic model identification procedure resulted in a model of four genes: BAK1, CDKN2B, GSTM1, and MT1F. The copy number profile combinations of these genes differentiated between AYA ALL patients at diagnosis depending on their risk of relapse. Deletions of CDKN2B and BAK1 in combination with amplification of GSTM1 and MT1F were associated with a higher probability of relapse. The performance of the model was poorer in other age groups, possibly because of different disease biology profiles.

Unlike all previous studies, we found that the outcome of AYA patients with ALL treated using pediatric or adult therapeutic protocols was comparable. The success of adult ALL therapy emphasizes the benefit of referral of patients to academic centers and adherence to research protocols. $9 \mathrm{p}$ deletions and instability are common features of ALL in adolescents and may act together with oncogene-activating translocations in leukemogenesis. New and more sensitive methods of molecular cytogenetics can reveal previously cryptic genetic aberrations with an important role in leukemic development and prognosis and that may be potential targets of therapy. aCGH also provides a viable approach for model design aiming at evaluation of risk of relapse in ALL. 


\section{LIST OF ORIGINAL PUBLICATIONS}

This thesis is based on the following original articles referred to in the text by Roman numerals I-V:

I Usvasalo A, Räty R, Knuutila S, Vettenranta K, Harila-Saari A, Jantunen E, Kauppila M, Koistinen P, Parto K, Riikonen P, Salmi TT, Silvennoinen R, Elonen E, Saarinen-Pihkala UM. Acute lymphoblastic leukemia in adolescents and young adults in Finland. Haematologica 2008;93(8):1161-1168.

II Usvasalo A*, Savola S*, Räty R, Vettenranta K, Harila-Saari A, Koistinen P, Savolainen ER, Elonen E, Saarinen-Pihkala UM, Knuutila S. CDKN2A deletions in acute lymphoblastic leukemia of adolescents and young adults-An array CGH study. Leukemia Research 2008;32(8):1228-1235.

III Usvasalo A, Ninomiya S, Räty R, Hollmén J, Saarinen-Pihkala UM, Elonen E, Knuutila S. Focal 9p instability in hematologic neoplasias revealed by comparative genomic hybridization and single-nucleotide polymorphism microarray analyses. Genes, Chromosomes \& Cancer 2010;49(4):309-318.

IV Usvasalo A, Räty R, Harila-Saari A, Koistinen P, Savolainen ER, Vettenranta K, Knuutila S, Elonen E, Saarinen-Pihkala UM. Acute lymphoblastic leukemias with normal karyotypes are not without genomic aberrations. Cancer Genetics and Cytogenetics 2009;192(1):10-17.

V Usvasalo A, Elonen E, Saarinen-Pihkala UM, Räty R, Harila-Saari A, Koistinen P, Savolainen ER, Knuutila S, Hollmén J. Prognostic classification of patients with acute lymphoblastic leukemia by using gene copy number profiles identified from array-based comparative genomic hybridization data. Leukemia Research (in press).

${ }^{*}$ These authors contributed equally to the study.

Study II was also included in Suvi Savola's thesis entitled Microarrays in molecular profiling of Ewing sarcoma family of tumors and CDKN2A aberrations (Helsinki 2009).

These articles were reprinted with the permission of their copyright holders. Some previously unpublished data are also presented. 


\section{ABBREVIATIONS}

1CR

$\mathrm{aCGH}$

ALL

AML

ARA-C

AUROC

AYA

BAC

BFM

CCR

cDNA

$\mathrm{CGH}$

CLL

CML

CNS

CR

DNA

DFS

EFS

FAB

FISH

HDAC

HLA

HOX

HR

hyper-CVAD

iAMP21

IGG

IR

$\mathrm{kb}$

$\mathrm{LOH}$

$\mathrm{Mb}$

M-bcr

$\mathrm{m}-\mathrm{bcr}$

MDS

MRD first complete remission

microarray comparative genomic hybridization

acute lymphoblastic leukemia

acute myeloid leukemia

cytosine arabinoside

area under the ROC curve

adolescents and young adults

bacterial artificial chromosome

Berlin-Frankfurt-Münster

continuous complete remission

complementary DNA

comparative genomic hybridization

chronic lymphocytic leukemia

chronic myeloid leukemia

central nervous system

complete remission

deoxyribonucleic acid

disease-free survival

event-free survival

French-American-British

fluorescence in situ hybridization

high-dose ARA-C

human leukocyte antigen

homeobox

high risk

hyperfractionated cyclophosphamide, vincristine, doxorubicin, and dexamethasone

intrachromosomal amplification of chromosome 21

immunoglobulin gene

intermediate risk

kilobase (pair)

loss of heterozygocity

megabase (pair)

major breakpoint cluster region

minor breakpoint cluster region

myelodysplastic syndrome

minimal residual disease 


$\begin{array}{ll}\text { mRNA } & \text { messenger ribonucleic acid } \\ \text { MT } & \text { metallothionein } \\ \text { NB } & \text { Naïve Bayes } \\ \text { NOPHO } & \text { Nordic Society of Paediatric Haematology and Oncology } \\ \text { OS } & \text { overall survival } \\ \text { PCR } & \text { polymerase chain reaction } \\ \text { Ph+ } & \text { Philadelphia chromosome-positive } \\ \text { RAG } & \text { recombination activating gene } \\ \text { ROC } & \text { receiver operating characteristic } \\ \text { RT-PCR } & \text { reverse transcriptase PCR } \\ \text { SCT } & \text { stem cell transplantation } \\ \text { SNP } & \text { single-nucleotide polymorphism } \\ \text { SR } & \text { standard risk } \\ \text { T-ALL } & \text { T-cell ALL } \\ \text { TCR } & \text { T-cell receptor } \\ \text { URD } & \text { unrelated donor } \\ \text { V(D)J } & \text { Variable, Diversity, and Joining genes } \\ \text { WBC } & \text { white blood cell count }\end{array}$

All gene symbols in the text are indicated in italics and are in accordance with the guidelines of the Human Genome Organization Nomenclature Committee (HGNC). Detailed information about these genes can be found at the website www.ncbi.nlm.nih.gov/gene. 


\section{INTRODUCTION}

In children, acute lymphoblastic leukemia (ALL) comprises about $25 \%$ of all malignancies. In adults, the proportion is less than $1 \%$. ALL is most common in preschool children. Another incidence peak is seen in adults aged over 50 years. In adolescents and young adults (AYA), ALL is relatively rare (Faderl et al. 2003). The survival rate of children with ALL has improved during the past four decades from $15 \%$ to over $80 \%$ (Gustafsson et al. 2000; Moghrabi et al. 2007). Prospective clinical cooperative trials have had a major impact on this favorable development. Despite extensive efforts to treat ALL in adults, the outcome remains in the range of 35-50\% (Linker et al. 2002; Kantarjian et al. 2004). AYA patients have a prognosis that lies between these age groups (Barry et al. 2007; Ribera et al. 2008). Treatment results of AYA with pediatric protocols have been better than those with adult protocols (Boissel et al. 2003).

ALL is a group of diseases with distinct cytogenetic abnormalities associated with certain clinical characteristics and outcome. The distribution of these subgroups changes with age. Subtypes associated with good prognosis are more common in children, whereas adults have more of the subtypes of poor prognosis (Pui et al. 1998). As with outcome, AYA patients form a separate group from children and adults with regard to disease biology. In AYA patients, the proportion of unspecified cytogenetic abnormalities not included in known subgroups of ALL is larger. This implies that clinically relevant chromosomal aberrations remain undiscovered. Microarray methods have provided a new approach to molecular cytogenetic analyses in addition to conventional methods. They enable screening of the whole genome in one experiment without prior assumption of possible aberrations (Mullighan et al. 2009a). They have already revealed previously undetected genetic changes and extended comprehension of possible mechanisms behind leukemia formation (Paulsson et al. 2006). They have also shown potential in classifying ALL patients into known biologic or prognostic subgroups (Yeoh et al. 2002).

Despite the improvement in outcome of ALL patients, the main challenge remains to identify patients with a high risk of relapse and to design ALL therapy according to the disease biology. Novel methods to discover new alterations in the blast cell genome play a crucial role when aiming at the best possible outcome for ALL patients with different subtypes of the disease. 


\section{REVIEW OF THE LITERATURE}

Acute lymphoblastic leukemia (ALL) is a malignant disease of bone marrow. It is characterized by uncontrolled multiplication of malignant, immature lymphoid cells. These cells have lost their capacity to differentiate into mature blood cells. In normal hematopoiesis, lymphoid cells differentiate along two major lines, the B-cell line and the T-cell line. Lymphoid malignancy can emerge from either of these lines and from different maturation stages of the lymphoid cells. ALL is not a single uniform disease, but rather consists of several disease subgroups with different cytogenetic and molecular genetic changes, clinical presentation, and outcome.

The incidence of acute leukemias in Finland is about 240 new patients/year. About 20\% of these are children. The peak incidence is seen at 2-5 years of age (4-5 patients/100 000). Another, smaller peak is seen in adults older than 50 years (1/100 000). In infants ( $<1$ year), ALL is rare. Of the pediatric leukemias, $75 \%$ are ALL. ALL is the most common malignant disease in children, accounting for approximately $25 \%$ of all pediatric malignancies. In adults, ALL constitutes about $20 \%$ of all acute leukemias and $<1 \%$ of all malignancies. Because of the higher incidence of malignancies in adults, the absolute number of patients with ALL is quite similar in children and adults (35-45/year in Finland). (Faderl et al. 2003; Engholm et al. 2009, NORDCAN: Cancer Incidence, Mortality, Prevalence and Prediction in the Nordic Countries, Version 3.5 http://www.ancr.nu).

\subsection{Development of ALL therapy}

\subsubsection{Children}

The cure rate for pediatric ALL has improved from 15\% in the late 1960s to figures approaching or even exceeding $80 \%$ today. Already in 1948, Farber and coworkers demonstrated a temporary remission in children with ALL treated with a folic acid antagonist, aminopterin. A few years later, administration of steroids was also shown to induce remission in ALL (Pearson et al. 1950). Despite these observations, ALL was considered a fatal disease until the 1960s, when the development of multiagent chemotherapy regimens used today started. In the 1960s, consecutive studies with combined multiagent chemotherapy showed prolonged survival. As the length of remission increased, the problem of central nervous system (CNS) involvement became more evident. The CNS was realized to 
be a hidden site of leukemia even if the CNS disease was not measurable at diagnosis. In the 1970s, when prophylactic CNS irradiation, and later also intrathecal therapy, was started, the chance of therapy discontinuation and also a permanent cure became more possible (Pinkel et al. 1972). Since then, carefully designed studies have led to the discovery of effective multiagent chemotherapy combinations, including routine use of prophylactic CNS-directed therapy. In the 1980s, delayed intensification was brought into the protocols by the Berlin-Frankfurt-Münster (BFM) study group, with a major impact on outcome (Henze et al. 1981). Thereafter, slow but continuous improvement has taken place due to the development of clinical treatment trials, risk-adapted therapy, follow-up of residual disease during treatment, better use of blood products and granulocyte-stimulating growth factors, treatment of infections, and improved nutritional support during treatment (Larson et al. 1998; Seibel et al. 2008).

Since 1981, the Nordic Society of Paediatric Haematology and Oncology (NOPHO) has maintained a population-based registry on all cases of pediatric ALL in the Nordic countries of Denmark, Finland, Iceland, Norway, and Sweden. From the 1980s to 1992, the treatment of ALL has developed from national protocols to uniform protocols in the Nordic countries, and in 1992 common Nordic protocols for all risk groups of pediatric ALL were introduced (Gustafsson et al. 1998). Thus far, the development of these protocols has led to three consecutive clinical trials for all risk groups. The most recent of these was introduced in 2008. During the 1980s the event-free survival (EFS) improved from about $50 \%$ to $70 \%$ (Lie et al. 1992). During the 1990s the survival of ALL patients was further improved, reaching $80 \%$ at the end of the decade and showing similar results by the most prominent research groups (Figure 1) (Eden et al. 2000; Gaynon et al. 2000; Gustafsson et al. 2000; Maloney et al. 2000; Pui et al. 2000; Schrappe et al. 2000b; Silverman et al. 2000).

Despite significant improvements in outcome for childhood ALL, one of the largest challenges remains that about $25 \%$ of patients experience relapse. Remarkably, two-thirds of these failures occur unpredictably in patients of standard-risk (SR) or intermediate risk (IR) treatment groups without unfavorable prognostic features at diagnosis (Gustafsson et al. 1998). A great deal of emphasis is therefore now being placed on developing new prognostic markers to refine the existing risk classification.

ALL in infants differs biologically from that of older children. The outcome of infants with ALL has been inferior compared with older children. In 1999, a large international collaborative trial, Interfant-99, was initiated in 22 countries, including the Nordic countries (Pieters et al. 2007). 


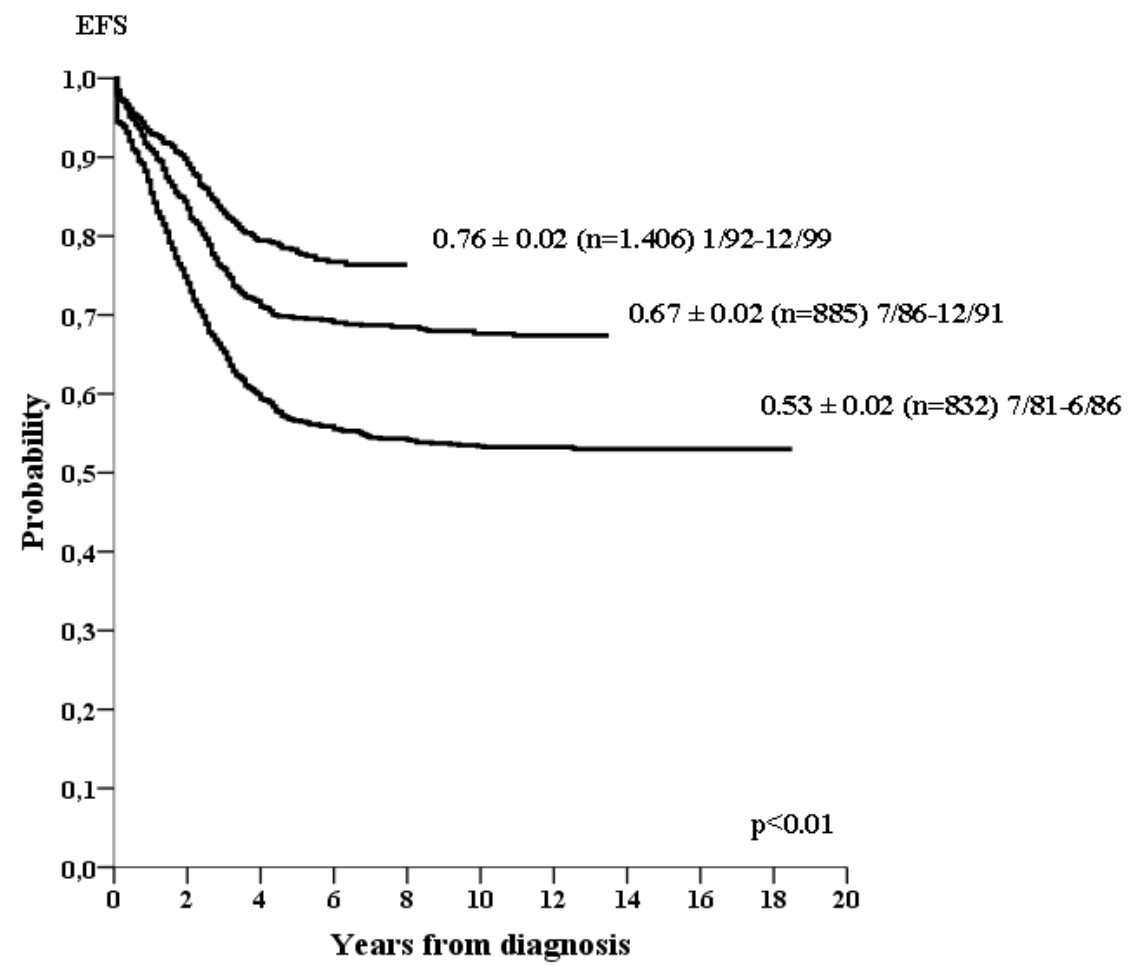

Figure 1. Event-free survival of children with acute lymphoblastic leukemia treated in Nordic countries during different time periods. Courtesy of Dr. Göran Gustafsson, NOPHO Annual Report 2000.

\subsubsection{Adults}

Measures have also been taken in treatment of adult ALL to lead to improved survival. Despite this, the progress in adult ALL therapy has been modest. During the 1980s the 5 -year disease-free survival (DFS) of adults was about 35\%, in contrast to about 50\% in children (Hussein et al. 1989). In the 1990s, the development of ALL treatment for adults started to lag behind. Although the complete remission (CR) rate is over $90 \%$, long-term survival has remained at a level of 35-50\% (Larson et al. 1998; Linker et al. 2002; Kantarjian et al. 2004; Thomas et al. 2004; Ribera et al. 2005; Rowe et al. 2005; Ribera et al. 2008). Recently, a French group reported an overall survival (OS) of 60\% after a 42-month follow-up of patients aged 15-60 years treated with a "pediatric-inspired" protocol (Huguet et al. 2009).

In adults, both relapse rate and treatment-related mortality have been considerably higher than in children (Pui et al. 2006). The inferior outcome of adults is probably partly due to poorer tolerance of therapy in adults, and partly because of evident changes in disease biology with age. The most notable difference is in the incidence of $t(9 ; 22)$; this ALL subgroup, associated with a very poor prognosis, accounts for about $30 \%$ of adult ALL, while being uncommon $(<5 \%)$ in children (Pui et al. 1998). A recent advance in this field has been 
the introduction of imatinib and other tyrosine kinase inhibitors. They have been used as part of combination regimens and also as a single agent. Although the capability of imatinib to improve cure rates is still uncertain, it has clearly extended the DFS (Thomas et al. 2004; de Labarthe et al. 2007; Schultz et al. 2009).

In Finland, there have been three consecutive clinical trials of adult ALL treatment since 1990, introduced by the Finnish Leukemia Group. All trials consist of six treatment blocks and maintenance therapy, and the duration of treatment is three years. In the first ALL90 trial, induction resembled that of the BFM regimen, including steroids, vincristine, anthracycline, and asparaginase. In the next ALL94 trial, induction was based on high doses of cytarabine (ARA-C) together with etoposide and anthracycline. The problem with this regimen was prolonged granulocytopenia, which led to increased risk of infections and delays with the next treatment block. A new induction design was therefore introduced in the ALL2000 trial, which was based on another regimen of hyperfractionated cyclophosphamide, vincristine, doxorubicin, and dexamethasone (hyper-CVAD). Regarding the total doses of different cytostatics administered during intensive chemotherapy in subsequent trials, the doses of steroids, asparaginase, and methotrexate have been reduced significantly, whereas those of cytarabine, cyclophosphamide, and anthracyclines have increased. The basis of maintenance therapy has been similar in all of the trials, containing oral mercaptopurine and methotrexate combined with vindesine/vincristine and steroid pulses (E. Elonen, personal communication).

\subsection{Adolescents and young adults with acute lymphoblastic leukemia}

As prognosis of pediatric ALL has improved, increasing interest has been paid to adolescents and young adults (AYA), a subgroup of ALL patients with an intermediate prognosis between that of younger children and older adults. Recently, several studies from the United States and Europe have compared the outcome of AYA in pediatric vs. adult clinical trials (Hallbook et al. 2002; Boissel et al. 2003; de Bont et al. 2004; Ramanujachar et al. 2007; Stock et al. 2008). In individual studies, the presenting clinical and biologic features in both treatment groups were similar, with the exception of median age. Despite differences in treatment approaches, all of these retrospective analyses have shown that the outcome of AYA patients is better when treated on pediatric protocols as opposed to adult protocols. The EFS on pediatric protocols has been 63-69\%, but significantly lower, 31-49\%, on adult protocols (Table 1). This is a result of both a better CR rate and a lower relapse rate in the subgroups treated with pediatric protocols. 
Table 1. Comparison of AYA ALL patients in pediatric vs. adult clinical trials.

\begin{tabular}{|c|c|c|c|c|}
\hline Study group & Period & $\begin{array}{c}\text { Age } \\
\text { (years) }\end{array}$ & EFS & Reference \\
\hline CCG / CALGB (USA) & $\begin{array}{l}1988- \\
2001\end{array}$ & $16-21$ & $\begin{array}{c}63 \% \text { vs. } 34 \% \\
(7 \text { years })\end{array}$ & Stock et al. 2008 \\
\hline $\begin{array}{l}\text { MRC ALL / UKALL } \\
\text { (UK) }\end{array}$ & $\begin{array}{l}1997- \\
2002\end{array}$ & $15-17$ & $\begin{array}{l}\text { 65\% vs. } 49 \% \\
(5 \text { years })\end{array}$ & Ramanujachar et al. 2007 \\
\hline $\begin{array}{l}\text { FRALLE-93 / LALA-94 } \\
\text { (France) }\end{array}$ & $\begin{array}{c}1993- \\
1999\end{array}$ & $15-20$ & $\begin{array}{l}67 \% \text { vs. } 41 \% \\
(5 \text { years })\end{array}$ & Boissel et al. 2003 \\
\hline $\begin{array}{l}\text { DCOG / HOVON } \\
\text { (Holland) }\end{array}$ & $\begin{array}{c}1985- \\
1999\end{array}$ & $15-18$ & $\begin{array}{l}69 \% \text { vs. } 34 \% \\
(5 \text { years })\end{array}$ & de Bont et al. 2004 \\
\hline $\begin{array}{l}\text { NOPHO / Swedish } \\
\text { adult (Sweden) }\end{array}$ & $\begin{array}{l}1992- \\
2000\end{array}$ & $10-40$ & $\begin{array}{c}66 \% \text { vs. } 31 \% \\
\text { (5 years) }\end{array}$ & Hallböök et al. 2006 \\
\hline
\end{tabular}

One obvious reason behind the gap in survival of adolescents in pediatric vs. adult trials is the study protocol. A major difference between protocols is usually the more intensive use of the nonmyelosuppressive drugs glucocorticoids, asparaginase, and vincristine by pediatric groups. On the other hand, pediatric protocols utilize lower doses of ARA-C and anthracyclines (Ramanujachar et al. 2006). Morbidity during induction and postremission deaths have been higher in AYA patients than in children and also on adult protocols compared with pediatric ones (Chessells et al. 1998; Kantarjian et al. 2000; Silverman et al. 2000; Annino et al. 2002; Thomas et al. 2004). Potential differences in the adherence to therapy protocols among pediatric vs. adult medical oncologists and their patients have also been debated (Chessells et al. 1998; Schiffer 2003; DeAngelo 2005). However, being retrospective in nature, reports published to date do not provide comprehensive or reliable compliance data.

In some pediatric trials, the upper age limit has been extended to also cover young adults. In the pediatric trial of the Dana-Farber Cancer Institute, the age limit was extended to 18 years (Barry et al. 2007). The EFS of patients aged 1-10 years tended to be superior compared to older patients, although the difference was not statistically significant. Adolescents had more treatment-related complications than patients $<10$ years of age, but no difference was reported between the age groups 10-15 years and 15-18 years. In Spain, patients aged 1-30 years were treated according to a pediatric protocol during 1996-2005 (Ribera et al. 2008). No difference in outcome was observed between patients 15-18 years and those 19-30 years. The Children's Cancer Group also reported an improved outcome for patients aged 16-21 years on a pediatric protocol, with a 5-year EFS of $72 \%$ (Nachman et al. 2009).

Based on the encouraging results of treatment of ALL in adolescents achieved by the pe- 
diatric hematology-oncology community, some adult cooperative groups have recently begun prospective studies utilizing unmodified pediatric designs or pediatric-inspired approaches for adults aged up to 30 years and even up to 60 years. At this point, the follow-up has been fairly short, but preliminary results suggest that it is feasible to apply the pediatric-inspired approach that focuses on dose-intensive use of glucocorticoids, asparaginase, and vincristine to treat older adults with ALL, at least until the age of 45 years (Huguet et al. 2009).

\subsubsection{Special considerations for adolescents and young adults as ALL patients}

In many countries, adolescent patients receive treatment from either pediatric or adult oncologists depending on the local referral pattern (DeAngelo 2005). ALL is the most common leukemia found in children and probably the most common cancer treated by pediatric oncologists. By contrast, the proportion of ALL in adult cancer patients is lower and the majority of adult leukemia patients have diagnoses such as acute myeloid leukemia, myeloproliferative disorders, or chronic leukemias. Virtually all children with ALL are referred to pediatric centers and treated in clinical trials by physicians with experienced support teams that focus primarily on this disease. In many countries, this is not the case with adult ALL patients, and many of them are not treated in clinical trials (Bleyer 2005). They are also more often treated at nonacademic centers. Patients treated in trials are shown to fare better than those who are not enrolled (Nachman et al. 1993). When treated in either adult or pediatric clinical trials, AYA patients comprise a relatively small percentage of ALL trial populations and are often analyzed together with patients aged 10-15 years in pediatric series or patients 20-30 years and older in adult clinical trials (Burke et al. 2007). Most adult ALL trials are designed for a broad age group of 16-60 years and take into account possible comorbidities and problems with tolerance to treatment. Younger adults may therefore be underdosed (Nachman 2005). One important factor among patients receiving pediatric treatment is the active role of parents and committed care of their offspring. The parents of a child with ALL usually ensure compliance of their child undergoing a prolonged and strenuous chemotherapy (Jeha 2003). Adolescence is the time for independence and a malignant illness poses a great challenge between the need for parental care and autonomy of the patient. Adolescents generally require intensive psychosocial support (Dini et al. 2008).

\subsection{Treatment of ALL}

The goal of ALL therapy is restoration of normal hematopoiesis, prevention of drugresistant subclones of blast cells, CNS prophylaxis, and elimination of minimal residual 
disease (MRD) through postremission consolidation (Faderl et al. 2003). The basis for ALL treatment is the combination of different cytostatic drugs administered in a dose- and time-intensive manner.

Most pediatric protocols are based on a model developed in Germany, the BFM protocol (Henze et al. 1981). The BFM regimen was originally formulated by the German BFM Pediatric Group and has later been adopted and modified by many groups, also by adult hematologic cooperative groups. The main principles are that early chemotherapy intensification (consolidation) is essential for prevention of resistant clones and that late intensification (reinduction) with new drugs or analogs of previously used drugs is necessary to eliminate drug-resistant cells.

Also in adult ALL, several cooperative groups have performed prospective trials to improve outcome and reduce treatment-related toxicity. Some studies have included patients over 60 years of age (Larson et al. 1998; Hallbook et al. 2002; Kantarjian et al. 2004). Although many regimens have been developed, most of them are based on either the BFM or hyperfractionated cyclophosphamide, vincristine, doxorubicin, and dexamethasone (Hyper-CVAD) regimens. The hyper-CVAD combination was developed at the MD Anderson Cancer Institute (Houston, Texas) originally for the treatment of mature B-cell ALL (Murphy et al. 1986). In ALL treatment, it has been investigated in adults only.

The treatment of ALL generally consists of remission-induction therapy, followed by consolidation (intensification) therapy and maintenance. All treatment protocols also include CNS-directed therapy in the form of intrathecal administration of methotrexate and/or ARA-C given throughout the systemic chemotherapy, starting early in the induction. In addition, CNS radiotherapy is used in some cases (Faderl et al. 2003; Pui et al. 2008).

\subsubsection{Induction}

The aim of remission induction therapy is to eradicate more than $99 \%$ of leukemic blast cells and restore normal hematopoiesis (Pui et al. 2006). Achieving CR with induction is important for long-term survival (Rowe et al. 2005; Bruggemann et al. 2006). The basic regimen for induction therapy includes at least a glucocorticoid (prednisone, prednisolone, or dexamethasone) and vincristine (Pui et al. 1998). Dexamethasone has shown higher drug levels in cerebrospinal fluid and has to a large degree replaced prednisone in induction therapy in adult trials (Jones et al. 1991; Bostrom et al. 2003). On the other hand, dexamethasone has been associated with more aseptic bone necroses and an increased incidence of infections (Hurwitz et al. 2000; Mitchell et al. 2005). Its use in pediatric trials is therefore variable, and 
it is mostly used in later phases in pediatric protocols. Adding an anthracycline (doxorubicin, daunorubicin, or idarubicin) has improved the CR rate and remission duration (Kantarjian 1994). In other studies, reduction of anthracyclines in induction for patients with a low risk of relapse has not resulted in decreased survival (Schrappe et al. 2000a; Moricke et al. 2008). Asparaginase is included in most pediatric trials and also in many BFM-based adult trials, often in lower doses than in pediatric therapy because of toxicity concerns (e.g. hypersensitivity, pancreatitis, liver toxicity, hyperglycemia, neuropathy, and coagulation disorders) in adults (Earl 2009). An adult trial without asparaginase has shown comparable outcomes to regimens including the drug (Kantarjian et al. 2004). Intensification of induction with cyclophosphamide has been used in pediatric trials as well as in adult trials, although its benefit in improving the rate or duration of remission is controversial (Larson et al. 1995; Annino et al. 2002). With this four- or five-drug combination in induction, the CR rates have been $97-99 \%$ for children and 78-93\% for adults (Annino et al. 2002; Hallbook et al. 2002; Linker et al. 2002; Thomas et al. 2004; Ribera et al. 2005; Rowe et al. 2005).

Different modifications of this "traditional" induction regimen have not led to substantial improvement in overall survival. Other approaches have therefore been introduced in adult trials, including early application of high-dose ARA-C (HDAC). In a Swedish study combining HDAC early in induction with a conventional induction, a CR rate of $85 \%$ was achieved. The CR rate for patients $<60$ years was $90 \%$. Despite the promising CR rates, remission duration was not superior to other approaches (Hallbook et al. 2002). HDAC has been administered also at the end of induction. In a study based on the hyper-CVAD regimen in combination with HDAC, the CR rate was as high as 92\% (Kantarjian et al. 2000; Kantarjian et al. 2004).

\subsubsection{Postinduction therapy}

Early intensification treatment after induction has the aim of eradicating residual leukemic cells, thus reducing the risk of relapse (Pui et al. 2008). Treatment consolidation after remission induction has improved treatment results in pediatric ALL (Henze et al. 1981; Schrappe et al. 2000b). In some trials, both early and late intensification is administered (Gustafsson et al. 2000; Hann et al. 2000).

Intensification regimens aiming at CNS consolidation include, e.g., high-dose methotrexate with mercaptopurine, or cyclophosphamide with ARA-C along with intrathecal administration of methotrexate (Larson et al. 1998; Harms et al. 2000; Ribera et al. 2005). In some trials, asparaginase has been administered, especially to higher risk patients, in high doses and prolonged duration in postremission therapy (Silverman et al. 2001; Moricke et al. 2008; Seibel et al. 2008). 
CNS radiotherapy has been shown to be an effective CNS prophylaxis (Pinkel et al. 1972; Omura et al. 1980). Nevertheless, owing to the cognitive and endocrine late effects and the increased risk of second malignancies, its use should be minimized (Pui et al. 2003). At present, CNS irradiation is limited to a selected high-risk group of patients. The outcome has been reported to be similar in patients treated with or without CNS irradiation (Moghrabi et al. 2007; Pui et al. 2009).

A delayed intensification with reinduction treatment was first introduced by the BFM group (Henze et al. 1981). Reinduction or late intensification given after consolidation or in the middle of maintenance means essentially repetition of an induction-like treatment with analogs of the drugs used in the primary induction. Replacing prednisone with dexamethasone in postinduction therapy phases has improved outcome (Pui et al. 2004).

The benefit of intensification treatment in adults has not been as clear as in children. However, some studies have shown improved outcome with intensive consolidation also in adults (Larson et al. 1995; Durrant et al. 1997; Kantarjian et al. 2004). Earlier administration of highdose methotrexate led to a higher survival rate and less CNS relapses (Linker et al. 2002). However, few adult protocols include a delayed intensification phase.

\subsubsection{Maintenance}

In ALL, patients not allocated to stem cell transplantation generally require a prolonged continuation treatment. Attempts to shorten the duration of chemotherapy have led to inferior results in both children and adults (Tsuchida et al. 2000). Thus, in most clinical trials, the total treatment duration is $2-3$ for all patients. The basis of continuation treatment consists of weekly oral or parenteral doses of methotrexate, and daily doses of mercaptopurine. The treatment intensity during maintenance seems to influence the long-term outcome. Adjustment of the doses of mercaptopurine and methotrexate to obtain a white blood cell count (WBC) level of $1.5-3.0 \times 10^{9} / 1$ is therefore recommended (Arico et al. 2005). Pulses of vincristine and corticosteroid at 4- to 8-week intervals are often added in maintenance, although the impact of this addition on long-term survival is ambiguous (Conter et al. 2007).

\subsubsection{Allogeneic stem cell transplantation}

ALL treatment consolidation with allogeneic stem cell transplantation (SCT) in first complete remission (1CR) is performed by using either an HLA-identical sibling donor or a matched unrelated donor (URD). Only about $20-30 \%$ of SCT candidates have a suitable sibling donor (Schrauder et al. 2008). URD from national and international donor registries 
has become an important alternative. The problem with URD has been treatment-related mortality, especially with HLA-mismatched cases (Marks et al. 2008; Fielding et al. 2009). In the Nordic countries, the use of URDs started in the early 1990s (Saarinen-Pihkala et al. 2004). The outcome of SCT patients with matched-sibling and unrelated donors was reported to be similar already in the late 1990s (Hongeng et al. 1997; Saarinen-Pihkala et al. 2001; Dahlke et al. 2006). Improvement in outcome with URD transplantations is a consequence of improvements in histocompatibility matching, graft versus host disease prevention, antiviral prophylaxis, and supportive care (Hongeng et al. 1997). Also a stronger graft versus leukemia effect has been suggested to lead to improved outcome of URD recipients, although some studies have failed to confirm this (Ringden et al. 2009).

Allo-SCT for pediatric ALL patients in 1CR has mostly been restricted to patients with a high risk of relapse because conventional chemotherapy produces very good outcome figures. During 1981-1991 in the Nordic countries, allo-SCT was performed only on patients with an available HLA-identical sibling donor. Consequently, $1 \%$ of pediatric ALL patients in the Nordic countries underwent allo-SCT in 1CR during this period. Indications for SCT in 1CR included high WBC $\left(>50 \times 10^{9} / 1\right)$ at diagnosis, T-cell ALL (T-ALL), extramedullary leukemia at diagnosis, poor response to induction therapy, and $\mathrm{t}(4 ; 11)(M L L$ rearrangement). Most patients had more than one of these poor prognostic factors (Saarinen et al. 1996). During the 1990s the indications included $t(9 ; 22)$ or $M L L$ rearrangement, high WBC with some other high-risk factors, and poor treatment response (Saarinen-Pihkala et al. 2004). The proportion of patients who received allo-SCT in 1CR was 3\%, of which $67 \%$ were URD transplantations. Treatment-related mortality was $14 \%$ in the sibling group and $17 \%$ in the URD group. Relapse rates were $36 \%$ and $14 \%$, respectively. The 5 -year EFS was significantly better in the URD group ( $65 \%$ vs. $45 \%, \mathrm{p}=0.02)$. The 10 -year OS of alloSCT recipients in 1CR during 1981-2001 was 59\% (Saarinen-Pihkala et al. 2006). The OS of all pediatric HR patients during 1992-2000 was 74\%. In the same period, SCT in 1CR proved beneficial relative to chemotherapy for selected pediatric HR patients (Saarinen-Pihkala et al. 2004). In the current NOPHO ALL-2008 protocol, the indications for SCT in 1CR are based on treatment response, including MRD. These are further classified based on immunophenotype, WBC, and cytogenetics.

In the British Medical Research Council Trials UKALL X and XI (1985-1997), no significant benefit was reported when comparing allogeneic SCT in 1CR with chemotherapy for very high-risk pediatric patients (Wheeler et al. 2000). On the other hand, in pediatric very high-risk ALL and high-risk T-ALL, allo-SCT in 1CR was shown to be superior to chemotherapy alone (Balduzzi et al. 2005; Schrauder et al. 2006). 
In adult ALL, several trials have included SCT in 1CR for all patients with a sibling donor in order to improve outcome (Gupta et al. 2004; Goldstone et al. 2008; Cornelissen et al. 2009). A French trial reported an improved outcome of patients with SCT from a sibling donor in high-risk adult patients (Thomas et al. 2004). An international collaborative study of British and American groups reported similar results for standard-risk adult patients (Goldstone et al. 2008). In that study, treatment-related mortality in the high-risk group outweighed the advantage of reduced relapse risk. In a Dutch-Belgian collaboration trial, patients with matched sibling donor had superior outcome relative to those without a suitable donor. This advantage was more pronounced in standard-risk patients (Cornelissen et al. 2009). In adult T-ALL, SCT in 1CR was shown to result in improved outcome (Marks et al. 2009). Also in adult ALL, allo-SCT from URD is suggested to lead to better outcome (Marks et al. 2008).

\subsection{Risk stratification of ALL patients}

One major factor behind the improvement of ALL treatment has been development of risk-adapted therapy, i.e. intensification of therapy according to the predicted risk of relapse. Regarding the details in risk stratification of ALL, no international consensus exists. While treatment regimens have improved, some previously important prognostic markers, such as male sex, have lost significance (Silverman et al. 2001; Pui et al. 2004). In 1993, the National Cancer Institute (NCI) introduced up-front risk factors for pediatric ALL; patients with B-cell precursor ALL 1-10 years of age with initial WBC $<50 \times 10^{9} / 1$ were included in the standard-risk category. The remaining patients were classified as high risk (Smith et al. 1996). Other commonly used factors include immunophenotype, chromosomal abnormalities, and response to induction therapy (Miller et al. 1989; Smith et al. 1996; Linker et al. 2002). Risk stratification has enabled gradual improvement in the treatment results (Moricke et al. 2008). Over the past decade, improvement in survival rates has reached a plateau, indicating that the maximum benefit of the evaluation of the currently applied risk factors has already been achieved (Seibel 2008). Identification and application of new factors to refine risk classification and development of new treatment strategies are therefore warranted. Microarray methods may give further insights into the biologic basis of ALL and may contribute to novel risk classification.

\subsubsection{Clinical factors}

Age at diagnosis is a strong prognostic indicator of outcome. Children aged 1-9 years are shown to have a better outcome than either infants or adolescents (Eden et al. 2000; Gaynon et al. 2000; Gustafsson et al. 2000). The outcome in adults is worse with increasing age (Annino et al. 2002; Kantarjian et al. 2004; Rowe et al. 2005). 
$\mathrm{WBC}$ is a prognostic variable, with increasing counts associated with poorer outcome (Annino et al. 2002; Seibel et al. 2008). This applies especially to patients with B-cell precursor disease, with $\mathrm{WBC}>30 \times 10^{9} / 1$ being associated with an inferior prognosis. In T-ALL, WBC $>100 \times 10^{9} / 1$ is associated with an increased risk of relapse (Rowe et al. 2005). Patients with very high WBC $\left(>400 \times 10^{9} / 1\right)$ are at high risk of leucostasis-induced early complications such as CNS hemorrhage and pulmonary and neurological events, as well as renal complications due to tumor lysis (Lowe et al. 2005).

\subsubsection{Biological factors}

Mature B-cell immunophenotype was earlier associated with poor outcome but is now of little prognostic importance in childhood ALL in the separate, intensive protocols and is actually associated with favorable prognosis in adults in contemporary treatment (Reiter et al. 1999). T-ALL has earlier been considered a subtype of poor prognosis. However, the development of protocols has reduced the importance of T-ALL as a prognostic factor (Goldberg et al. 2003; Pui et al. 2004). In some studies of adult ALL, the outcome of patients with T-cell immunophenotype has been superior to that of B-cell precursor ALL (Rowe et al. 2005; Marks et al. 2009). Among T-ALL, the differentiation status seems to influence outcome. PreT-ALL and mature T-ALL have been reported to have inferior outcome to thymic T-ALL (Baak et al. 2008).

Although genetic abnormalities do not explain entirely the differences in treatment outcome, they do provide important prognostic information. The $t(9 ; 22)$, rearrangements affecting the chromosomal location 11q23 and the $M L L$ gene, and hypodiploidy ( $<44$ chromosomes per leukemic cell) all confer a poor outcome, whereas hyperdiploidy (>50 chromosomes), $\mathrm{t}(12 ; 21)$ leading to ETV6-RUNX1 (TEL-AML1) fusion, and trisomies of chromosomes 4, 10, and 17 are associated with a favorable prognosis (Harris et al. 1992; Moorman et al. 2007).

\subsubsection{Response to treatment}

Response to therapy, the reduction of leukemic cells during remission induction therapy, has a great independent prognostic importance even in low-risk patients defined by clinical and biological features (Gaynon et al. 2000; Hann et al. 2000; Pui et al. 2000; Schrappe et al. 2000b; Bruggemann et al. 2006). Morphology-based methods traditionally used to evaluate treatment response detect blast cells if present in quantities $\geq 5 \%$ of all cells. These methods therefore are not sufficiently sensitive to measure cytoreduction at lower blast levels.

Polymerase chain reaction and flow-cytometric methods, being at least 100-fold more 
sensitive than morphology-based methods, now allow MRD detection at very low levels $(<0.01 \%)$. This provides a useful means of identifying patients at very low or high risk of relapse (Coustan-Smith et al. 2002). Also fluorescence in situ hybridization (FISH) can be used for MRD monitoring, the sensitivity being about $10^{-3}$ (0.1\%) (El-Rifai et al. 1997). The prerequisite for successful MRD follow-up is a diagnostic bone marrow sample of good quality with adequate analysis.

Patients with $0.01 \%$ MRD in the early phases of treatment (weeks 4-12) have inferior prognosis relative to patients negative for MRD at a detection level of $10^{-4}$ (van Dongen et al. 1998; Borowitz et al. 2008). MRD positivity was demonstrated to have prognostic value in adult patients without other adverse prognostic factors (Bruggemann et al. 2006). The end-induction MRD status also reflects the induction therapy given (zur Stadt et al. 2001).

High levels of MRD early in postinduction have also been associated with inferior prognosis (Cave et al. 1998; van Dongen et al. 1998; Bassan et al. 2009). Moreover, MRD monitoring during maintenance treatment and follow-up can be used for early detection of molecular relapse, and hence, for early treatment intervention (Raff et al. 2007). In the current NOPHO ALL-2008 protocol, end-induction and day $79 \mathrm{MRD}$ are included as prognostic and stratification criteria.

\subsubsection{Risk factors in children and adults}

One of the reasons for the inferior treatment outcome in adults with ALL is the differing distribution of the risk factors in different age groups. Adults have much more of the cytogenetic subtypes associated with poor prognosis, whereas subtypes of favorable prognosis are common in children (Pui et al. 1998; Forestier et al. 2006). Interestingly, one report on adult ALL suggested that age was not a prognostic factor when the effect of cytogenetics on survival was taken into account (Pullarkat et al. 2008). This leads to the assumption that the inferior prognosis of older patients could at least partly be due to an age-related increase in unfavorable cytogenetics. Little difference is present in clinical or biologic features among patients aged 10-20 years (Barry et al. 2007).

\subsection{Cytogenetics in ALL}

ALL is a group of cytogenetically distinct diseases related to clinical characteristics. The cytogenetic grouping of ALL facilitates understanding of the differences in etiology and epidemiology of different disease subtypes. The main reasons for performing cytogenetic analysis in ALL include obtaining information on prognosis and monitoring the disease 
and MRD status at levels beyond the sensitivity of cytomorphologic methods. The association of chromosomal changes with prognosis in ALL was first reported by Secker-Walker et al. (1978) who showed that first remissions of children with hyperdiploid ALL were longer than those having ALL of other cytogenetic categories. The frequency of abnormal karyotypes in adult ALL has mostly been slightly higher than in pediatric ALL, about $70-80 \%$ in different studies of adult patients compared with 60-70\% in pediatric patients (Gaynon et al. 2000; Thomas et al. 2001; Linker et al. 2002; Kantarjian et al. 2004; Pullarkat et al. 2008; Seibel et al. 2008).

There are essentially two types of chromosomal aberrations: changes in chromosome numbers and structural abnormalities. Numerical abnormalities may apply to the whole chromosome set, resulting in ploidy changes. They may also involve individual chromosomes (aneuploidy). High hyperdiploidy ( $>50$ chromosomes) is common in children with ALL, occurring in about $25 \%$ of pediatric ALL, but is rare in adults $(<10 \%)$ (Chessels et al. 1997; Thomas et al. 2001; Forestier et al. 2006). Children with a high hyperdiploid karyotype have an excellent outcome, with a 5-year EFS exceeding $80 \%$. The chromosomal gains occur in a nonrandom pattern, with chromosomes X, 4, 6, 10, 14, 17, 18, and 21 often involved (Mertens et al. 1996). The effects of additional chromosomes on leukemia pathogenesis are unknown. Hypodiploidy is rare in all age groups, although more common in adults (4$9 \%$ ), and is associated with a very poor prognosis (Kantarjian et al. 2000).

\subsubsection{Chromosomal translocations}

Chromosomal translocations that activate specific genes are a characteristic feature in ALL. Translocations often activate transcription-factor genes, which frequently encode proteins important in transcriptional cascades (Armstrong et al. 2005).

The most common translocation in pediatric B-cell precursor ALL, seen in about $25 \%$ of cases, is $\mathrm{t}(12 ; 21)(\mathrm{p} 13 ; \mathrm{q} 22)$, resulting in the formation of the ETV6-RUNX1 (TEL-AML1) fusion gene (Rubnitz et al. 1997; Uckun et al. 2001). It is rare ( $<5 \%)$ in adults (Jabber Al-Obaidi et al. 2002). This translocation has been associated with good prognosis. It is a cryptic translocation discovered by FISH in 1994 (Romana et al. 1994). Although the mechanisms of leukemogenesis of ETV6-RUNX1-positive leukemia remain unclear, data demonstrate the importance of both ETV6 and RUNX1 in the regulation of hematopoietic-cell development (Hock et al. 2004). The ETV6-RUNX1 fusion protein in B-cell progenitors is suggested to lead to disordered early B-lineage lymphocyte development, characteristic of leukemic lymphoblasts. An important secondary event, the deletion of the normal ETV6 allele from the chromosome 12 homolog not involved in the translocation, supports the assumption that loss of ETV6 function may play a role in leukemogenesis (Cave et al. 1997). 
The most frequent chromosomal translocation in adults is $\mathrm{t}(9 ; 22)(\mathrm{q} 34 ; \mathrm{q} 11)$, which leads to the formation of $B C R-A B L$ fusion and the Philadelphia chromosome. The proportion of Philadelphia chromosome-positive $(\mathrm{Ph}+)$ patients increases with age. It is seen in about $30 \%$ of adult B-cell precursor ALLs, but in less than $5 \%$ of childhood cases (Pui et al. 2000; Schrappe et al. 2000a; Thomas et al. 2004; Mancini et al. 2005; Ribera et al. 2005). The presence of Philadelphia chromosome in chronic myeloid leukemia (CML) was reported by Nowell and Hungerford in 1960 and was reported to occur also in ALL in 1970 (Propp et al. 1970). The translocation causes fusion of the BCR signaling protein to the ABL nonreceptor tyrosine kinase. This results in constitutive tyrosine kinase activity and complex interactions of the fusion protein with many other transforming elements, affecting the function of genes involved in cell differentiation, proliferation, and survival (Ren 2005). The translocation breakpoint site in the BCR gene varies between CML and ALL. In most CML patients and in over $20 \%$ of adult ALL patients, the breakpoint is found within a region known as the major breakpoint cluster region (M-bcr). The resulting $B C R-A B L$ gene encodes a p210 ${ }^{\text {BCR-ABL }}$ fusion protein. In most ALL cases, the breakpoint site falls further upstream, within the minor bcr $(\mathrm{m}-b c r)$. This leads to a transcript encoding a smaller fusion protein p190 ${ }^{\text {BCR-ABL }}$ (Melo 1996). $t(9 ; 22)$ is a poor prognostic feature regardless of age. Being the most common genetic aberration in adults, this might explain part of the inferior prognosis of adult ALL patients relative to children. Recently, combined treatment with tyrosine kinase inhibitors, cytostatics, and allogeneic SCT in 1CR has been shown to prolong disease-free survival of $\mathrm{Ph}+$ patients (Wassmann et al. 2005).

The $M L L$ gene in chromosome 11 is a common target for chromosomal translocations in acute leukemias. It can have multiple translocation partners, 64 of which are well characterized at present (Meyer et al. 2009). The most common rearrangement of 11q23 involving the $M L L$ gene in ALL is $\mathrm{t}(4 ; 11)(\mathrm{q} 21 ; \mathrm{q} 23)$. In this translocation, $M L L$ is rearranged with the AFF1 (AF4) gene. Another common form is the $\mathrm{t}(11 ; 19)(\mathrm{q} 23 ; \mathrm{p} 13)$, with the MLLT1 (ENL) gene as the translocation partner (Meyer et al. 2009). MLL rearrangements are specifically associated with ALL in infants, although they are present in low numbers also in older children and adults. Over $70 \%$ of children younger than 1 year have a translocation involving 11q23 (Biondi et al. 2000). MLL rearrangements are associated with a very poor prognosis in infants, with EFS rates of about 45-50\% (Biondi et al. 2006; Pieters et al. 2007). Older patients with the rearrangement fare significantly better.

The $\mathrm{t}(1 ; 19)(\mathrm{q} 23 ; \mathrm{p} 13)$ resulting in the fusion gene TCF3-PBX1 (E2A-PBX1) is present in less than 5\% of the B-cell precursor ALL cases (Uckun et al. 1998; Kantarjian et al. 2000; Mancini et al. 2005; Garg et al. 2009). The protein product of the fusion gene has an effect on cell differentiation arrest. TCF3 on chromosome 19 is a transcription factor and plays a critical role in 
lymphocyte development (Sigvardsson et al. 1997). The $t(1 ; 19)$ impairs one copy of the TCF3 locus, suggesting that loss of TCF3 function may contribute to leukemogenesis in this ALL subtype. PBX1 belongs to the homeobox (HOX) genes. Dysregulation of these genes is known to have a role in leukemogenesis. $P B X 1$ has the ability to alter HOX gene-dependent regulatory programs. It therefore seems likely that dysregulation of $P B X 1$ function contributes to leukemogenesis (Armstrong et al. 2005). Both balanced and unbalanced forms of the translocation exist. In the unbalanced form, the derived chromosome 1 is lost. The prognostic value of $t(1 ; 19)$ has been controversial. Children with the unbalanced form of the translocation are shown to have a significantly better outcome than those with the balanced one. Aggressive chemotherapy has reduced the association with poor prognosis.

T-ALL accounts for about $10-15 \%$ of pediatric and 25\% of adult ALL cases (Gaynon et al. 2000; Thomas et al. 2001; Annino et al. 2002; Moghrabi et al. 2007; Marks et al. 2009). It is most common in patients aged 20-40 years. The value of chromosomal abnormalities in T-ALL in the risk assessment has not been as high as in B-cell precursor ALL (Marks et al. 2009). Although the cytogenetics of B-cell precursor and T-ALL overlap to some extent, there are distinct differences. Important genes in T-cell development are shown to be involved also in T-ALL. Translocations seen in T-ALL often involve one of the T-cell receptor loci. More than $30 \%$ of T-ALL patients are observed to have rearrangements of T-cell receptor genes (TCR) in 14q11 ( $\alpha$ and $\delta$ ), 7q34 ( $\beta$ ), and 7p14 ( $\gamma$ ) (Cauwelier et al. 2006). In these rearrangements, TCR genes and particularly their promoter and enhancer elements are brought into close proximity of oncogenes, leading to their aberrant expression (Rabbitts 1994). A common rearrangement in pediatric ALL is $\mathrm{t}(11 ; 14)(\mathrm{p} 13 ; \mathrm{q} 11)$, affecting the LMO2 gene (Schneider et al. 2000; Karrman et al. 2009). In adult ALL, TCR rearrangement by t(10;14)(q24;q11) translocating TLX1 (HOX11) gene is more common (Marks et al. 2009). These translocations lead to overexpression of the affected genes. Overexpression of TLX1 is associated with favorable prognosis in T-ALL (Baak et al. 2008). Also other members of the HOX gene family are translocated close to the TCR genes and thereby overexpressed. These genes encoding transcription factors take part in the regulation of hematopoiesis and normal T-cell development (Graux et al. 2006). Other partner genes in such translocations include e.g. MYC, TAL1, LYL1, and LMO1 (Erikson et al. 1986; Mellentin et al. 1989; Xia et al. 1991; Baer 1993; Cauwelier et al. 2006). Rearrangements other than those affecting TCRs also lead to overexpression of oncogenes, e.g. $\mathrm{t}(5 ; 14)(\mathrm{q} 35 ; \mathrm{q} 32)$, which leads to an association of BCL11B with TLX3 (HOX11L2), leading to overexpression of TLX3 (su et al. 2006). Aberrant TLX3 expression is associated with inferior prognosis (Baak et al. 2008). Some translocations lead to the formation of fusion genes. The MLL gene is often involved in such fusion gene formation (Graux et al. 2006). 


\subsubsection{Cooperating mutations}

Although fusion oncogenes encoded by chromosomal translocations are a hallmark of pathogenesis of ALL, it seems likely that other genetic lesions are also needed to induce overt leukemia (Knudson 1971). A well-characterized example is the deletion or epigenetic silencing of the cyclin-dependent kinase inhibitor 2A gene (CDKN2A) located in 9p21.3. This gene encodes the tumor suppressors p16 ${ }^{\mathrm{INK} 4 \mathrm{~A}}$ and $\mathrm{p} 14^{\mathrm{ARF}}$ (Lukas et al. 1995; Stott et al. 1998). Inactivation of this gene neutralizes both the TP53 and retinoblastoma pathways, which control the transition of cell cycle from G1 phase to S phase, thus serving as tumor suppressor proteins. Deletions of CDKN2A are present in about $70 \%$ of T-ALL and $30 \%$ of B-cell precursor ALL (Bertin et al. 2003).

Multiple copies of the RUNX1 (AML1) gene in chromosome 21 have been identified as a recurrent abnormality in ALL, also referred to as intrachromosomal amplification of chromosome 21 (iAMP21) (Harewood et al. 2003). iAMP21 is reported to occur in about 1.5\% of pediatric B-lineage ALL. This genomic change has been associated with poor prognosis (Robinson et al. 2003). The amplified area has shown great complexity, with multiple regions of amplifications and deletions varying in location and extent (Strefford et al. 2006). However, the chromosomal area encompassing the RUNX1 gene is always amplified (Robinson et al. 2007).

NOTCH1 has been identified as a partner gene in $\mathrm{t}(7 ; 9)$, found in $<1 \%$ of T-ALL cases (Ellisen et al. 1991). It encodes a transmembrane receptor that regulates normal T-cell development (Maillard et al. 2005). Despite the rare involvement of NOTCH1 in translocations, recent studies have shown its importance in T-ALL through activating mutations. Such mutations involving NOTCH1 are present in more than 50\% of T-ALL patients (Weng et al. 2004; Grabher et al. 2006; Marks et al. 2009). The mechanisms by which aberrant NOTCH signaling causes T-ALL remain unclear. Expression of oncogenes, such as $M Y C$, probably plays an important role. Evidence suggests that the MYC oncoprotein is an important downstream mediator of the pro-growth effects of NOTCH1 signaling in developing thymocytes (Weng et al. 2004). Activating mutations in NOTCH1 can induce T-ALL in experimental models and could be the initiatory event in most human T-cell leukemias (Grabher et al. 2006).

\subsection{Cytogenetic and molecular genetic methods in ALL}

Two important milestones in the development of cytogenetics include the discovery that the true chromosome number of man is 46 and the development of techniques for the culture of bone marrow and blood to improve metaphase preparations (Tjio et al. 1956; Tjio et al. 
1962). Since 1963, the evolving International System for Human Cytogenetic Nomenclature (ISCN) has standardized and facilitated the description of chromosomal abnormalities (Shaffer et al. 2009).

\subsubsection{Chromosomal banding}

In the 1970s, chromosomal banding techniques enabled more accurate identification of individual chromosomes. Chromosomal banding gives a global overview of the whole genome. Initially, fluorochromes were used (Q-banding) (Caspersson et al. 1970). G-banding utilizes enzymatic treatment (Figure 2) (Seabright 1971). By the end of the 1980s, close to 30 recurrent translocations and inversions had been identified in ALL (Raimondi 1993). G-banding in ALL is often impaired by poor chromosome morphology, imperfect banding, and low mitotic activity of malignant cells. Cryptic rearrangements, i.e. changes affecting regions smaller than a chromosomal band, are extremely difficult to detect with G-banding (Ma et al. 1999).

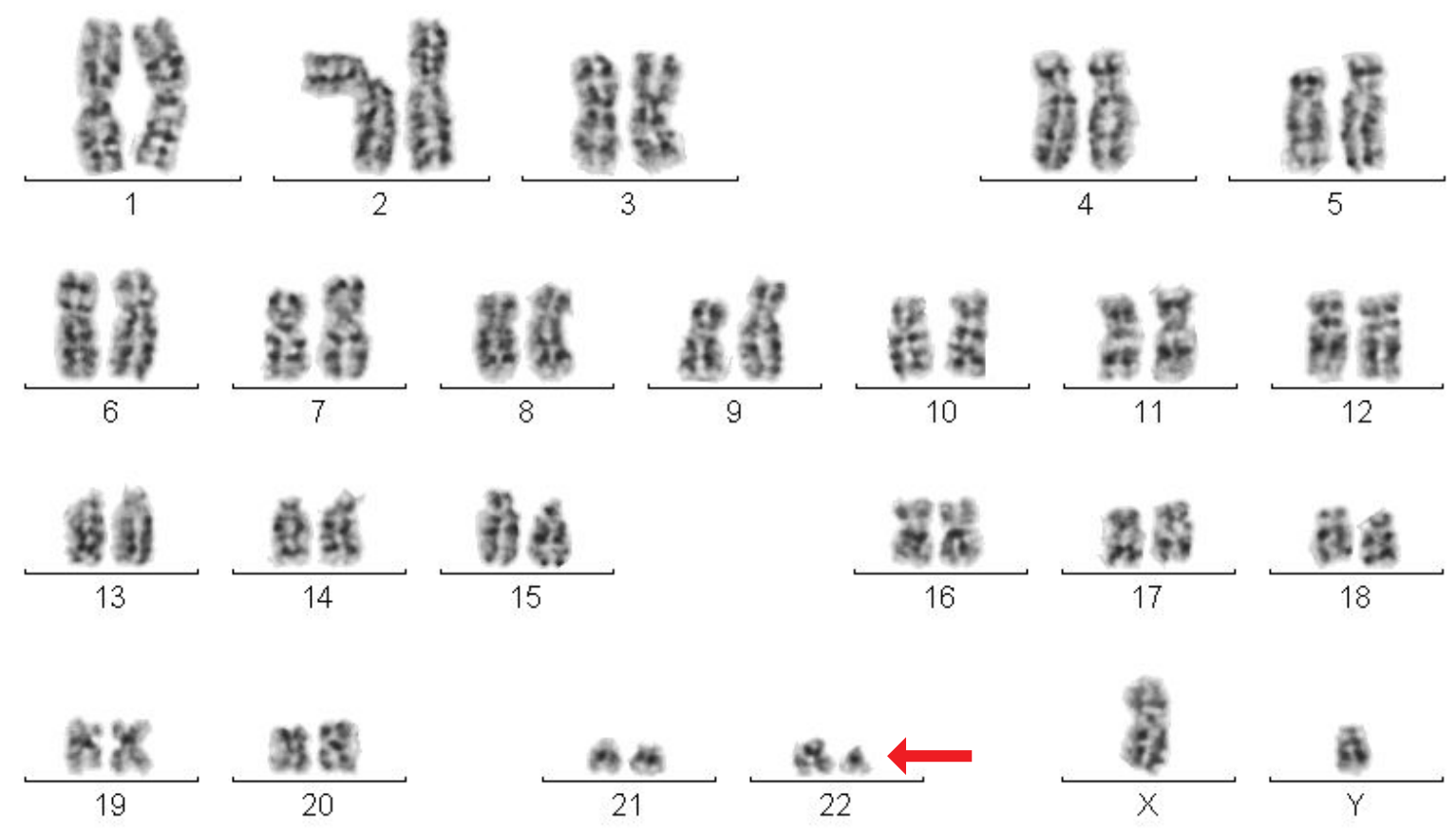

Figure 2. A G-banded karyogram of an ALL patient with $\mathrm{t}(9 ; 22)(\mathrm{q} 34 ; \mathrm{q} 11.2)$. The Philadelphia chromosome is indicated with an arrow. Courtesy of the Laboratory of Molecular Pathology, HUSLAB, Helsinki. 


\subsubsection{Fluorescence in situ hybridization}

In the 1980s, cytogenetics was broadened to molecular genetics by the development of fluorescence in situ hybridization (FISH). FISH is crucial in detecting ETV6-RUNX1 fusion, a common but cryptic abnormality in pediatric ALL (Romana et al. 1994). The basis of FISH is binding of a DNA probe to its complementary sequence in a target genome. The resolution of this method is restricted to the defined chromosomal regions of the FISH probes used.

Essentially three kinds of probes are used in the cytogenetic analysis of hematologic malignancies. Centromeric probes can be applied to detect numeric chromosomal changes, but they do not give information about the normality of the chromosome structure. Locus-specific FISH probes are used to detect translocations, inversions, and specific deletions (Figure 3). Whole-chromosome painting probes are a mixture of sequences from the entire length of a chromosome. They are useful for identifying the components of highly rearranged chromosomes or marker chromosomes (Kearney 1999).

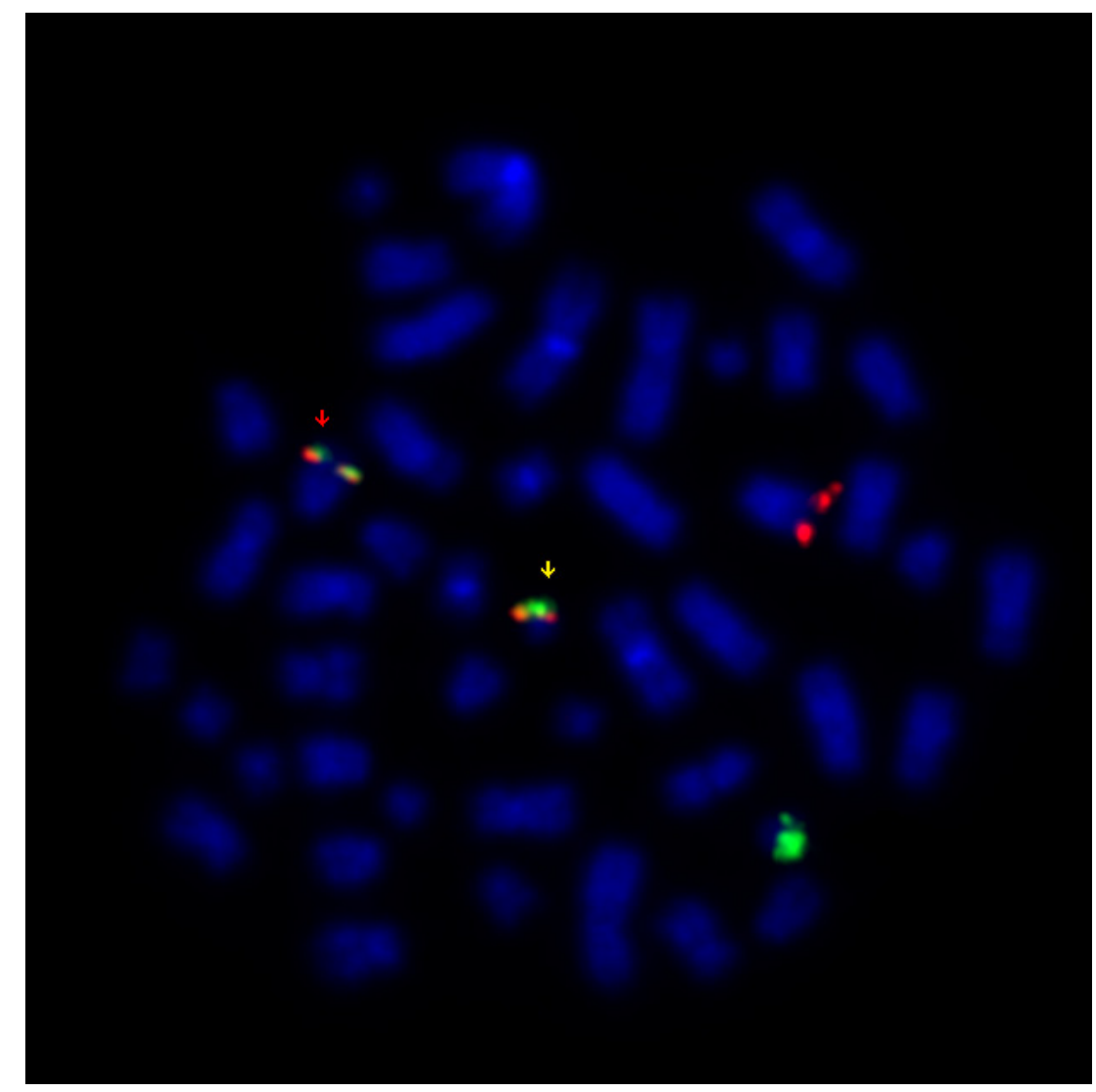

Figure 3. A metaphase cell of a Philadelphia chromosome-positive ALL patient observed by FISH with locus-specific probes. Single red and green signals indicate a normal $A B L$ gene in chromosome 9 and a normal $B C R$ gene in chromosome 22, respectively. The red-green fusion signals represent the $B C R-A B L$ fusion in derivative chromosomes 9 (red arrow) and 22 (yellow arrow), respectively. Courtesy of the Laboratory of Molecular Pathology, HUSLAB, Helsinki. 
In addition to diagnosis, metaphase FISH can also be utilized in MRD monitoring of patients with chromosome trisomy or translocation. In patients with monosomies as the only aberration, metaphase FISH yields a high false-positive result (5-10\%) (El-Rifai et al. 1997).

One application of the FISH technique with whole-chromosome probes is multicolor FISH (M-FISH). It has enhanced the detection of multiple novel abnormalities and determination of complex karyotypes (Speicher et al. 1996). This method is based on the hybridization of 24 differentially labeled human chromosome painting probes. This allows simultaneous identification of each chromosome pair and the sex chromosomes in different colors in a single metaphase (Figure 4).

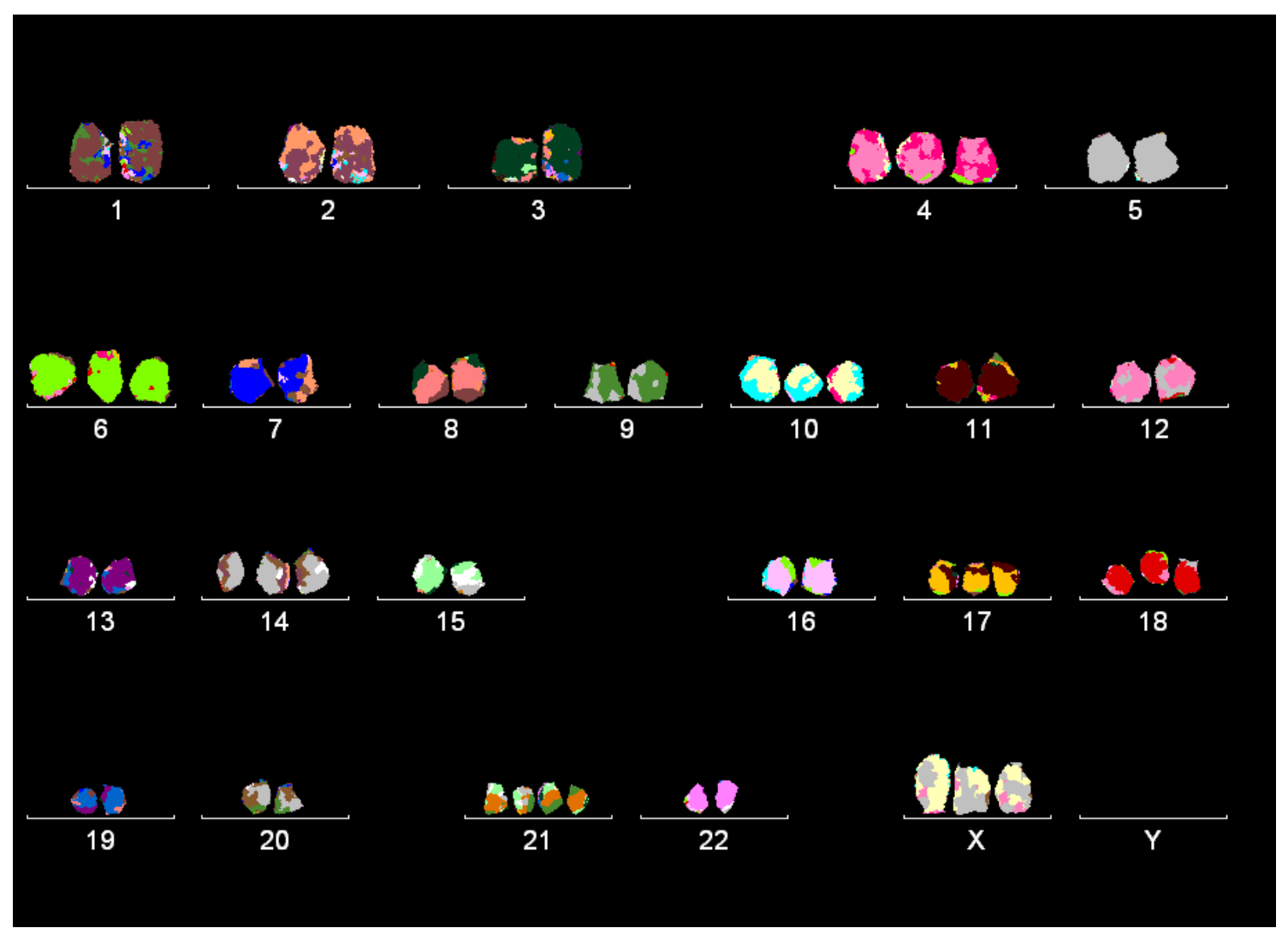

Figure 4. Karyotype analysis by M-FISH of a patient with hyperdiploidy. The karyotype is marked $m$ ish $55, \mathrm{XX},+\mathrm{X},+4,+6,+10,+14,+17,+18,+21,+21$. Courtesy of the Laboratory of Molecular Pathology, HUSLAB, Helsinki.

Today, the Human Genome Project serves as a tool to manufacture probes for practically any DNA sequence. In hematologic malignancies, the proliferative activity of cells is often low, making metaphase analysis unreliable. One advance in FISH is the ability to use nondividing cells as targets, known as interphase FISH (Cremer et al. 1986). Interphase FISH can be used reliably at diagnosis of ALL for screening of significant aberrations such as $\mathrm{t}(12 ; 21), \mathrm{t}(9 ; 22)$, and $M L L$ gene rearrangements (Harrison et al. 2005). 


\subsubsection{Polymerase chain reaction}

At the end of the 1980s, polymerase chain reaction (PCR) transformed molecular technology (Saiki et al. 1988). Fusion genes at the site of chromosomal rearrangements and the corresponding fusion messenger RNAs (mRNA) provide tumor-specific markers suitable for reverse transcriptase PCR (RT-PCR) amplification. For PCR, only small amounts of patient material is needed, no dividing cells are required, and PCR is a highly sensitive method with the ability to detect one leukemic cell among $10^{5}-10^{6}$ normal cells (Campana et al. 1995). Quantitative PCR assays are used for residual disease monitoring. MRD monitoring is most commonly accomplished by detection of clone-specific immunoglobulin gene (IGG) or T-cell receptor (TCR) gene rearrangement by PCR amplification. Another application is PCR amplification of abnormal fusion gene products followed by translocations (Campana et al. 1995; van Dongen et al. 1998). As information on complementary DNA (cDNA) sequences increases, PCR protocols for many individual translocations have been produced. Each RT-PCR reaction is specific for an individual genetic rearrangement. As a high number of fusion genes and breakpoint variants have been identified, numerous PCR reactions or a multiplex approach are needed for effective screening at diagnosis.

\subsubsection{Comparative genomic hybridization}

DNA copy number alteration is one potential mechanism for changes in gene expression, which in turn underlie biologic processes and disease development. Some variation is seen in healthy individuals, other variations occur in the course of normal processes, and still others participate in causing various disease states. Whole-genome DNA analysis using comparative genomic hybridization (CGH) was first reported in 1992 by Kallioniemi and colleagues. It is a method for determining copy number gains or losses between two samples of DNA, by competitively hybridizing differently labeled DNA on metaphase chromosomes (Kallioniemi et al. 1992). The advantages of this method are coverage of the whole genome in one experiment and no need for dividing cells. It is independent of chromosome morphology. It allows detection of gains or losses of genetic material at a resolution lower than $5 \mathrm{Mb}$. Its major limitation is the inability to detect balanced chromosome alterations (translocations, inversions). Moreover, the proportion of the cell population carrying an aberration should exceed 25\% (Gebhart et al. 2000).

\subsection{Categorization of ALL with microarray analyses}

DNA microarrays provide a tool for genome-wide analysis of DNA copy number alterations or gene expression. The techniques are based on the complementary base pairing 
of nucleic acids. A labeled sample is hybridized to an array slide with probes formed by known nucleic acid sequences. Complementary nucleic acid strands of the sample and probes on the array are paired according to base pairing rules.

Microarray methods are still mainly restricted to research use, but as these methodologies are being refined and validated they may soon be used in routine ALL diagnosis and management. In research, the amount of data produced by microarray studies creates new challenges for analysis of results. When classifying patients to subgroups or finding specific sets of genes according to expression profiles, bioinformatics expertise is required. Class prediction can be accomplished using clustering analysis techniques. They reveal genes with similar expression patterns. Clustering is often unsupervised, but a supervised approach can also be used if information about data grouping is available. Clustering methods usually include independent training and test data sets for building and evaluating the classifier (Eisen et al. 1998; Ringner et al. 2002; Allison et al. 2006; Dupuy et al. 2007).

\subsubsection{Gene expression studies}

Microarrays measuring gene expression patterns have been widely used in ALL research. Gene expression microarrays measure the expression of tens of thousands of mRNAs or gene transcripts simultaneously. Oligonucleotides or cDNA fragments act as probes on the array chip (Schena et al. 1995).

Gene expression arrays have been used to classify leukemia as ALL or acute myelogenous leukemia (AML) (Golub et al. 1999). Samples with $M L L$ rearrangement were reported to have a distinct expression profile, distinguishing these cases from other ALL subclasses (Armstrong et al. 2002). A report of a large series of pediatric ALL patients showed that accurately classifying patients into different subgroups with gene expression profiling is possible (Yeoh et al. 2002). Profiles of diagnostic bone marrow samples of 327 ALL cases segregated patients into seven groups. These corresponded to six known subtypes of ALL (T-ALL, hyperdiploid, $\mathrm{t}(12 ; 21), \mathrm{t}(9 ; 22), \mathrm{t}(1 ; 19), M L L$ rearrangements) and one additional novel group without a unifying cytogenetic abnormality. These genes were also capable of distinguishing respective adult ALL subclasses (Kohlmann et al. 2004). Other reports with similar results using expression array for ALL classification have been published (Moos et al. 2002; Ross et al. 2003; Andersson et al. 2007; Den Boer et al. 2009). Recently a 62-gene classifier was determined using previously published data sets. This classifier was applicable, without any modifications, to a new independent patient sample for class prediction (Li et al. 2009). This is an encouraging result when aiming at a classifier gene set suitable for clinical diagnosis of different patient sets. 
In a recent report analyzing pediatric ALL with gene expression arrays, a new subclass representing as much as $15-19 \%$ of B-cell precursor ALL was defined. The expression signature of patients with B-cell precursor ALL negative for known genetic subtypes resembled that of $B C R-A B L$-positive patients. These $B C R-A B L$-like patients also had a poor outcome, similar to $B C R-A B L$-positive patients. Multivariate analysis revealed this subtype to be an independent risk factor for poor prognosis (Den Boer et al. 2009). Thus far, these poor-prognosis patients have been identified by gene expression profiling only.

The usefulness of expression arrays in predicting MRD status of patients has been demonstrated by several groups (Cario et al. 2005; Flotho et al. 2007; Bhojwani et al. 2008). Gene expression profiling has also been utilized for risk classification and prediction of relapse in ALL (Teuffel et al. 2004; Bhojwani et al. 2008). In one study, genes related to MRD positivity were tested for their capability to predict relapse of leukemia. Among 40 genes predictive of relapse, 14 showed independent prognostic significance after adjustment for other risk factors (Flotho et al. 2007). Apart from this report, identification of an expression signature that could serve as an independently significant risk classifier has been difficult (Bhojwani et al. 2008).

\subsubsection{Microarray CGH}

An application of CGH with a higher resolution is microarray CGH (aCGH), first introduced by Solinas-Toldo et al. in 1997. Instead of metaphase chromosomes, it uses as probes bacterial artificial chromosomes (BACs), cDNAs, or oligonucleotides mapped directly to a genomic sequence (Solinas-Toldo et al. 1997; Pollack et al. 1999; Carvalho et al. 2004). Oligonucleotidebased aCGHs provide a robust platform for detecting copy number alterations throughout a genome using total genomic DNA (Barrett et al. 2004). This method is capable of detecting submicroscopic changes in DNA copy number to a resolution of $<1 \mathrm{Mb}$. aCGH does not, however, provide information on location of the altered sequence causing the change in copy number. Moreover, the method does not detect balanced rearrangements such as translocations.

aCGH has been successfully used to reveal otherwise cryptic aberrations in a leukemic genome and to characterize structural abnormalities (Paulsson et al. 2006). aCGH detects the majority of cytogenetic changes other than balanced translocations and provides additional information on aberrations not detected by cytogenetics (Strefford et al. 2007; Rabin et al. 2008). Most patients with a normal karyotype by G-banding have been shown to have copy number alterations (Kuchinskaya et al. 2008). Deletion of the short arm of chromosome 9, especially the 9p21.3 locus, is demonstrated to be a common alteration in ALL, predominantly in the T-ALL subtype (Strefford et al. 2007). Despite the wide variety in size of these deletions, 
the CDKN2A gene in 9p21.3 is always involved. Similarly to expression profiling, aCGH has been applied to discriminate patients with different treatment response and MRD status. Patients who were negative for MRD had significantly more gain in 1q23-qter, indicating the presence of an unbalanced $t(1 ; 19)$ (q23;p13). MRD-positive patients had more deletions of regions harboring immunoglobulin genes (Steinemann et al. 2008).

\subsubsection{Single-nucleotide polymorphism arrays}

In single-nucleotide polymorphism (SNP) arrays, the probes are known SNP areas. They have been introduced to determine both DNA copy number and loss of heterozygosity $(\mathrm{LOH})$ in one experiment (Maciejewski et al. 2009). SNPs are not evenly distributed in the genome, and SNP arrays offer a poor coverage of genomic regions with low SNP incidence. Analyses of ALL samples by SNP arrays have given results similar to aCGH, indicating that losses outnumber gains in lymphoblasts and that submicroscopic deletions are a common phenomenon in ALL (Kuiper et al. 2007; Mullighan et al. 2007; Paulsson et al. 2008). Also CDKN2A deletions have been reported at about the same frequency as with aCGH (Kuiper et al. 2007). Deletions in areas encompassing genes that regulate B-cell development have been shown to be a hallmark of ALL (Kuiper et al. 2007; Mullighan et al. 2007; Paulsson et al. 2008). These genes include PAX5 (in 30\% of B-cell precursor ALL), EBF1, IKZF1, IKZF3, LEF1, $T C F 3$, and BLNK. Copy number alterations also change to some extent from diagnosis to relapse. The majority of both gains and losses persist from diagnosis to relapse, and all patients have persisting alterations. However, nearly $90 \%$ of patients may also have novel alterations at the time of relapse (Yang et al. 2008).

A study concerning $B C R-A B L$-positive ALL showed the $I K Z F 1$ deletion to be a frequent event in this subtype (Mullighan et al. 2008; lacobucci et al. 2009; Martinelli et al. 2009). The transcription factor encoded by the IKZF1 gene is important in the earliest stages of lymphoid lineage differentiation. Interestingly, in the novel $B C R$ - $A B L$-like subgroup defined by the expression signature, more than $80 \%$ of patients had one or more deletions in the genes IKZF1, TCF3, EBF1, and PAX5 (Den Boer et al. 2009). Another study revealed an independent correlation between the IKZF1 deletion and an inferior outcome. The gene expression signature of IKZF1-deleted patients closely resembled that of BCR-ABL patients (Mullighan et al. 2009b). Gene expression and copy number alteration studies have led to the suggestion that $I K Z F 1$ mutations are a key determinant of poor outcome in both $B C R-A B L$-positive and -negative B-cell precursor ALL (Martinelli et al. 2009; Mullighan et al. 2009b).

These studies have been mostly conducted on childhood ALL cases. Despite the differences in cytogenetic entities of ALL between children and adults, one study has shown the 
deletion pattern to be remarkably similar in different age groups of ALL patients (Paulsson et al. 2008). In addition to copy number variations, SNP arrays enable the detection of copyneutral LOH. In SNP studies, this phenomenon has been demonstrated to be a common feature of ALL (Kuiper et al. 2007; Kawamata et al. 2008). However, small LOH areas were detected frequently also in nonleukemic samples, indicating that such areas are probably congenital (Kuiper et al. 2007). 


\section{AIMS OF THE STUDY}

Adolescents and young adults (AYA) as ALL patients have not been as well studied as children, and their prognosis remains inferior to that of children. The aim of this study was to characterize AYA ALL patients in Finland.

Specific aims were as follows:

1. To characterize AYA aged 10-25 years with ALL by the conventional risk factors.

2. To determine the proportions of biologic subgroups of ALL in AYA patients in the context of the whole age range from newborns to individuals over aged 60 years.

3. To compare outcome of AYA patients in Finland when treated with pediatric vs. adult ALL protocols.

4. To identify possible molecular genetic changes by aCGH in ALL patients with normal karyotype at diagnosis when investigated by conventional methods.

5. To search for new prognostic criteria by using aCGH.

6. To search for novel recurrent aberrations in ALL possibly important in leukemogenesis.

7. To search for gene combinations associated with poor prognosis by using aCGH data and mathematical modeling. 


\section{PATIENTS AND METHODS}

\subsection{Patients}

This is a nationwide study in Finland focusing on adolescents and young adults with ALL. The work was performed in collaboration with the pediatric and adult hematology units at the five university hospitals in Finland.

A total of 245 adolescent and young adult (AYA) patients aged 10-25 years diagnosed with ALL during 1990-2009 were included. Table 2 shows a summary of the patients included in different studies. The study was approved by the appropriate Institutional Review Boards and the National Authority for Medicolegal Affairs.

The population-based study describing the clinical characteristics and outcome of patients (I) included 225 AYA patients diagnosed during 1990-2004. Of these, 128 were treated in pediatric and 97 in adult hematology units. Eight adult ALL patients were excluded: three with Down's syndrome, one with other mental retardation, one Jehovah's Witness who received strongly modified therapy, and three who died at about the time of diagnosis without appropriate therapy (I, Table S1).

In Study II, deletions in chromosome 9p were explored in AYA ALL patients. Of the 225 AYA ALL patients included in Study I, the 54 for whom a bone marrow sample for aCGH analysis was available at diagnosis were included.

In Study III, 140 ALL patients diagnosed during 1990-2009 with available DNA were analyzed with aCGH to examine instability in chromosome 9p. Of these, 41 were aged 2-9 years, 74 were 10-25 years (the 54 included in Study II), and 25 were 26-65 years. In addition, aCGH analyses of patients with acute myeloid leukemia (AML, $n=50$ ), chronic lymphocytic leukemia (CLL, $n=20$ ), and myelodysplastic syndrome (MDS, $n=37$ ) were included.

In Study IV, DNA copy number alterations of AYA patients with initially normal or failed karyotype were examined. Of the 231 (225 included in Study I) AYA ALL patients diagnosed during 1990-2007, 89 had either normal karyotype at diagnosis $(n=80)$ or the analysis had failed $(n=9)$ ( $32 \%$ of pediatric and $36 \%$ of adult patients). DNA from the initial samples for aCGH was available for 27 of these 89 patients. Twenty-six patients 
had normal karyotype, and for one patient the karyotype analysis failed in G-banding at diagnosis.

In Study V, gene copy number profiles capable of predicting relapse in ALL were determined. Of the 231 (225 included in Study I) AYA patients diagnosed during 1990-2007, DNA from the initial samples for aCGH was available for 60 (54 included in Study II). As an external assessment, a group of children (2-9 years, $n=19)$ and older adults ( $>26$ years, $\mathrm{n}=24$ ) with ALL were included in Study V (both groups also included in Study III).

In Studies II-V, ALL patients with available DNA were included. Year of diagnosis did not differ between patients with available DNA and those without.

An analysis including all age groups was also performed. The following patients were included: infants ( $<1$ year) diagnosed in 2000-2008 $(\mathrm{n}=14)$, children aged 1-9 years diagnosed in 2000-2006 ( $\mathrm{n}=83)$, adolescents aged 10-16 years diagnosed in 2000-2007 $(\mathrm{n}=38)$, young adults aged 17-25 years diagnosed in 2000-2007 $(\mathrm{n}=38)$, and older adults aged over 26 years diagnosed in 2000-2008 $(n=32)$. Patients aged 1-9 years and over 26 years were diagnosed at Helsinki University Central Hospital. In other age groups, all patients diagnosed in Finland during the study period were included.

Table 2. Patients included in Studies I-V.

\begin{tabular}{|c|c|c|c|c|c|}
\hline Study & n & $\begin{array}{c}\text { Year of } \\
\text { diagnosis } \\
\end{array}$ & $\begin{array}{c}\text { Age of } \\
\text { patient }\end{array}$ & Frame & Restrictions \\
\hline I & 225 & $1990-2004$ & $10-25$ & ALL, population based & $\begin{array}{l}8 \text { adult patients not } \\
\text { included (see text) }\end{array}$ \\
\hline II & 54 & $1990-2004$ & $10-25$ & ALL & $\begin{array}{c}\text { DNA available for } \\
\text { aCGH }\end{array}$ \\
\hline III & 140 & 1990-2009 & $2-65$ & ALL, AML, CLL, MDS & $\begin{array}{l}\text { DNA available for } \\
\text { aCGH }\end{array}$ \\
\hline IV & 27 & $1990-2007$ & $10-25$ & $\begin{array}{c}\text { ALL, normal } \\
\text { karyotype / analysis } \\
\text { failed }\end{array}$ & $\begin{array}{c}\text { DNA available for } \\
\text { aCGH }\end{array}$ \\
\hline $\mathrm{V}$ & 103 & $1990-2007$ & $2-65$ & ALL & $\begin{array}{c}\text { DNA available for } \\
\text { aCGH }\end{array}$ \\
\hline
\end{tabular}




\subsubsection{Risk classification}

The pediatric NOPHO protocols included stratification to standard, intermediate-risk (IR), and high-risk (HR) groups. Patients with standard (low) risk were children aged 1-10 years, by definition not included in the AYA series. The risk criterion for pediatric IR was initial WBC $10-50 \times 10^{9} / 1$ or age $>10$ years. Criterion for pediatric HR was WBC $>50$ x 10\%/l, T-ALL, cytogenetic changes associated with poor prognosis ( $M L L$ rearrangement, $t(9 ; 22), t(1 ; 19)$, hypodiploidy), slow response to induction therapy (>25\% lymphoblasts in the bone marrow on day 15 and/or $>5 \%$ on day 29), or CNS/testis involvement (SaarinenPihkala et al. 2004).

\subsubsection{Treatment}

The primary therapy for ALL was centralized to five university hospitals. Allocation to pediatric vs. adult programs was based on age; patients 16 years or younger were generally treated in pediatric units and those older than 16 years in adult units.

ALL patients treated in pediatric units were treated mainly according to NOPHO protocols. There were three different treatment protocols for the pediatric intermediate-risk group in 1990-2004: BFM-83 IR 1990-1991 ( $\mathrm{n}=9$ ) (Schrappe et al. 2000b), NOPHO ALL-92 IR 1992-1999 ( $\mathrm{n}=40)$ (Gustafsson et al. 2000), and NOPHO ALL-2000 IR 2000-2004 ( $\mathrm{n}=7$ ) (Table 3). For the high-risk group, two protocols were available: Nalle-90 HR 1990-1999 $(\mathrm{n}=49)$ (Gustafsson et al. 2000; Saarinen-Pihkala et al. 2004) and NOPHO ALL-2000 HR 2000-2004 $(\mathrm{n}=23)$ (Table 3). The NOPHO ALL IR protocols consisted of induction, consolidation, delayed intensification, and maintenance, and the total duration of therapy was 2 (92 IR) or 2.5 (2000 IR) years. In the HR protocols, induction resembled that of NOPHO IR, the total duration of treatment being 2 years. The backbone in all NOPHO protocols was consolidation with high-dose methotrexate, together with high-dose ARA-C in the HR protocols. Cranial irradiation was used in Nalle-90 HR for children 5 years and older, but in NOPHO ALL-2000 HR it was restricted to patients with special risk factors or CNS involvement. The NOPHO HR protocols had an LSA2-L2 type maintenance (Anderson et al. 1983; Saarinen-Pihkala et al. 2004). 
Table 3. Pediatric NOPHO ALL-2000 treatment protocols.

\begin{tabular}{|c|c|c|c|c|}
\hline & \multicolumn{2}{|c|}{ NOPHO ALL-2000 IR } & \multicolumn{2}{|c|}{ NOPHO ALL-2000 HR } \\
\hline & Single dose & Days & Single dose & Days \\
\hline \multicolumn{5}{|l|}{ Induction } \\
\hline Prednisolone $\left(\mathrm{mg} / \mathrm{m}^{2}\right)$ & 60 & $1-36$ & 60 & $1-36$ \\
\hline Vincristine $\left(\mathrm{mg} / \mathrm{m}^{2}, \max .2 .5 \mathrm{mg}\right)$ & 2 & $1,8,15,22,29,36$ & 2 & $1,8,15,22,29,36$ \\
\hline Doxorubicin $\left(\mathrm{mg} / \mathrm{m}^{2}\right)$ & 40 & 1,22 & 40 & $1,22,36$ \\
\hline L-Asparaginase $\left(\mathrm{IU} / \mathrm{m}^{2}\right)$ & 6500 & $37,40,44,47$ & 6500 & $37,40,44,47$ \\
\hline Methotrexate IT (mg) & 12 & $1,8,15,29$ & 12 & $1,8,15,29,57,85$ \\
\hline Cyclophosphamide $\left(\mathrm{mg} / \mathrm{m}^{2}\right)$ & & & 1000 & 57,85 \\
\hline Cytarabine $\left(\mathrm{mg} / \mathrm{m}^{2}\right)$ & & & 75 & $59-62,65-68,87-90,93-96$ \\
\hline Mercaptopurine PO $\left(\mathrm{mg} / \mathrm{m}^{2}\right)$ & & & 60 & $58-71,86-99$ \\
\hline \multicolumn{5}{|l|}{ Consolidation } \\
\hline Methotrexate $\left(\mathrm{mg} / \mathrm{m}^{2}\right)$ & 5000 & $1,29,57$ & 8000 & 1,43 \\
\hline Cytarabine $\left(\mathrm{mg} / \mathrm{m}^{2}\right)$ & 75 & $8-11,15-18,36-39,43-46$ & 4000 & $22-24$ \\
\hline Mercaptopurine PO $\left(\mathrm{mg} / \mathrm{m}^{2}\right)$ & 25 & $1-57$ & & \\
\hline Methotrexate IT (mg) & 12 & $1,29,57$ & 1,43 & \\
\hline \multicolumn{5}{|l|}{ Delayed intensification } \\
\hline Dexamethasone $\left(\mathrm{mg} / \mathrm{m}^{2}\right)$ & 6 & $1-15$ & 10 & $1-15$ \\
\hline Vincristine (mg $\left./ \mathrm{m}^{2}, \max .2 .5 \mathrm{mg}\right)$ & 2 & $1,8,15,22$ & 2 & $1,8,15,22$ \\
\hline Daunorubicin $\left(\mathrm{mg} / \mathrm{m}^{2}\right)$ & 30 & $1,8,15,22$ & & \\
\hline Doxorubicin $\left(\mathrm{mg} / \mathrm{m}^{2}\right)$ & & & 30 & $1,8,15$ \\
\hline L-Asparaginase $\left(\mathrm{IU} / \mathrm{m}^{2}\right)$ & 6500 & $1,4,8,11$ & 6500 & $1,4,8,11$ \\
\hline Cyclophosphamide $\left(\mathrm{mg} / \mathrm{m}^{2}\right)$ & 1000 & 36,64 & 1000 & 36 \\
\hline Cytarabine $\left(\mathrm{mg} / \mathrm{m}^{2}\right)$ & 75 & $37-40,44-47,65-68,72-75$ & 75 & $38-41,44-47$ \\
\hline Thioguanine PO $\left(\mathrm{mg} / \mathrm{m}^{2}\right)$ & 60 & $36-49,64-77$ & 60 & $37-47$ \\
\hline Methotrexate IT (mg) & 12 & $1,36,64$ & 12 & 1 \\
\hline \multicolumn{5}{|l|}{ Consolidation II } \\
\hline Methotrexate $\left(\mathrm{mg} / \mathrm{m}^{2}\right)$ & & & 8000 & 1 \\
\hline Cytarabine $\left(\mathrm{mg} / \mathrm{m}^{2}\right)$ & & & 4000 & 22 \\
\hline Methotrexate IT (mg) & & & 12 & 1 \\
\hline \multicolumn{5}{|l|}{ Interim maintenance } \\
\hline Vincristine (mg $/ \mathrm{m}^{2}$, max. $\left.2.5 \mathrm{mg}\right)$ & & & 2 & 1,29 \\
\hline Dexamethasone $\left(\mathrm{mg} / \mathrm{m}^{2}\right)$ & & & $\begin{array}{l}6 \mathrm{mg} / \mathrm{m}^{2} \\
\times 5 \text { days }\end{array}$ & 1,29 \\
\hline Methotrexate PO $\left(\mathrm{mg} / \mathrm{m}^{2}\right)$ & & & 20 & Once weekly x 8 \\
\hline \multicolumn{5}{|l|}{ Consolidation III } \\
\hline Methotrexate $\left(\mathrm{mg} / \mathrm{m}^{2}\right)$ & & & 8000 & 1 \\
\hline Cytarabine $\left(\mathrm{mg} / \mathrm{m}^{2}\right)$ & & & 4000 & 22 \\
\hline Methotrexate IT (mg) & & & 12 & 1 \\
\hline \multicolumn{5}{|l|}{ Maintenance } \\
\hline LSA2-L2 & & & 2 cycles & \\
\hline Dexamethasone $\left(\mathrm{mg} / \mathrm{m}^{2}\right)$ & $\begin{array}{l}6 \mathrm{mg} / \mathrm{m}^{2} \\
\mathrm{x} 7 \text { days }\end{array}$ & $\begin{array}{c}\text { At 8-week } \\
\text { intervals x 5/ } 13\end{array}$ & $\begin{array}{l}6 \mathrm{mg} / \mathrm{m}^{2} \\
\mathrm{x} 5 \text { days }\end{array}$ & $\begin{array}{l}\text { At } 4 \text {-week intervals } \\
\text { until } 2 \text { years from diagnosis }\end{array}$ \\
\hline Vincristine (mg $\left./ \mathrm{m}^{2}, \max .2 .5 \mathrm{mg}\right)$ & 2 & $\begin{array}{c}\text { At 8-week } \\
\text { intervals x } 5 / 13\end{array}$ & 2 & $\begin{array}{l}\text { At } 4 \text {-week intervals } \\
\text { until } 2 \text { years from diagnosis }\end{array}$ \\
\hline Methotrexate $\left(\mathrm{mg} / \mathrm{m}^{2}\right)$ & 5000 & $29,85,141,197,253$ & & \\
\hline Mercaptopurine PO $\left(\mathrm{mg} / \mathrm{m}^{2}\right)$ & 75/day & & 75/day & \\
\hline Methotrexate PO (mg/m²) & 20/week & & 20/week & \\
\hline Methotrexate IT (mg) & 12 & $29,85,141,197,253$ & & \\
\hline
\end{tabular}


For adult ALL, no risk stratification was employed. Three protocols of the Finnish Leukemia Group were used: ALL90 1990-1993 ( $\mathrm{n}=31)$, ALL94 1994-1999 ( $\mathrm{n}=43)$, and ALL2000 2000-2004 (n=23) (I, Table S2). The adult ALL protocols comprised six therapy blocks and maintenance. The total duration of treatment was three years. These three protocols contained relatively high total doses of vincristine, dexamethasone, and metothrexate (I, Table 1). However, the cumulative dose of metothrexate in the pediatric protocols, including maintenance, was clearly higher than in the adult protocols. Regarding corticosteroids, vincristine, or asparaginase, no significant difference was present in the cumulative doses. The dose of asparaginase in the currently used adult protocol ALL2000 has been reduced because of liver toxicity and thrombotic complications. The total cumulative doses of anthracyclines in adult protocols were about twice those of pediatric protocols. Epipodophyllotoxins or mitoxanthrone were not included in pediatric protocols. During the study period in both adult and pediatric protocols $\mathrm{Ph}+$ patients were treated mainly without imatinib.

Allogeneic SCT in 1CR was performed on 28 of the AYA patients (14 pediatric, 14 adults). In the pediatric treatment group, the indications were very high initial $\mathrm{WBC}(\mathrm{n}=1), \mathrm{Ph}+$ $\operatorname{ALL}(\mathrm{n}=4), M L L$ rearrangement $(\mathrm{n}=1)$, T-ALL with high WBC $(\mathrm{n}=2)$, poor response to induction therapy $(n=2)$, and unknown $(n=4)$. For adults, allo-SCT was offered if a matched related donor was available.

The accessory groups of children under 1 year, children 1-9 years, and adults over 26 years, all diagnosed in or after the year 2000, were treated with Interfant-99 and 2006, NOPHO ALL-2000, and ALL2000 protocols, respectively.

\subsection{Methods}

\subsubsection{Diagnostic studies}

Diagnosis of ALL was based on bone marrow aspirate and biopsy slides (Harris et al. 1994). ALL blast morphology was evaluated according to the French-American-British (FAB) classification (Bennett et al. 1976; Bennett et al. 1981). Immunophenotyping was performed by flow cytometry. Regarding cytogenetic studies, G-banding was performed at all centers. During the study period chromosomal CGH, FISH (M-FISH, locus specific for e.g. ETV6-RUNX1, MLL rearrangement, CDKN2A-locus, $B C R-A B L$, and whole chromosome probes), Southern blot and PCR (for detection of TCR and IGG rearrangements), and multiplex RT-PCR (for screening of known translocations) became more widely applied for detailed analyses of the cytogenetic and molecular genetic changes. 


\subsubsection{Definition of relapse}

Bone marrow relapse was defined morphologically with $\geq 5 \%$ blasts in the marrow. CNS relapse was defined as a leukocyte count of $\geq 5 / \mu \mathrm{l}$ in the cerebrospinal fluid with documentation of blasts. Testicular relapse was defined as a painless enlargement verified by biopsy.

\subsubsection{Microarray CGH}

Extraction of genomic DNA used either frozen bone marrow, bone marrow cell nuclei in fixative (acetic acid-methanol, 1:3), or bone marrow mononuclear cell pellets stored at $-70^{\circ} \mathrm{C}$. A standard nonenzymatic method was used for frozen bone marrow samples. Puregene DNA Purification Kit (Gentra Systems, Minneapolis, MN, USA) was used for fixatives and cell pellets. DNA concentration was measured by using a Nanodrop spectrophotometer (Thermo Scientific, Wilmington, DE, USA). The quality of DNA was controlled by using agarose gel electrophoresis. Male and female reference DNAs were extracted by the standard phenol-chloroform method from pooled blood samples (4 males, 4 females) kindly provided by the Finnish Red Cross Blood Transfusion Service.

Agilent protocol for $44 \mathrm{~K}$ and $244 \mathrm{~K}$ microarrays was used for digestion, labeling, hybridization, and data analysis of genomic DNA according to the manufacturer's instructions. The reference and sample DNAs were fragmented, and the fragmented DNA was labeled by random priming using the BioPrime array labeling kit (Invitrogen, Carlsbad, CA, USA) with Cy5-dUTP and Cy3-dUTP dyes (Perkin-Elmer, Wellesley, MA, USA). The labeled samples were purified, combined, and hybridized to Human Genome CGH 44B or 244A oligo microarray slides (Agilent Technologies Santa Clara, CA, USA). The samples were hybridized against gender-matched reference DNAs.

The array images were analyzed and the data extracted using Feature Extraction Software (Agilent Technologies), including dye normalization (Linear Lowess). For data analysis, CGH Analytics software version 3.5 (Studies II and IV) and DNA Analytics software version 4.0 (Study III) were used. The starting and ending points of the aberrations were confirmed by using the ADM-2 algorithm with a 6.0 threshold (Agilent Technologies).

\subsubsection{SNP arrays}

In addition to aCGH, SNP microarrays were performed on seven ALL patients in Study III for confirmation of aCGH results. Affymetrix SNP 6 (Affymetrix, Inc., Santa Clara, CA, USA) was used according to the manufacturer's protocol. Genomic DNA (250 ng) 
was digested either with NspI or StyI (NEB, Hitchin, Herts, UK). Each NspI- or StyI- digested DNA was ligated using a corresponding adaptor (Affymetrix). Each reaction was then amplified by PCR reactions using a common PCR primer 002 (Affymetrix). The PCR products were purified using Agencourt AMPure (Agencourt Bioscience Corporation, Beverly, MA, USA). The purified DNA products were fragmented by using a fragmentation reagent (Affymetrix). Fragmented DNA was labeled with the DNA labeling reagents (Affymetrix). Hybridization was performed by using Genome-Wide-Human SNP Array 6.0 (Affymetrix).

In Study III, also AML patients screened with SNP array were included. Affymetrix GeneChip Human Mapping 50K Array Xba 240 (Affymetrix, Santa Clara, CA, USA) was applied to adult AML cases $(n=26)$ described in a previous report (Tyybakinoja et al. 2008).

\subsubsection{Statistical methods}

In the statistical analyses, SPSS software, version 15.0 (SPSS Inc., Chicago, IL, USA) was used. The clinical characteristics and outcome were compared between pediatric and adult treatment groups of ALL patients (10-25 years) (I). Comparison was also made between patients with and without $9 p$ deletions (II). Comparisons of clinical characteristics were performed using the Mann-Whitney U-test for continuous variables and Chi-square test for categorized variables. The Kaplan-Meier method (Kaplan et al. 1958) with log-rank test (Peto et al. 1977) was used to analyze outcome. Event-free survival (EFS) was defined as the time from diagnosis to the first event (relapse, death, second malignancy). Overall survival (OS) was defined as the time from diagnosis to death. The patients were censored on the day of the last follow-up if no event had occurred. Patients who received allogeneic stem cell transplantation (SCT) in first complete remission (1CR) were censored on the day of the SCT. Exception was made when comparing Ph+ ALL with other patients since allo-SCT in 1CR was considered optimal therapy for Ph+ ALL. The data were retained for follow-up on May 31, 2007 (I, II).

The methods of bioinformatics are described in detail in Study V. Briefly, receiver operating characteristic (ROC) analysis was used to assess the value of single genes or sets of genes as prognostic classifiers (Swets 1988) (V). A ROC curve can be drawn by calculating true and false-positive rates. The area under the ROC curve (AUROC) corresponds to the probability of correctly classifying two given patients into two classes, one from each class (Hilgers 1991). The principle of maximum likelihood was used to estimate a Naïve Bayes (NB) classifier form the categorical (loss-normal-gain) array data (Hastie et al. 2001). For the continuous log-ratio data, a linear regression model was applied. The 
coefficients of the linear model were estimated using the method of least-squares (Hastie et al. 2001).

A list of 41 genes linked in previous studies to cytostatic drug resistance or prognosis in ALL was taken as a starting point for identifying prognostic classifiers (Holleman et al. 2004) (V, Table S1). The search procedure for the optimal model of predicting relapse included genes that were recurrently aberrated in either the relapse or no-relapse group and were selected by filtering out those genes aberrated in less than $20 \%$ of cases. After the filtering, five genes were left for model designing. Every combination of genes was tested in an exhaustive manner. Each model was trained and the training accuracy and validation error estimated by repeatedly excluding a certain proportion of the data to be the validation set.

For assessment of the prognostic classifier derived from aCGH data of AYA ALL patients $(V)$, the relapse status classes were randomly permuted to assess the statistical significance of the prognostic model. In addition, to evaluate the accuracy of the model in the different ALL patient groups, the model was tested in two groups not used in the identification of the model: pediatric patients 1-9 years of age and adult patients over 26 years of age. This did not validate the original model for relapse prediction in AYA ALL, but was informative regarding the overall assessment of the prognostic validity for pediatric and adult patients. 


\section{RESULTS}

\subsection{Patient characteristics (I, II)}

In the AYA ALL population, the age distribution at diagnosis indicated decreasing incidence with age (Figure 5).

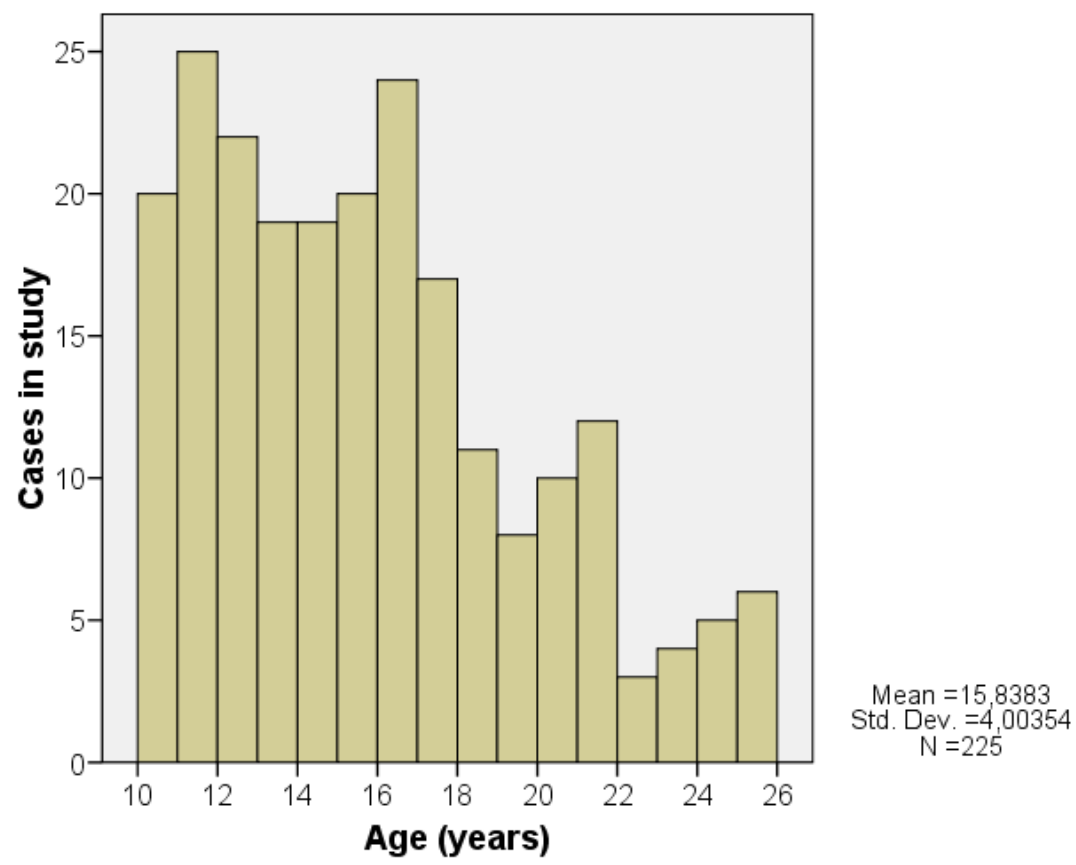

Figure 5. Age distribution of AYA ALL patients at diagnosis in Study I.

Except for age, the key clinical characteristics in the pediatric and adolescent treatment groups were essentially similar (I, Table 2). In most patients, the initial WBC was below $50 \times 10^{9} / 1$ (Figure 6). 


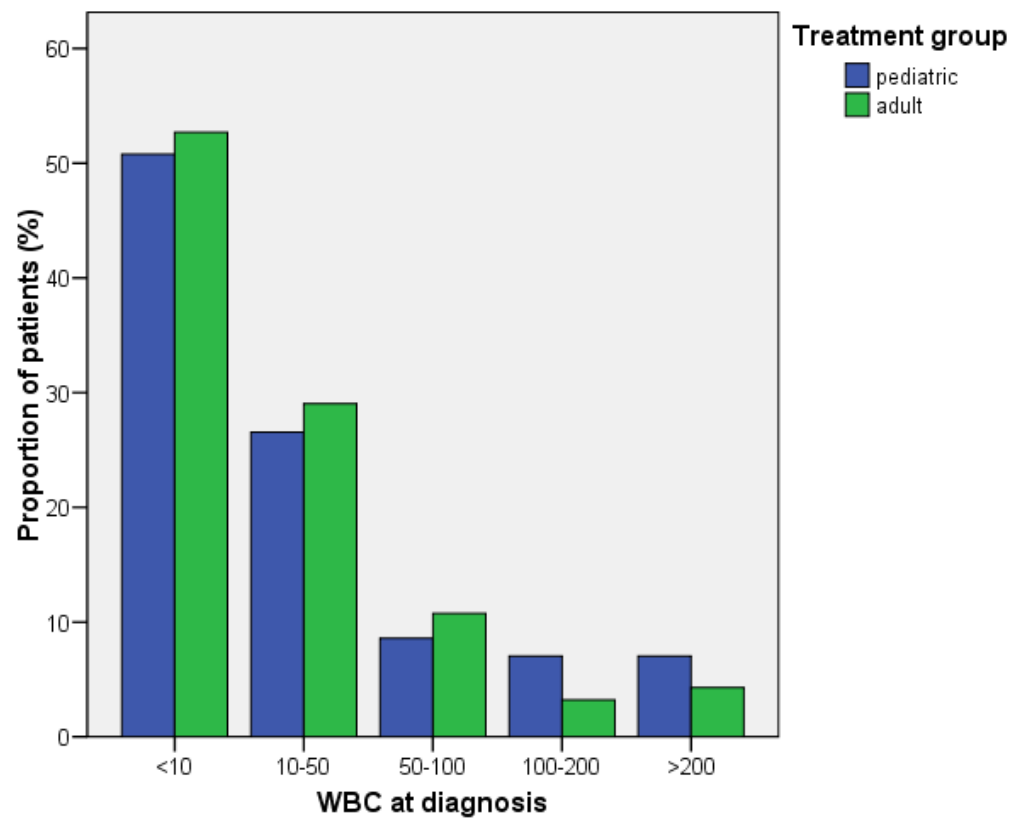

Figure 6. Proportions of AYA patients with different WBC levels on pediatric and adult protocols in Study I.

Less than $20 \%$ in both groups had T-ALL. In the adult group, younger patients (16-20 years) had less T-ALL (15\%) than older ones (24\%). The proportion of the ETV6-RUNX1 (TEL-AML1) subtype in the pediatric group was only $3 \%$, and even lower, $1 \%$, in adults. Hyperdiploidy ( $\geq 50$ chromosomes) was more frequent in the pediatric group (18\%) than in the adult group (4\%) $(\mathrm{p}=0.002)$. $\mathrm{Ph}+$ subtype was infrequent in both groups $(8 \%$ and $4 \%$, respectively) (Figure 7 ).
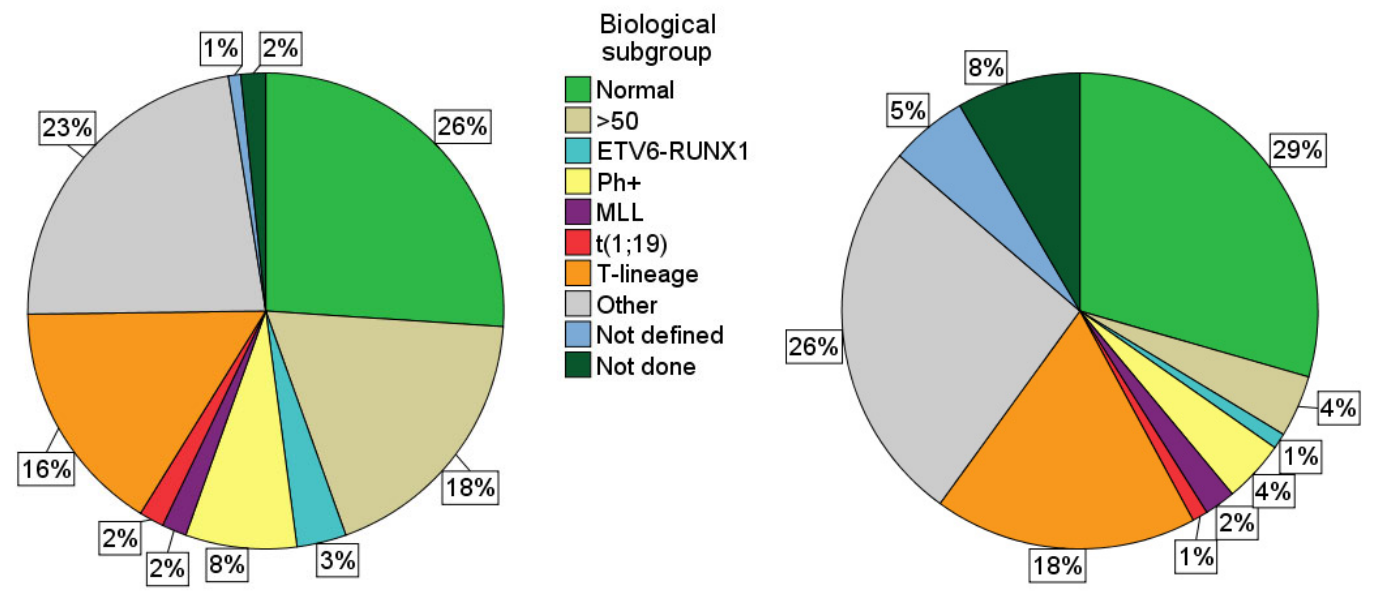

Figure 7. Distribution of biologic subgroups of AYA patients among the (A) pediatric (10-16 years) and (B) adult (17-25 years) treatment groups in Study I. Only about $20 \%$ of the patients were screened for $\mathrm{t}(12 ; 21)$; of these, about $10 \%$ were positive. 
In AYA ALL patients, subtypes associated with poor prognosis (high initial $\mathrm{WBC}, \mathrm{Ph}+$, $M L L$ rearrangement, hypodiploidy, and T-ALL) were more common in patients with deletion in the chromosomal region 9p21.3 than in patients without the deletion. In particular, the initial WBC was higher in the group with the deletion (II, Table 2).

When analyzing the biological subgroups of ALL patients from all age groups, the number of $M L L$ rearrangement-positive patients declined steeply after the age of 1 year. High peaks of hyperdiploidy and ETV6-RUNX1 were seen in the group of 1-9 years. T-ALL was most common in patients aged 1-9 years; in older age groups, there was a lower but steady number of T-ALL patients. The number of individuals with $\mathrm{Ph}+$ subtype increased markedly after the age of 26 years (Figure 8).

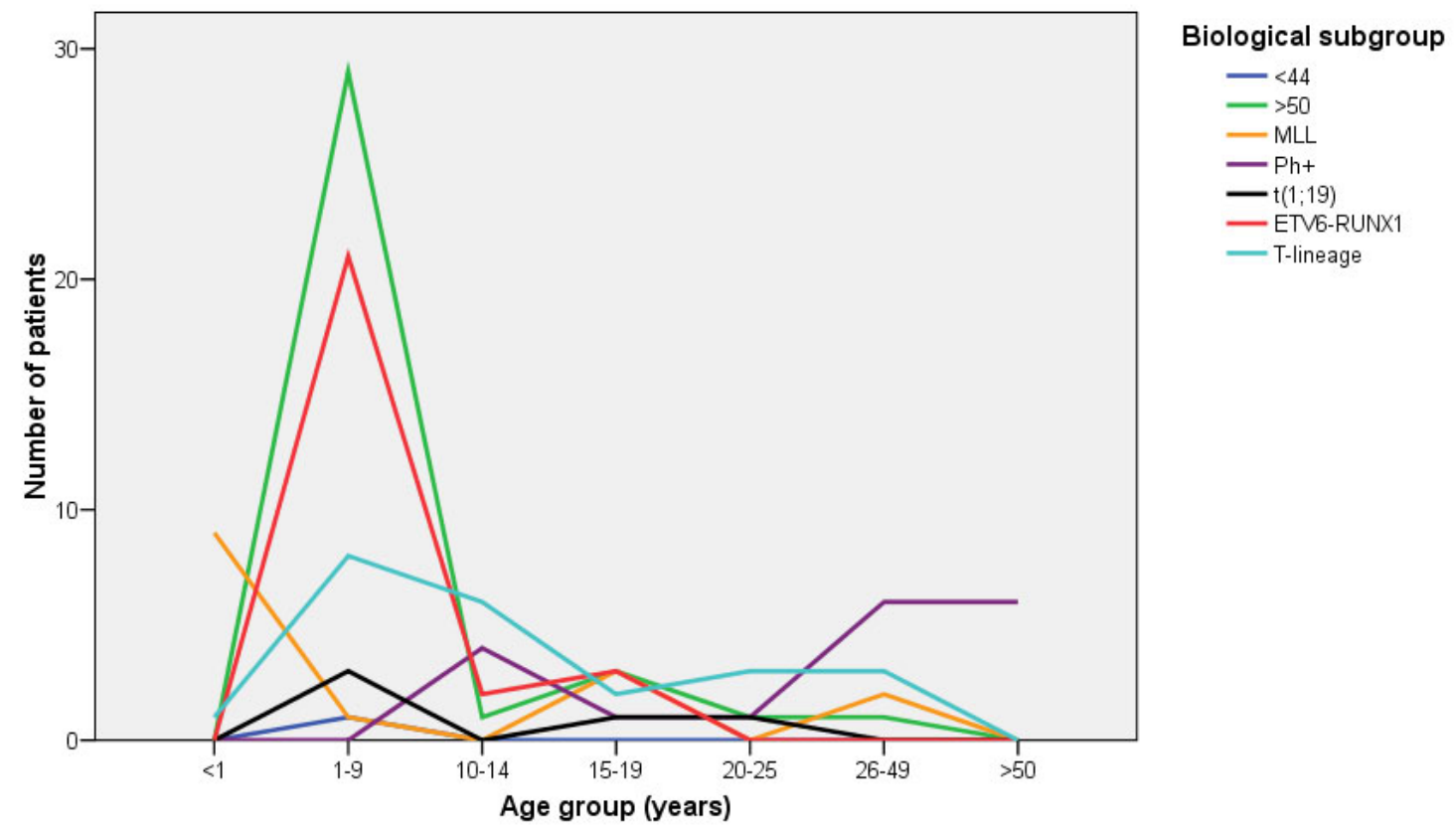

Figure 8. Number of patients with known biologic subtypes of ALL in different age groups.

\subsection{Outcome (I)}

Among AYA ALL patients diagnosed during 1990-2004, the induction death rate was $4 / 128(3 \%)$ in the pediatric and 5/97 (5\%) in the adult group $(\mathrm{p}=0.44)$. The remission rate was $96 \%$ in the pediatric and $97 \%$ in the adult group. The figure for those remaining in first continuous complete remission (1CCR) on chemotherapy was 56\% (Figure 9). 


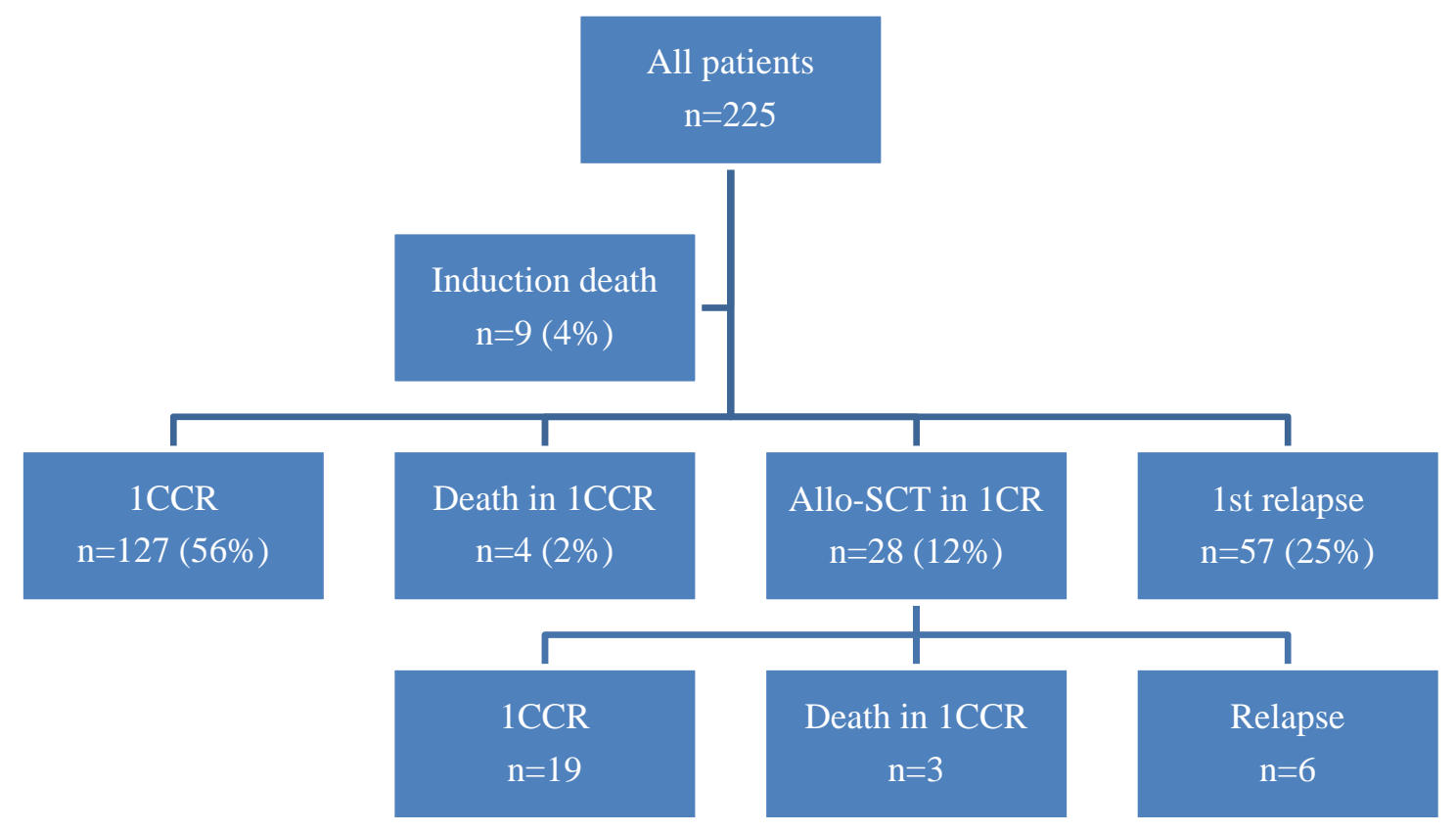

Figure 9. All AYA patients with ALL included in Study I. In induction deaths, both resistant disease and toxic deaths are included.

Of the AYA patients, 28 (14 pediatric, 14 adult, $\mathrm{p}=0.43$ ) underwent allogeneic stem cell transplantation in first remission. Nine of these were $\mathrm{Ph}+$ patients. Allogeneic SCT in second remission was performed on 29 (46\%) of the relapsed patients.

In the whole AYA cohort (including patients treated with SCT), the relapse rate was comparable in the two groups $(26 \%, n=33$, in pediatric, and $31 \%, n=30$, in adult patients, $\mathrm{p}=0.40$ ) (Figure 9). Of those who relapsed, 49 (78\%) achieved a second remission but only $16 / 49$ (33\%) remained in second remission after a median follow-up of 3.5 years.

The 5- and 10-year EFS for AYA patients was $62 \%$ and $57 \%$, and the OS $72 \%$ and $67 \%$, respectively. The 5 -year EFS was $67 \%$ in the pediatric group, and $60 \%$ in the adult group (n.s.). The OS rates did not differ between the groups (77\% vs. 70\%, n.s.) (Figure 10). Censoring of patients with allo-SCT in 1CR on the day of SCT did not influence EFS or OS. Donor vs. no donor analysis was not done. Comparing survivals of each treatment group (pediatric IR, HR, and adult) in different time periods revealed no significant difference. 


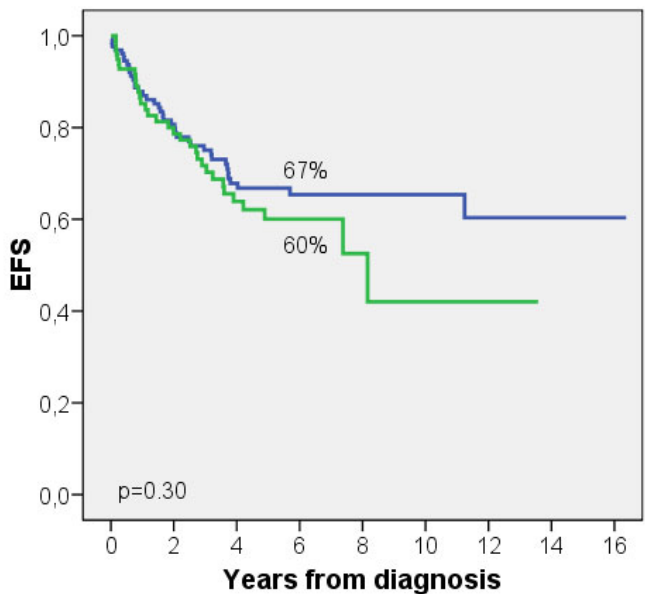

A

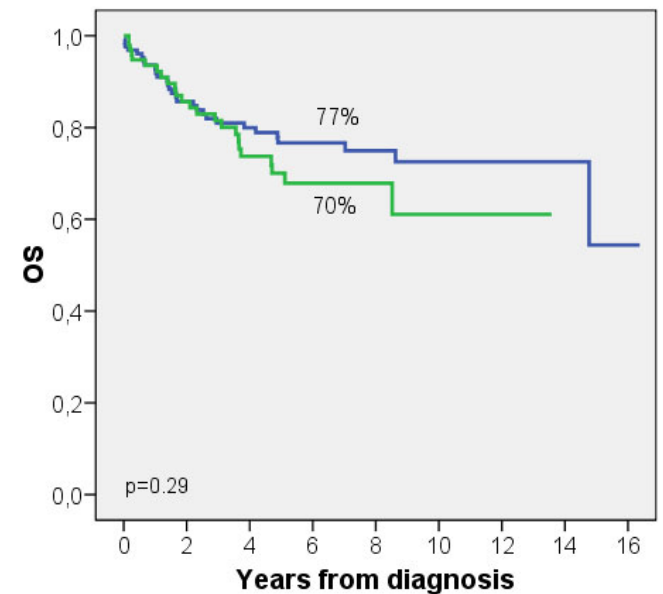

B

Figure 10. (A) EFS and (B) OS of AYA ALL patients treated with pediatric and adult protocols. Five-year survivals are indicated.

Comparison of survivals in all age groups disclosed a superior 5-year EFS of patients aged 1-9 years. The worst outcome was seen in patients 26 years or older. In the age groups of 1016 years and 17-25 years, the EFS was intermediate. Infants ( $<1$ year) had relatively high survival, which may be explained by the low number of infant patients and the short follow-up in the study. The overall survival showed the same trend for different age groups (Table 4).

Table 4. Event-free survival and overall survival at 3 years of ALL patients in different age groups.

\begin{tabular}{cccc}
\hline Age (years) & n & EFS (\%) & OS (\%) \\
\hline$<1^{\star}$ & 14 & 63 & 70 \\
$1-9$ & 83 & 78 & 90 \\
$10-16^{\ddagger}$ & 38 & 68 & 73 \\
$17-25^{\ddagger}$ & 38 & 70 & 78 \\
$>26$ & 32 & 51 & 53 \\
\hline
\end{tabular}

${ }^{\star}$ Follow-up intermediate, median 2.5 years and range $0.1-6.9$ years. The number of patients in this group was low.

${ }^{\star}$ Different patient material and smaller cohort than in Study I.

\subsection{Prognostic factors in AYA ALL (I, II)}

Among AYA patients with ALL, survival did not differ between male and female patients. Very high $\left(\geq 100 \times 10^{9} / \mathrm{l}\right) \mathrm{WBC}$ was associated with poor prognosis: the 5-year EFS in this group ( $\mathrm{n}=25)$ was $27 \%$ compared with $69 \%$ for the others $(\mathrm{p}<0.05)$ (Figure 11$)$. 


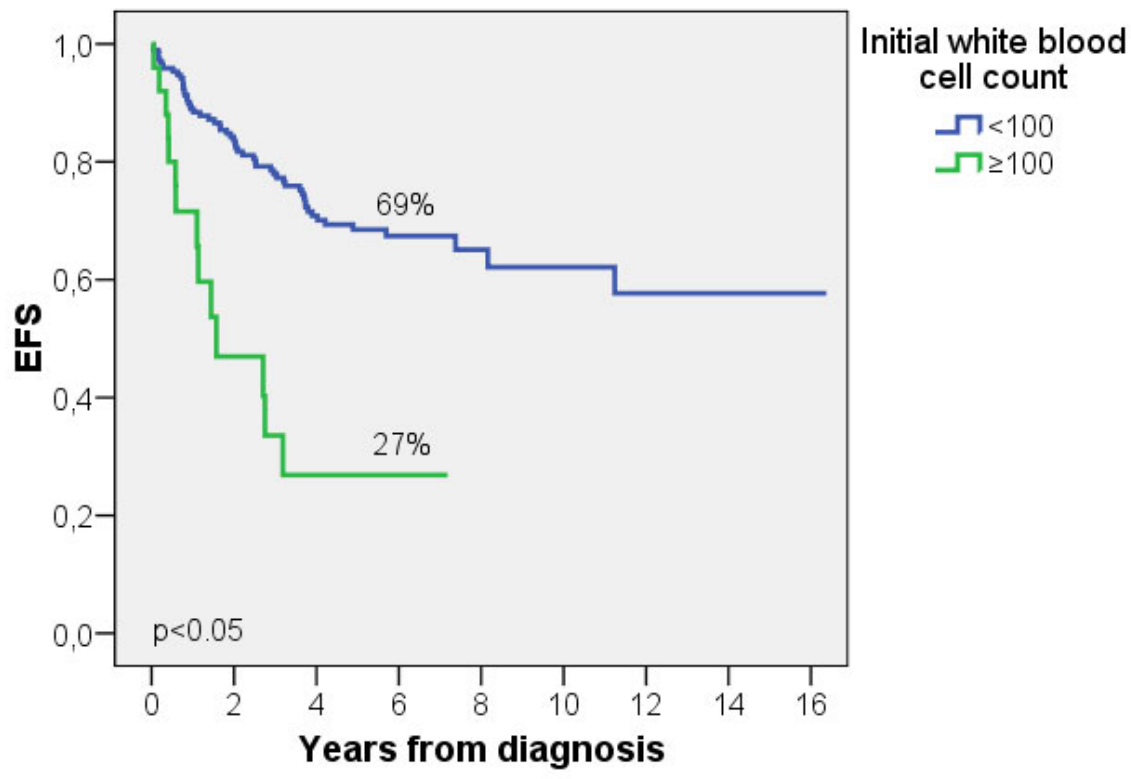

Figure 11. EFS of patients with $\mathrm{WBC} \geq 100 \times 10^{9} / 1$ and those with $\mathrm{WBC}<100 \times 10^{9} / 1$. Five-year survivals are indicated.

Age as a prognostic factor was not significant within the age range of 10-25 years, the 5 -year EFS being 69\% for patients aged 10-15 years and 58\% for those aged 20-25 years $(\mathrm{p}=0.24)$. Patients in the pediatric IR group had a superior outcome to those in the pediatric HR group and the adult group (Figure 12).

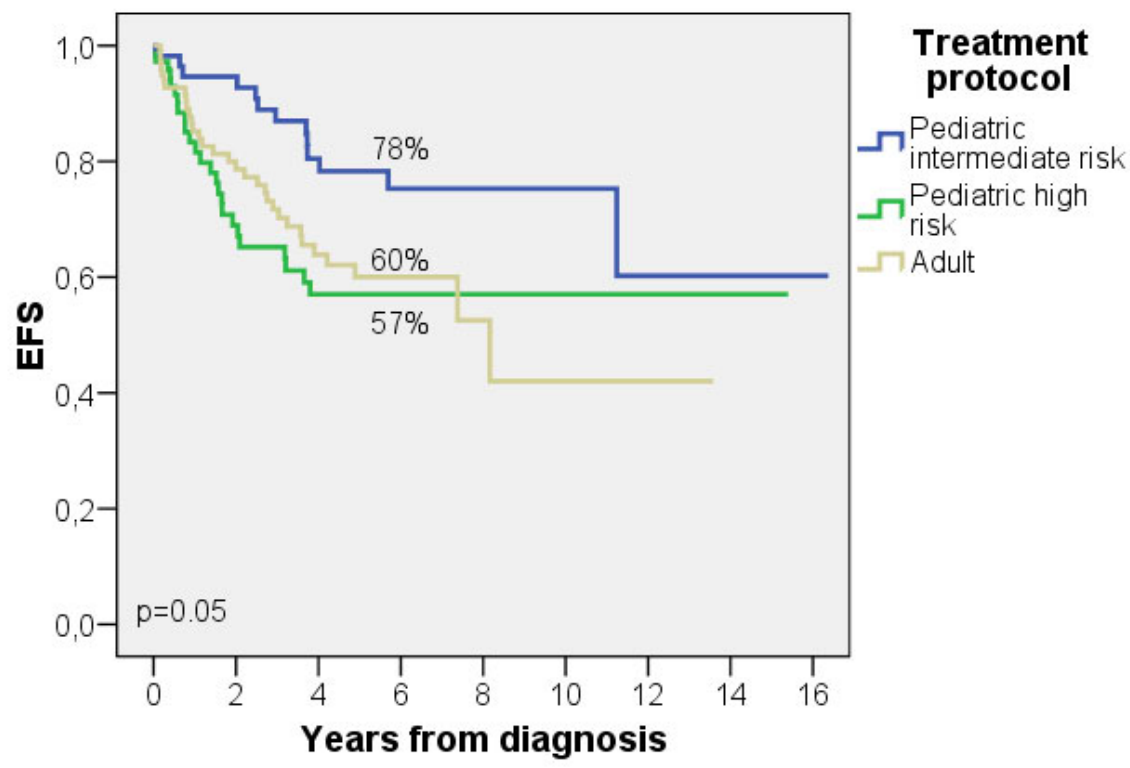

Figure 12. EFS of patients treated with pediatric IR or HR protocols or with adult protocols. Five-year survivals are indicated. 
T-cell immunophenotype showed a trend to be associated with inferior outcome (5-year EFS 53\% for T-ALL vs. $67 \%$ for B-cell precursor ALL, $\mathrm{p}=\mathrm{n}$.s.). While the outcomes were similar in the pediatric and adult groups regarding B-cell precursor ALL, for T-ALL the EFS and OS tended to be superior in pediatric patients.

The number of Philadelphia chromosome-positive patients was small in both treatment groups (9 pediatric, 4 adult). $\mathrm{Ph}+$ patients were treated mainly without imatinib. Nine out of the 13 patients (69\%) underwent allogeneic stem cell transplantation in 1CR. The overall survivals at 5 years were $55 \%$ and $72 \%$, respectively $(p=0.23)(I)$.

Deletion in 9p21.3 had no significant impact in the outcome of AYA ALL patients (II). The 5 -year EFS for patients with and without the deletion was $62 \%$ vs. $70 \%(p=0.34)$ and the OS was $67 \%$ vs. $76 \%$ ( $p=0.26$ ), respectively (II, Figure 3 ). The number of additional aberrations was not associated with outcome, nor was zygosity of the $9 p$ deletion.

\subsection{DNA copy number alterations detected with aCGH}

\subsubsection{Deletion in 9p detected with aCGH (II-IV)}

Deletions in 9p were restricted to ALL (III). None of the patients with AML, CLL, or MDS had this abnormality. The CDKN2A locus in 9p21.3 was deleted in 58/140 ALL patients (41\%) of all ages (III). In AYA ALL patients, the deletion was present in 25/54 (46\%) patients (II), in 15/33 (46\%) of the B-cell precursor ALL and 5/8 (63\%) of the T-ALL cases (II, Table 2). Deletions affecting 9p21.3 were the most common aberrations in AYA patients with initially normal karyotype ( $\mathrm{n}=27$ ) (IV). Of the 27 cases, 23 had aberrations, and the 9p21.3 deletion was detected in 11 patients (IV, Table 1). The only gene always included in 9p21.3 deletions was CDKN2A.

Of the 9p21.3 deletions in AYA ( $\mathrm{n}=25), 15$ (60\%) were less than $5 \mathrm{Mb}$ (II). Twelve of these small deletions were homozygous. Overall, homozygous deletions were found in 19 (76\%) of the AYA patients with a CDKN2A deletion (II, Table 1). Nine cases (36\%) had a smaller homozygous deletion area detected within a broader heterozygous deletion (II) (Figure 13). Three of the nine cases had a homozygously deleted area of $<200 \mathrm{~kb}$. The smallest overlapping region of the deletions in 9p21.3 was only $12.2 \mathrm{~kb}$ (II, Figure 1 ). The whole $\mathrm{p}$ arm of chromosome 9 or a major part of it was deleted in 7/25 cases (28\%). The number of other aberrations in AYA patients with a 9p21.3 deletion detected by aCGH ranged from 0 to 13 . 


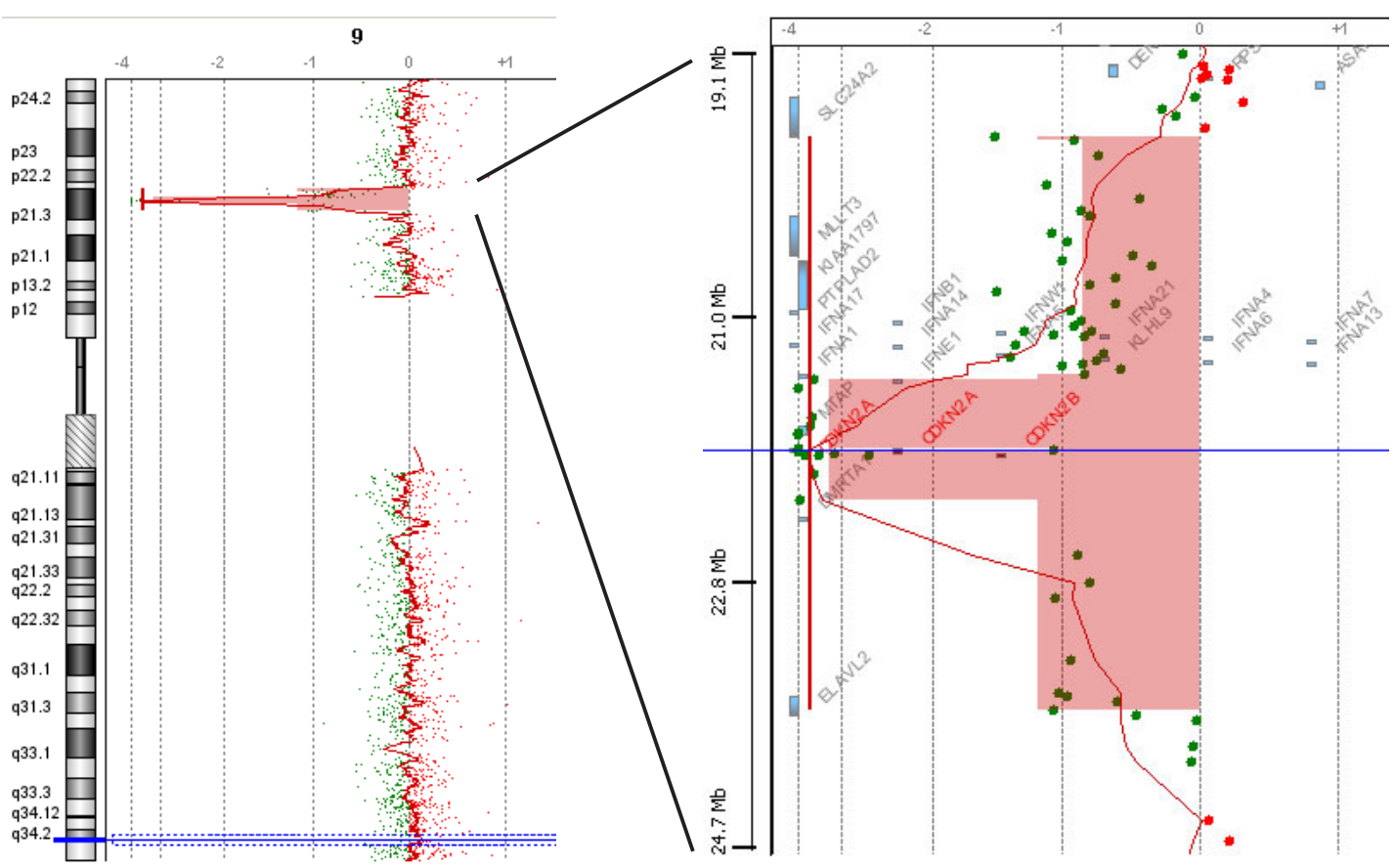

Figure 13. Deletion of 9p21.3. A small homozygously lost region encompassing the CDKN2A and $C D K N 2 B$ genes within a larger heterozygous deletion. A chromosome view is presented on the left and a focused genomic view on the right. The scatter plot represents the ratio between test and reference sample DNA copy numbers. Red dots indicate a copy number gain and green dots copy number loss in the corresponding chromosomal area.

\subsubsection{Instability of 9p (III)}

$9 \mathrm{p}$ instability was defined as homozygous loss within a larger heterozygous one or multiple separate areas of copy number loss in 9p (Figures 13 and 14). Of the 140 ALL patients (aged 2-65 years), 27 (19\%) presented with the instability. Both heterozygously and homozygously lost regions were present. The size of the lost area varied from $0.03 \mathrm{Mb}$ to the whole short arm of chromosome 9. The largest homozygous loss spanned 6.786 $\mathrm{Mb}$ and the smallest $0.015 \mathrm{Mb}$ (III, Table S1). One patient had a complicated deletion pattern, with eight separate deleted regions at 9p (Figure 14). One deleted area embraced a smaller homozygous deletion within a heterozygous one. Other deletions were heterozygous in this patient. Nine patients had in 9p two separate, partly homozygously deleted areas. The remaining patients $(n=17)$ presented instability in the form of a homozygous deletion within a larger heterozygous one (Figure 13). The instability was the only copy number aberration detected in five patients. CDKN2A gene was always homozygously deleted. Another gene invariably deleted was $C D K N 2 B$. Other recurrently deleted genes in 9p instability were IFN genes (93\%), MTAP (93\%), MLLT3 (67\%), PTPLAD2 (67\%), PAX5 (63\%), and JAK2 (15\%) (III, Table 3). IKZF1 (IKAROS family zinc finger) gene in 7p12 was deleted in 10 patients with the 9p instability (37\%) and in 22/140 ALL patients (16\%). 
Two patients had homozygous loss of hsa-mir -31, a microRNA known to regulate IKZF1. Thirteen (47\%) of the patients with 9p instability were previously found to have some oncogene-activating translocation and fusion gene formation or structural chromosomal aberrations. Five patients had 9p instability, t(9;22), and IKZF1 deletion.

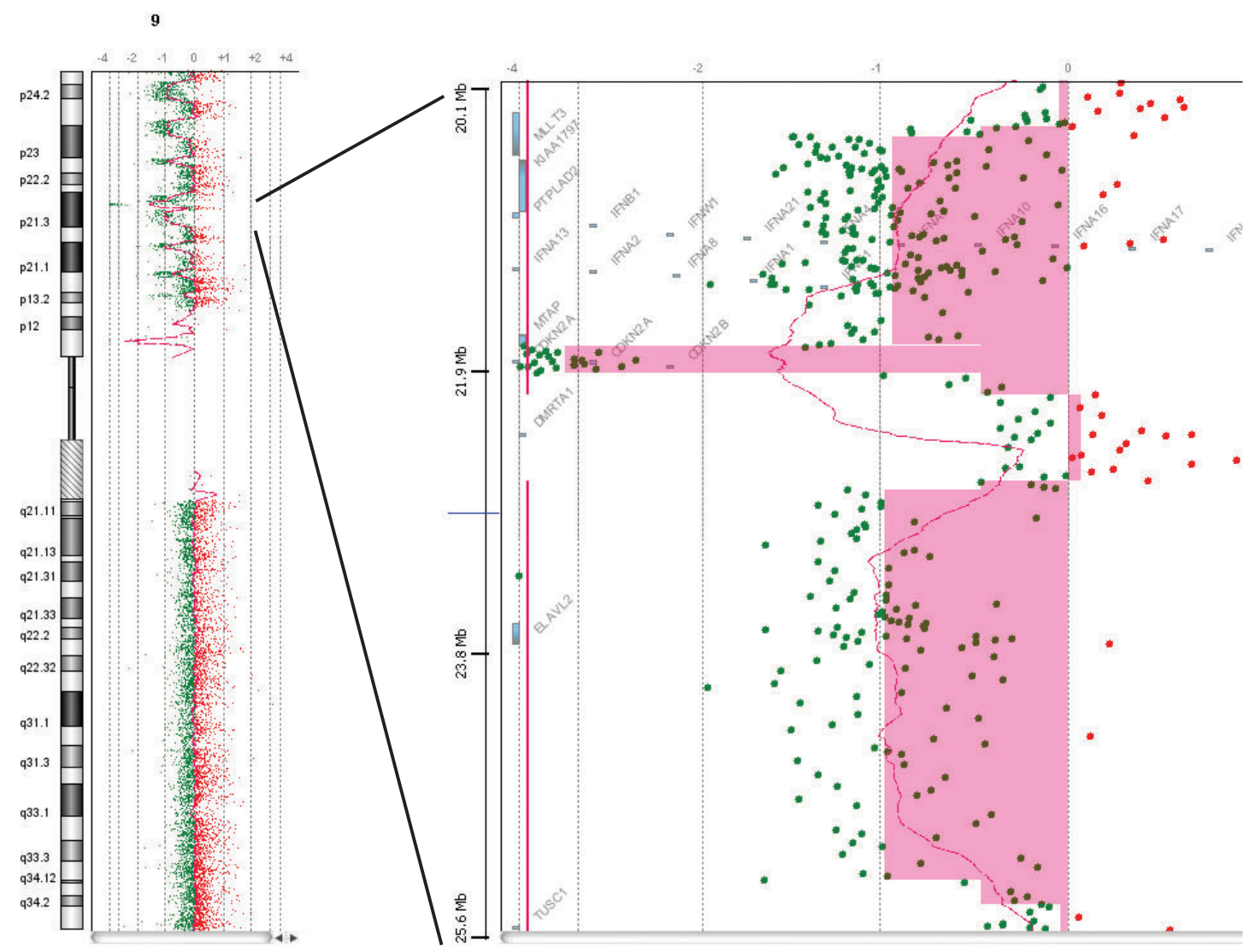

Figure 14. Example of 9p instability detected with aCGH. Eight separate heterozygously lost areas and one small homozygously lost area in 9p21.3 encompassing the CDKN2A gene.

\subsubsection{Copy number alterations in patients with initially normal karyotype (IV)}

AYA ALL patients with previously normal $(n=26)$ or failed $(n=1)$ karyotype analysis were analyzed with aCGH. In addition to losses in 9p21.3, a variable number of other copy number alterations were detected with aCGH (IV, Figure 1). Regarding molecular cytogenetics, only four patients remained normal even after aCGH examination. In the 27 patient samples, a total of 53 aberrations were detected in 23 samples (1-7 aberrations per sample, mean 2.3) (Table 5). Losses were detected in 19 of 23 cases and gains in 10 of 23 cases. Altogether 39 losses and 14 gains were detected. In addition to losses in 9p21.3, other recurrent aberrations included gain in 21q, loss in 6q, loss in 12q23 q24, loss in 16q22.1, and loss in 17q11.2. Ten patients (37\%) had only one aberration, in $50 \%$ of cases being the loss of 9p. Deletions less than $5 \mathrm{Mb}$ were seen in 13 patients (Table 6). 
Table 5. Summary of aberrations in Study IV.

\begin{tabular}{lcc}
\hline & n & No. of patients \\
\hline Aberrations & 53 & 23 \\
Losses & 39 & 19 \\
Gains & 14 & 10 \\
Losses only & & 13 \\
Gains only & 4 \\
Single aberration & 10 \\
Most common aberration & & \\
$\quad$ del 9p21.3 & & 11 \\
Submicroscopic deletions $(<5 \mathrm{Mb})$ & 16 & 13 \\
\hline
\end{tabular}

Table 6. Summary of recurrent submicroscopic deletions in Study IV.

\begin{tabular}{ccccc}
\hline $\begin{array}{c}\text { Chromosomal } \\
\text { location }\end{array}$ & $\begin{array}{c}\text { No. of } \\
\text { patients }\end{array}$ & $\begin{array}{c}\text { Size of minimal } \\
\text { region of overlap } \\
(\mathbf{M b})\end{array}$ & $\begin{array}{c}\text { No. of genes in the } \\
\text { minimal region of } \\
\text { overlap }\end{array}$ & Potential target genes \\
\hline $9 \mathrm{p} 21.3$ & 8 & 0.03 & 2 & $C D K N 2 A, C D K N 2 B$ \\
$16 \mathrm{q} 22.1$ & 2 & 0.8 & 45 & $\begin{array}{c}\text { E2F4, TPPP3, ACD, } \\
\text { TRADD, CTCF, ELMO3, } \\
\end{array}$ \\
& 2 & 1.3 & 14 & THAP11 \\
$17 \mathrm{q} 11.2$ & 2 & & UTP6, NF1, ATAD5 \\
\hline
\end{tabular}

\subsection{Prognostic classifier of ALL patients based on aCGH data (V)}

As a result of the filtering for genes recurrently aberrated, five genes (BAK1, CDKN2A, CDKN2B, GSTM1, and MT1F) were left for selection for the prognostic model. The selection procedure executed with Naïve Bayes as the base classifier resulted in a set of four genes (BAK1, CDKN2B, GSTM1, and MT1F) revealed to be the most significant. These genes were included both in NB classifier using categorical data and the linear model using continuous log-ratio data.

The parameters of the prognostic NB model denoted the probabilities of a gene having either a loss, gain, or being normal (no gain or loss) (V, Table 4). The class posterior probabilities were calculated with the Bayes's rule assuming equal prior probabilities (Table 7). 
A trend was observed that combinations with more aberrations more likely led to a "relapse" decision. At least 3 of the 4 genes aberrated were combinations with the highest probability for relapse. $B A K 1$ and/or $C D K N 2 B$ were deleted in cases classified in the "relapse" decision group. The two genes were never amplified in these cases. On the other hand, GSTM1 and/ or MT1F were amplified in cases with a probability of relapse of more than $70 \%$.

Table 7: Losses and gains of the prognostic marker genes and the subsequent prognostic decision made with the Naïve Bayes classifier.

\begin{tabular}{cccccc}
\hline BAK1 & CDKN2B & GSTM1 & MT1F & $\begin{array}{c}\text { Prognostic } \\
\text { decision }\end{array}$ & $\begin{array}{c}\text { Probability of } \\
\text { relapse }\end{array}$ \\
\hline 0 & del & amp & del & no relapse & 0.0753 \\
0 & 0 & 0 & 0 & no relapse & 0.1869 \\
0 & amp & 0 & 0 & no relapse & 0.2147 \\
0 & 0 & amp & 0 & no relapse & 0.3016 \\
0 & 0 & 0 & amp & no relapse & 0.3072 \\
0 & 0 & del & 0 & no relapse & 0.3453 \\
0 & del & 0 & 0 & no relapse & 0.3830 \\
amp & 0 & del & 0 & no relapse & 0.4217 \\
del & 0 & 0 & 0 & no relapse & 0.4248 \\
\hline 0 & 0 & amp & amp & no relapse & 0.4775 \\
& & & & & \\
0 & 0 & del & amp & relapse & 0.5208 \\
0 & del & amp & 0 & relapse & 0.5844 \\
0 & del & 0 & amp & relapse & 0.6258 \\
\hline del & 0 & amp & 0 & relapse & 0.6380 \\
\hline 0 & del & del & 0 & relapse & 0.6631 \\
del & 0 & del & 0 & relapse & 0.6770 \\
del & del & 0 & 0 & relapse & 0.7008 \\
\hline 0 & del & amp & amp & relapse & 0.7116 \\
del & del & 0 & amp & relapse & 0.7434 \\
del & del & amp & 0 & relapse & 0.7458 \\
del & del & amp & amp & relapse & 0.8482 \\
\hline
\end{tabular}

The linear model estimated from the data can be written as follows:

ALL score (related to risk of relapse) $=-0.9582 * \operatorname{logratio}\left({ }^{\prime} \mathrm{BAK1}\right)$ - 0.2823 * logratio('CDKN2B') + 0.1637 * logratio('GSTM1') + 0.5544* logratio('MT1F').

This gives a similar interpretation with the NB model, with a positive sign indicating that gain increases relapse risk, and a negative sign implying that deletion is the mechanism increasing the risk of relapse. 
Both the linear and NB models were assessed with regard to prognostic accuracy by using the cross-validation setting. The prognostic accuracies in training and the validation set measured by AUROC for the NB model were 0.7548 (training) and 0.6722 (validation). To validate the prognostic accuracies of the models, we executed a randomized permutation test. This time, no data were excluded. We randomly permuted the class labels relapse/ no-relapse and estimated the NB classifiers for 10000 repetitions of the random permutations. The AUROC values for the randomized NB classifiers are seen as an empirical distribution of AUROC values under the assumption of the null hypothesis, i.e. that the classifier is noninformative in relapse prediction. The NB classifier had an AUROC value of 0.7685 when estimated from the whole data set. The p-value can be readily calculated to be $\mathrm{p}=0.0009$ and deemed statistically significant. Similarly, for the linear model, the AUROC estimated from the whole data set was 0.7401 and the p-value 0.0043 .
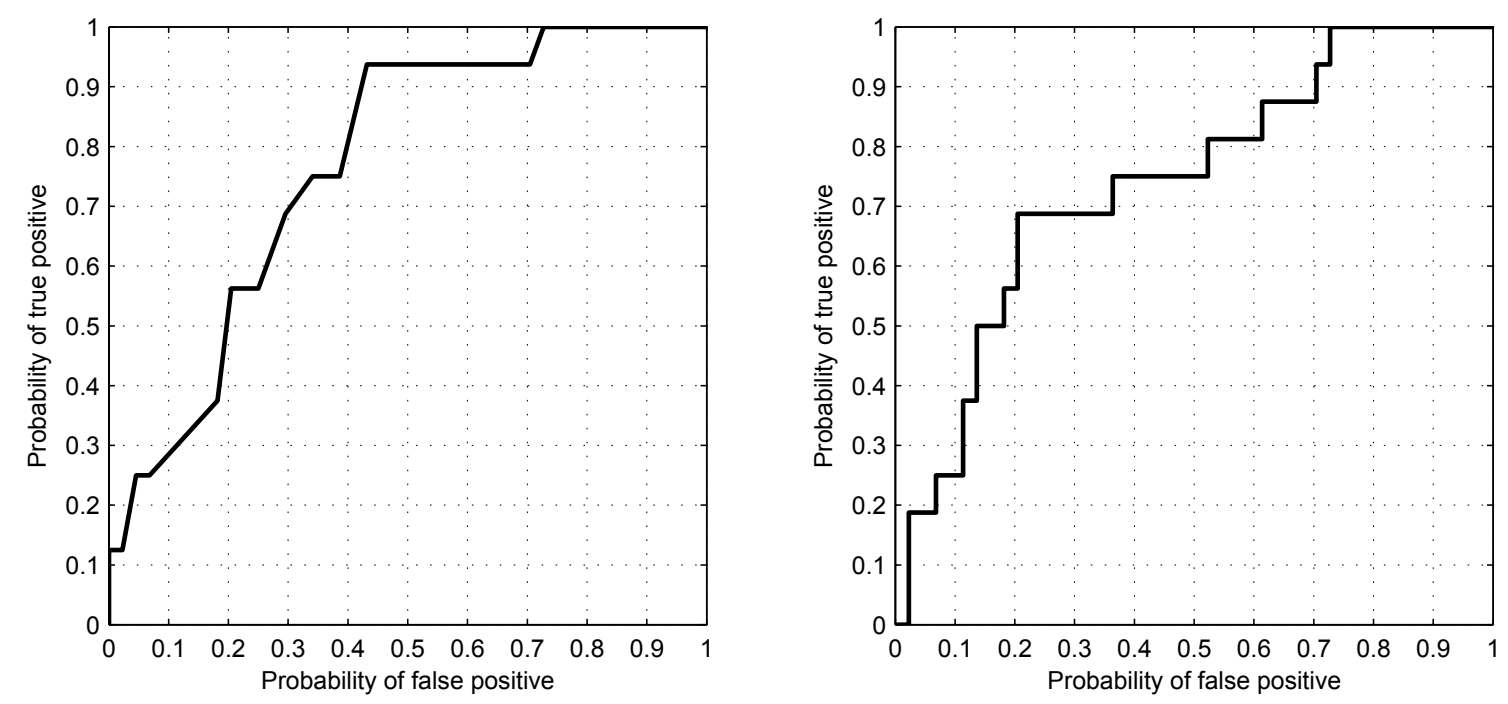

Figure 15. Prognostic accuracy of (A) Naïve Bayes and (B) linear models visualized with ROC curves for the AYA patients. The $\mathrm{x}$-axis indicates the probability of false positives and the $\mathrm{y}$-axis the probability of true positives. The corresponding AUROC values are $0.7685(\mathrm{p}=0.0009)$ for the NB and $0.7401(\mathrm{p}=0.0043)$ for the linear model. The $\mathrm{p}$-values are calculated by comparing each of the models with a noninformative prediction.

Performances of possible sensitivity-specificity trade-offs can be seen in the ROC curves (Figure 15). For instance, we can achieve $70 \%$ correct detection if we accept $30 \%$ false-positive alarms. The linear model yielded a similar performance. The prognostic accuracies for children and adults were inferior to those for the AYA material (V, Figure 4). The AUROC values for the NB and linear models were $0.6354(\mathrm{p}=0.4320)$ and $0.5000(\mathrm{p}=0.9585)$ in children and $0.6759(\mathrm{p}=0.1860)$ and $0.5926(\mathrm{p}=0.4960)$ in adults, respectively. 


\section{DISCUSSION}

ALL is typically a disease of children aged 1-9 years. In AYA, it occurs rarely. The incidence increases with age, and a smaller peak is seen in older adults. In children and older adults, the disease has typical characteristics: a high number of hyperdiploid and ETV6-RUNX11 subtype cases in children and Philadelphia-positive patients in adults (Pui et al. 1998). Children have an excellent prognosis, with survivals exceeding $80 \%$, as opposed to older adults, with survivals of less than 50\% (Thomas et al. 2004; Moghrabi et al. 2007). The outcome of AYA aged 10-25 years lies between these groups. The incidence of ALL in AYA is lower; the typical pediatric subtypes are less common, and the increase in the number of adult subtypes has not yet started (Figure 8).

AYA patients are treated with both pediatric and adult protocols, and their treatment results are thus analyzed relative to younger children or older adults. The outcome of AYA patients is inferior to that of children. Several recent studies report that AYA with ALL have a better outcome when treated with pediatric protocols than with adult ALL protocols (Boissel et al. 2003; de Bont et al. 2004; Hallbook et al. 2006; Ramanujachar et al. 2007; Stock et al. 2008).

The reported differences in survival of AYA patients on different protocols and the somewhat unclear profile of biologic subtypes in this age group have raised interest towards ALL in AYA in Finland. To explore these topics, we collected a retrospective populationbased cohort of ALL patients in Finland diagnosed at ages 10-25 years during 1990-2004.

\subsection{Adolescents and young adults as a group of ALL patients (I)}

In Finland, referral of adolescent patients to pediatric or adult centers is done based on the patient's age. Patients 16 years and younger are treated by pediatricians, whereas older patients are treated in adult centers with adult protocols. This makes it impossible to compare the treatment outcome of same-aged patients treated with either pediatric or adult trials in Finland, as has been done in many previous studies with adolescents in other countries. Another factor that clearly differs from most other countries is that adults, like children, with ALL are treated in a centralized fashion at five academic centers in Finland that participate in prospective, population-based studies. Furthermore, it can be speculated that the compliance and adherence to protocols are usually very good in all age groups in Finland. 
Analysis of Finnish ALL patients in the AYA age group revealed no significant difference in outcome in those treated with pediatric and adult ALL protocols, the 5-year EFS being $67 \%$ and $60 \%$, respectively. This result is exceptional in the context of other reports on AYA patients (Table 8). It reflects the superior results with adult protocols in Finland relative to other studies. Our outcome with pediatric protocols compares favorably with outcomes in Europe (Gatta et al. 2003). The centralization of adult ALL treatment to university hospitals and the prospective clinical treatment trials of the Finnish Leukemia Group probably play an important role in these results. Potential additional contributing factors are discussed below.

Table 8. Comparison of AYA ALL patients on pediatric vs. adult clinical trials including the present study.

\begin{tabular}{|c|c|c|c|c|c|c|c|}
\hline Study group & Period & $\mathbf{n}$ & $\begin{array}{c}\text { Age } \\
\text { (years) }\end{array}$ & CR & EFS & p-value & Reference \\
\hline CCG / CALGB & $\begin{array}{l}1988- \\
2001\end{array}$ & 321 & $16-21$ & $90 \%$ & $63 \%$ vs. $34 \%$ & $<0.05$ & Stock et al. 2008 \\
\hline MRC ALL / UKALL & $\begin{array}{l}1997- \\
2002\end{array}$ & 128 & $15-17$ & $98 \%$ vs. $94 \%$ & $65 \%$ vs. $49 \%$ & $<0.05$ & $\begin{array}{l}\text { Ramanujachar et } \\
\text { al. } 2007\end{array}$ \\
\hline $\begin{array}{l}\text { FRALLE-93 / } \\
\text { LALA-94 }\end{array}$ & $\begin{array}{l}1993- \\
1999\end{array}$ & 177 & $15-20$ & $94 \%$ vs. $83 \%$ & $67 \%$ vs. $41 \%$ & $<0.05$ & Boissel et al. 2003 \\
\hline DCOG / HOVON & $\begin{array}{l}1985- \\
1999\end{array}$ & 91 & $15-18$ & $98 \%$ vs. $91 \%$ & $69 \%$ vs. $34 \%$ & $<0.05$ & de Bont et al. 2004 \\
\hline $\begin{array}{l}\text { NOPHO / Swedish } \\
\text { adult }\end{array}$ & $\begin{array}{l}1992- \\
2000\end{array}$ & 243 & $10-40$ & $99 \%$ vs. $90 \%$ & $66 \%$ vs. $31 \%$ & $<0.05$ & $\begin{array}{l}\text { Hallböök et al. } \\
2006\end{array}$ \\
\hline $\begin{array}{l}\text { NOPHO (Finland) } \\
\text { / Finnish Leukemia } \\
\text { Group }\end{array}$ & $\begin{array}{l}1990- \\
2004\end{array}$ & 225 & $10-25$ & $96 \%$ vs. $97 \%$ & $67 \%$ vs. $60 \%$ & 0.25 & Present study \\
\hline
\end{tabular}

The main differences between the pediatric and adult protocols in Finland lie in the doses of methotrexate, anthracyclines, and epipodophyllotoxins, the first being administered in higher doses in pediatric protocols, whereas the total doses of anthracyclines and epipodophyllotoxins were higher in adult protocols. In the adult protocols, the doses of corticosteroids, vincristine, and asparaginase, traditionally considered important components of ALL treatment in children, were equivalent or higher than in pediatric protocols and relatively high compared with many other protocols used for adult ALL (Linker et al. 2002; Thomas et al. 2004). One regimen that has led to a good outcome in young adults is the hyper-CVAD (5-year survival of $51 \%$ for patients $<40$ years) (Kantarjian et al. 2004). This regimen contains far higher doses of cyclophosphamide than the Finnish protocols, but lower doses of vincristine, methotrexate, and epipodophyllotoxins.

In the treatment of ALL in children, risk assessment according to NOPHO protocols was 
performed, whereas for adults no risk stratification was employed. While no differences in outcome emerged between the pediatric and adult protocols in our study, one patient group fared better than the others, with a 5-year EFS of 78\%. These were the pediatric patients initially categorized in the intermediate-risk group (in patients over 10 years, $\mathrm{WBC} \leq 50 \times 10^{9} / 1$, B-cell precursor ALL, no adverse cytogenetics, no extramedullary disease, good response to induction) (Figure 12). These patients did very well on the antimetabolite-based, relatively nontoxic NOPHO-IR protocols. Similarly, in a recent report on young adults aged 16-21 years treated with a pediatric protocol, patients without high-risk features had the best outcome (Nachman et al. 2009). However, many treatment protocols, e.g. those of the Pediatric Oncology Group and the Children's Oncology Group, have categorized all children over 10 years as high-risk patients. Our results indicate that a group with more favorable prognosis exists also in this age category and that the NOPHO risk stratification of pediatric ALL patients was feasible also in adolescents.

One advantage of this study is its population-based patient material. The extensive registration system in Finland made it possible to ascertain inclusion of all patients in the study. On the other hand, a retrospective study also has certain limitations. Registration of clinical data, e.g. adverse effects of treatment or schedule of treatment, was not uniform among different hospitals or during different time periods. Moreover, the development of cytogenetic methods had a major influence on the interpretation of results.

\subsection{Cytogenetics in AYA ALL (I)}

Regarding cytogenetics, hyperdiploidy was more common in younger AYA patients, $18 \%$ in the pediatric and $4 \%$ in the adult treatment group. The analysis of cytogenetis was hampered by only G-banding being systematically performed on all patients throughout the study period. This most likely had an influence on the relatively high proportion of patients with normal karyotype or those classified in the subgroup "other". This applies also to the small proportion of ETV6-RUNX1 fusion-positive patients in both subgroups. FISH screening for this cryptic translocation started in the late 1990s in pediatric patients. In adult ALL, this was not part of routine diagnostics during the study period. $t(12 ; 21)$ was screened from only about $20 \%$ of all patients during the study period; of these, about $10 \%$ were positive. $B C R-A B L$ fusion was uncommon in both groups, and a bit surprisingly was more common in patients aged 10-16 years. This may reflect the true situation since detection of $\mathrm{t}(9 ; 22)$ was more reliable throughout the study period. In any case, the analysis of all age groups with the proper cytogenetic data shows the peaks of hyperdiploidy and ETV6-RUNX1 in children aged 1-9 years, MLL rearrangements in infants, and $\mathrm{Ph}+$ in adults over 26 years. The proportion of unspecified chromosomal abnormalities in AYA patients might be larger than in other age groups. 


\subsection{Copy number alterations in AYA ALL patients detected by aCGH}

Precise determination of cytogenetic aberrations in leukemic blast cells is important for several reasons, including better understanding of leukemogenesis, assessment of prognosis, and detection of markers suitable for MRD follow-up. High-resolution oligoarray CGH proved to be a powerful and reliable tool to detect copy number alterations in AYA ALL patients, as has also been shown by others (Strefford et al. 2007; Rabin et al. 2008). Even so, certain limitations of the technique exist, the most important being inability to detect balanced genetic rearrangements, and the challenge of interpreting copy number changes without known significance (Maciejewski et al. 2009).

\subsubsection{Deletions of $9 p$ (II-IV)}

Deletion of the chromosomal region 9p21.3 affecting the CDKN2A gene was the most common copy number alteration, detected in over $40 \%$ of the ALL patients analyzed. It was also the most common alteration detected in AYA patients with an initially normal karyotype, seen in $41 \%$ of cases. The CDKN2A deletion seemed to be more prevalent in T-ALL (63\%) than in B-cell precursor ALL (45\%). The proportion of CDKN2A deletion in B-cell precursor ALL was clearly higher than reported by others (30\%) (Mirebeau et al. 2006; Kuiper et al. 2007). One explanation for this difference might be the patient material being restricted to AYA in our study. This is supported by a recent report, where CDKN2A deletions were present in $28 \%$ of children with B-cell precursor ALL, but in $50 \%$ of adults (Kim et al. 2009).

CDKN2A deletions are as a rule detected by commercial FISH probes with 150-200 kb coverage in clinical diagnostics. Even if FISH is considered cost-effective and reliable, it may overlook microdeletions that are smaller than the probe size (Perry et al. 1997; Savola et al. 2007). The aCGH analysis of AYA ALL revealed eight cases (8/54 analyzed) with microdeletions of 9 p21.3 of less than $200 \mathrm{~kb}$. In $15 \%$ of ALL patients, the FISH probes that are commercially available would accordingly miss the CDKN2A deletion.

Although widely studied, the prognostic value of deletions in 9p and CDKN2A remains controversial (Heyman et al. 1996; van Zutven et al. 2005; Mirebeau et al. 2006; Kim et al. 2009). In this study, no significant difference in outcome between patients with or without the deletion was discovered. In the subgroup of patients with the CDKN2A deletion, adverse prognostic features at diagnosis were more common than in the subgroup without the deletion. In patients with poor prognostic characteristics at diagnosis, the CDKN2A deletion was 
associated with inferior prognosis. However, this difference was not significant.

\subsubsection{Instability of $9 p$ (III)}

In addition to single losses in the short arm of chromosome 9, instability of 9p was detected in almost $20 \%$ of ALL patients. Of patients with any kind of 9p deletion, 47\% had 9p instability. This phenomenon was restricted to ALL and was not detected in other hematologic neoplasias. The high proportion of patients with either single 9p loss or 9p instability indicates that silencing of the genes within this genomic region may have a role in leukemogenesis. Methylation of the promoter regions of $C D K N 2 A$ and $C D K N 2 B$, another mechanism possibly leading to silencing of these genes, is detected in up to $80 \%$ of ALL patients (Kim et al. 2009). Patients with heterozygous deletion of the genes often have hypermethylation of the remaining alleles (Novara et al. 2009). Mechanisms of silencing other than deletions were not investigated in our study.

Variability existed in the size, breakpoints, and number of genes deleted in 9p instability from case to case, in accordance with the findings of others (Novara et al. 2009). However, the CDKN2A gene was always homozygously deleted. Many of the genes deleted in $9 p$ instability are known to be involved in ALL or are associated with lymphocyte function. CDKN2A and CDKN2B take part in cell cycle regulation and act as tumor suppressors (Hannon et al. 1994; Lukas et al. 1995; Weber et al. 2002). The IFN genes contribute to the lymphocyte antiviral function (Isaacs et al. 1981). IFNA and IFNB also induce the transcription of TP53, contributing to tumor suppression (Takaoka et al. 2003). PAX5 is important for B-lineage commitment in early progenitors (Nutt et al. 1999).

No general genomic instability was detected, suggesting that $9 \mathrm{p}$ instability is instead related to the structure of the $9 \mathrm{p}$ region or the genes therein. $9 \mathrm{p}$ instability was detected often together with $B C R-A B L$ fusion or some other oncogene-activating translocation, suggesting an interaction between these changes in leukemogenesis. A similar finding has been reported by others (Sulong et al. 2009). Of the patients with 9p instability, 37\% also showed deletion of IKZF1. In addition, homozygous deletion of the miRNA mir 31 was detected in two patients. This is a known regulator of $I K Z F 1$. One important mechanism of deletions of CDKN2A and $I K Z F 1$ in ALL is suggested to be an aberrant RAG (recombination activating gene) -enzyme mediated V(D)J recombination (Kitagawa et al. 2002; lacobucci et al. 2009; Novara et al. 2009). This is a physiological phenomenon at the immunoglobulin and T-cell receptor loci during the differentiation of lymphoid cells, but ectopic V(D)J recombination seems to be a major cause of some chromosomal aberrations (Fugmann et al. 2000; Davila et al. 2001). The similarity of breakpoint mechanisms of CDKN2A and IKZF1 deletions may explain the co-deletion of the genes observed in our study. 


\subsection{3 aCGH analysis for patients with initially normal karyotype (IV)}

About one-third of AYA ALL patients fell within the "normal" subgroup of cytogenetics at diagnosis. Although the proportion is similar to that reported in other studies (Kantarjian et al. 2004; Pullarkat et al. 2008; Seibel et al. 2008), an important limitation affecting this figure is the partially incomplete cytogenetic analysis of the patients, as discussed earlier. However, even with the more modern techniques used today in ALL diagnostics and classification, some affected patients remain without any detectable cytogenetic abnormality.

In our study of copy number alterations of patients with normal karyotype, losses outnumbered gains, in accordance with other studies (Mullighan et al. 2007). Of the deletions, $41 \%$ were small $(<5 \mathrm{Mb})$, accounting for $30 \%$ of all aberrations. The proportion of microdeletions has been even higher $(>50 \%)$ in some studies (Paulsson et al. 2008). In our study, no submicroscopic gains were detected. Nevertheless, about half of the aberrations were larger than $20 \mathrm{Mb}$ and should have been detected with conventional methods. The discrepancy between previous results and our findings could be explained by poor quality of metaphases or a low number of dividing cells, which are common phenomena in ALL and may easily hamper G-banding and FISH.

In addition to deletions in $9 \mathrm{p}$, some recurrent deletions were detected. In two cases, a microdeletion was observed in 17q11.2, which is a region encompassing the NF1 gene. NF1 inactivation has been associated with juvenile myelomonocytic leukemia, including a risk of progression to acute myelogenous leukemia. In a recent report, NF1 microdeletion was detected in 3 of 103 pediatric T-ALL patients, without any clinical evidence of neurofibromatosis (Balgobind et al. 2008). In our material, one of the patients had T-ALL, and for the other the immunophenotype was not defined. Two cases had microdeletions in 16q22.1. About 40 genes are located in the deleted region, including E2F4. This gene has been proven to be a mediator in Myc-induced apoptosis and may also have a role in hematologic malignancies (Rempel et al. 2000; Leone et al. 2001). Large deletions (17-100 Mb) in $6 q$ were seen in $15 \%$ of cases. Deletion of this region has been reported in $10 \%$ of pediatric ALL patients with SNP microarrays (Kuiper et al. 2007).

Using aCGH, we were able to decrease the proportion of cytogenetically normal patients to $15 \%$, a figure that could be improved further with more sensitive or dissimilarly designed microarray platforms, such as oligoarrays with denser probe localization, or SNP arrays. Our results indicate that a subtype of ALL with normal karyotype probably does not exist. With more detailed analysis, previously undetected changes can be revealed, as also suggested by others (Kuchinskaya et al. 2008; Bungaro et al. 2009). 


\subsection{Prognostic classification of ALL based on aCGH analysis (V)}

Classification of ALL to different biologic subgroups or prognostic groups has been done by multiple methods, most recently by gene expression profiling (Yeoh et al. 2002; Den Boer et al. 2009). Even though the accuracy of classification to biologic subgroups has been satisfactory in individual studies, it has proven difficult to construct a model for relapse prediction. Also the gene sets determined in one study have been difficult to apply to other completely independent patient samples (Li et al. 2009).

In this study, data on gene copy numbers measured by aCGH were used to determine a gene set that would differentiate between ALL patients at diagnosis who had a high risk of relapse and those who did not. We identified two models for prognostic purposes; the linear model was based on continuous log-ratio data, and the Naïve Bayes (NB) model, which predicts relapse status, was based on categorical data of copy number profiles of patients. The use of two models was chosen because categorical data were considered easier in clinical application. On the other hand, continuous data represent the original array data and should therefore be included in the analyses as such. Our results show that the NB model based on categorical data may have performed slightly better than the linear model (AUROC values 0.7685 and 0.7401 , respectively). This suggests that modification from continuous to categorical data may give an advantage when analyzing copy number data produced by aCGH.

To develop a classifier with relevant genes in leukemia, we utilized a list of 41 genes associated with resistance to cytostatic drugs or prognosis as a starting point (Holleman et al. 2004). We evaluated in 60 AYA patients the copy number pattern of these genomic areas. We also filtered out regions that were rarely aberrated. This resulted in a combination of four genes (BAK1, CDKN2B, GSTM1, and MT1F) that best predicted the probability of relapse in an individual patient according to the model. Interestingly, the CDKN2A gene was not included in the final model. However, when testing for the best possible model, the CDKN2A was included in the second-best classifier combination.

The combinations with the highest probability for relapse had at least 3 of the 4 genes aberrated in the NB model. BAK1 and/or CDKN2B were deleted in cases classified in the "relapse" decision group (Table 7). The two genes were never amplified in these cases. GSTM1 and/or MT1F were amplified in the cases with a probability of relapse of over $70 \%$. A similar interpretation was achieved with the linear model based on the original log-ratio data. These results are in accordance with the function of these genes. BAK1 
accelerates programmed cell death (Chittenden et al. 1995; Kiefer et al. 1995). Deletion of the gene turns off the apoptotic effect. CDKN2B, mostly deleted together with CDKN2A, which is mapped close to it, is known to cause cell cycle arrest and act as tumor suppressor as described above. GSTM1 catalyzes conjugation of glutathione to alkylators, accordingly inactivating these drugs. Overexpression of the gene may lead to resistance to alkylating agents (lyer et al. 1998). Also MT1F, one of the metallothioneins (MT) with an important role in cellular processes, is suggested to be involved in chemotherapy resistance (Shimoda et al. 2003). MT expression has been linked to reduction of drug-induced apoptosis (Jin et al. 2004). Overexpression of MTs leads to resistance against cisplatin, alkylating agents, and anthracyclines (Sauerbrey et al. 1994).

The method used for determination of a classifier has certain limitations. Using a list of 41 genes as a starting point, we clearly left uncovered a great deal of information potentially important in leukemogenesis. The IKZF1 gene, recently associated with poor prognosis (Den Boer et al. 2009; Mullighan et al. 2009b), was not included on the list used for model design in this study. On the other hand, the aim was merely to determine a classifier with relevant genes linked to relapsing leukemia rather than to explore the mechanisms of leukemogenesis. In addition, the number of patients was relatively low. To assess the accuracy of the prognostic model derived from the AYA patient data, we tested it on two other data sets: pediatric patients and adult patients. Our proposed prognostic model did not perform well in these patient cohorts. The prognostic accuracy of our model may thus be inadequate for clinical purposes. This suggests biological dissimilarity of ALL in different age groups, although the poor generalization capacity of the model for children and older adults might also reflect the weakness of the classifier.

\subsection{Possible differences in the etiology of ALL in children and adults}

The differences in cytogenetics of pediatric and adult ALL are well established (Figure 8). The background of these differences is not, however, fully understood. In childhood ALL, retrospective analysis of neonatal blood spots have demonstrated that common gene fusions, such as MLL rearrangements or ETV6-RUNX1 fusion, often arise prenatally (Gale et al. 1997; Wiemels et al. 1999). Studies of identical twins with concordant ETV6-RUNX1-positive ALL have shown a variable and protracted latency to clinically evident disease (Wiemels et al. 1999). This is in accordance with the common opinion that such a translocation alone is insufficient to induce overt leukemia, but rather two or several independent genetic lesions are needed for the development of a progressively malignant clone. Several possibilities are speculated to cause the "second hit", including viral and bacterial infections, radiation, 
and chemicals (Greaves 2003; Greaves 2006). Data from a recent SNP array analysis on pediatric ALL give support to these speculations. Structural aberrations were rare in patients with $M L L$ rearrangement, a typical ALL subtype of infants, and more frequent in patients with ETV6-RUNX1 or BCR-ABL fusion (Mullighan et al. 2007). This implies that besides $M L L$ rearrangement only a few genetic changes are needed, whereas subtypes of slower progression require several additional changes.

The origin of initiating genetic translocations in utero can partly explain the etiology of pediatric ALL, but this does not have a major role in adults. Epigenetic regulation of gene expression, especially by methylation of DNA and regulating micro-RNAs, has become an interesting target of biological research (Osada et al. 2007; Roman-Gomez et al. 2007). Cancer cells have abnormal DNA methylation patterns compared with normal cells (Ting et al. 2006). Aberrant methylation is associated with inappropriate transcriptional silencing of genes. In cancer cells, aberrant hypermethylation of areas surrounding gene promoter regions is found in practically every type of human neoplasm. Hypermethylation of the promoters of many tumor suppressor genes results in gene inactivation without mutations. Silenced tumor suppressor genes along with activating mutations in oncogenes lead to the unrestricted growth of cancer cells. Methylation of multiple genes has been shown to be a common phenomenon in ALL (Garcia-Manero et al. 2002). The degree of methylation may change with age; adult ALL patients have a higher number of methylated genes than children with ALL (Gutierrez et al. 2003; Roman-Gomez et al. 2004). Hypermethylation of tumor suppressor genes has been associated with inferior outcome (Roman-Gomez et al. 2004). These factors may have a role in explaining the differences in ALL subtypes and outcome between children and adults (Roman-Gomez et al. 2007).

\subsection{General discussion and future prospects}

Discussions have recently centered around the question of whether AYA with ALL should be treated by pediatricians with pediatric protocols or whether the treatment protocols of these patients should at least include more pediatric protocol elements (Jeha 2003). Our results indicate that the survival rates of AYA do not necessarily need to be any lower with adult ALL treatment protocols. The fact remains, however, that AYA with ALL have an inferior outcome to children aged less than 10 years. A deeper understanding of the special features of ALL in the adolescent age group is needed when aiming at more efficient therapy; therapy guidelines should be based on biological subgroups rather than age groups.

As improvement in treatment results in ALL has reached a plateau, the need for new 
insights into the molecular genetics of the disease is evident. Better understanding of the biology of ALL offers an opportunity to identify new targets for treatment and to develop more specific therapies. The aim is to decrease the risk of relapse and the side-effects of therapy with targeted drugs. One successful example of novel targeted drugs is tyrosine kinase inhibitors in the treatment of $B C R-A B L$-positive leukemia. Knowledge of biology of cellular resistance to drugs might lead to modulation of resistance instead of increasing the doses and intensifying the schedules of existing drugs. Hypermethylation as a stable but in principle reversible phenomenon is also suggested as a target for new therapies in the form of hypomethylating drugs (Kihslinger et al. 2007).

Data produced by different microarray studies about genes associated with ALL subtypes and treatment outcome are rapidly increasing. In addition, technologies continue to develop, and new platforms are being designed. These will provide a higher probe density, optimal probe distribution, and the possibility for both copy number alterations and LOH detection. However, novel DNA sequencing methods will potentially challenge microarray techniques (Shendure 2008). The constantly advancing field of molecular genetics places great demands on research. Information yielded by novel technologies on e.g. disease classification and outcome prediction should be validated in future prospective trials. Prognostic gene sets, including the most promising genes from recent expression studies, may be incorporated in ALL treatment stratification in the future. 


\section{SUMMARY AND CONCLUSIONS}

Depending on the treatment protocol used, the prognosis of ALL in AYA patients may be comparable with pediatric and adult protocols. In the Finnish AYA cohort, contrary to all previous reports, the outcomes with pediatric and adult protocols were not significantly different. High WBC $\left(\geq 100 \times 10^{9} / 1\right)$ was associated with inferior prognosis in AYA ALL patients. Age, sex, or immunophenotype were not statistically significant risk factors. All patients aged over 10 years need not necessarily be classified as high-risk patients. In the AYA age range, a group without adverse prognostic factors was treated with a pediatric intermediate-risk protocol. These patients fared significantly better than those receiving pediatric high-risk or adult treatments.

ALL without any cytogenetic or molecular genetic aberrations of lymphoblasts probably does not exist. The majority of ALL patients with normal karyotype by conventional methods were revealed to have one or several copy number alterations detected by aCGH. Children and adult ALL patients have typical distributions of biologic subgroups of ALL. In AYA patients, unspecified chromosomal abnormalities are relatively more common.

Deletions in chromosome 9p are a common phenomenon in ALL. In these deletions, the $C D K N 2 A$ gene is always affected. In patients with only one molecular genetic aberration, $9 p$ deletions are the most common abnormalities. Some deletions of the 9 p21.3 region are too small to be detected with conventional methods. Also instability of $9 p$ is commonly seen in ALL and seems to be restricted to ALL only among hematologic malignancies. It is often detected together with oncogene-activating translocations such as $t(9 ; 22)$. Deletion of $I K Z F 1$ was also detected in $37 \%$ of patients with $9 \mathrm{p}$ instability. The prognostic impact of $9 \mathrm{p}$ deletions remains unclear.

aCGH data enabled a set of genes relevant in relapse prediction to be elucidated. Applying statistical analysis on aCGH measurements of AYA ALL patients, a model of four genes (BAK1, CDKN2B, GSTM1, and MT1F) was identified as a prognostic classifier. The predictive value of the model in other age groups was poorer. This might reflect the different biologic background of ALL in different age groups. 


\section{ACKNOWLEDGEMENTS}

This study was carried out in 2004-2010 at the Hospital for Children and Adolescents, University of Helsinki. My sincere gratitude is due to Professors Mikael Knip and Christer Holmberg as well as Docent Jari Petäjä, the Head of the Hospital for Children and Adolescents, and Docent Eero Jokinen, the Head of Department of Pediatrics, for providing excellent research facilities. Professor Markku Heikinheimo, the Head of the Pediatric Graduate School in Helsinki and of the National Graduate School of Clinical Investigation, is acknowledged for providing a support network for young researchers.

I feel privileged to have had two excellent supervisors, Professor Ulla Pihkala and Docent Erkki Elonen, and I owe my deepest gratitude to them for guiding me through this project. They have taught me the principles of scientific research and writing, and having them as an example, has also helped me grow as a doctor and a hematologist. Ulla has been a tireless advisor and source of encouragement. She has always found time for me, known how to get me past difficult periods, and created a supportive atmosphere in our meetings. Erkki has been a reliable cornerstone throughout these years. His calm and sensible attitude in every situation has convinced me that any problem can be solved.

Docents Veli Kairisto and Anne Mäkipernaa are warmly thanked for the skillful and careful review of this thesis and for constructive criticism. Docent Anne Mäkipernaa together with Doctor Päivi Kinnunen served as my thesis committee. I am grateful to them both for their interest, support, and help during this project.

All of my collaborators and co-authors are gratefully acknowledged. Their contribution and comments have been crucial for the completion of the original publications. I am most indebted to Professor Sakari Knuutila from Haartman Institute for introducing me to the field of cytogenetics and providing the main laboratory facilities to perform the microarray analyses. Päivi Asmundela, Tarja Nieminen, and all others in the Laboratory of Molecular Pathology, Helsinki University Central Hospital Laboratory, are thanked for their diligence in this project. I extend a special thanks to Tarja Salonen, an excellent geneticist, for answering my endless questions concerning cytogenetics and for providing me with some of the pictures in this thesis publication. I am deeply grateful to Docent Jaakko Hollmén for his great work with mathematical modeling and, especially, for explaining its principles to me. I am much obliged to Jaana Vettenranta for providing the NOPHO register data for this work. I thank my fellow researchers, the present and former members of the CMG research group, for helping me in the laboratory and offering scientific advice. Shinsuke Ninomiya is warmly thanked 
for his valuable participation in the microarray analyses. Suvi Savola is acknowledged for her major contribution to the second publication.

I am grateful to my friends and fellow researchers at Biomedicum 2. My roommate Satu is especially thanked for bringing joy and laughter into our work space and for observing helicopters with me. I am also grateful to Helena O., Anne, Marianne, Hanne, Mervi, Helena V., and all others on the $6^{\text {th }}$ floor. I am indebted to my colleagues and friends at the Hospital for Children and Adolescents, especially those at the Division of Hematology-Oncology and Stem Cell Transplantation, for encouragement during these years. Having the opportunity to work with them at the clinic every now and then has helped me to keep in mind the true value of being a pediatrician. I also warmly thank the nurses and other staff at the hematology ward for their support and help. I am grateful to the staff of the emergency clinic for the neverending night duties and countless unforgettable moments they have shared with me. Docent Merja Kajosaari, my mentor since my first steps as a pediatrician, is warmly acknowledged for her wise guidance and particularly for her valuable friendship.

Carol Ann Pelli is warmly acknowledged for the linguistic editing and Joonas Hirn, a dear friend, for the layout of this thesis. The cover was skillfully designed by Jouko Raudasoja.

I am deeply grateful to my dear parents for their love and support. My sister Virpi and her family are warmly thanked for their friendship and shared moments. My beloved goddaughters Emilia and Sara are cherished for organizing amusement for me and for being hilarious company. The summer I spent on the island of Nötö writing this thesis with lunch breaks and evenings with the girls remains as one of my dearest memories.

I am most grateful to all my friends, scouts and non-scouts alike. They have kept me going. Trips to Nötö, Lapland, Norway, and Kenya; hiking, sailing, climbing, and cycling; and long discussions about life are among the many activities that have been essential for my wellbeing. An unconditional life-long friendship is what I appreciate above all else. I express my deepest gratitude to Terhi, the best of all friends.

This study was financially supported by the Nona and Kullervo Väre Foundation, the Foundation for Paediatric Research, the Finnish Cancer Organizations, the National Graduate School of Clinical Investigation, the Association of Hematology, the University of Helsinki, and the Finnish Medical Foundation.

Helsinki, February 2010

Anu Usvasalo 


\section{REFERENCES}

Allison DB, Cui X, Page GP \& Sabripour M. Microarray data analysis: from disarray to consolidation and consensus. Nat Rev Genet 7:55-65, 2006.

Anderson JR, Wilson JF, Jenkin DT, Meadows AT, Kersey J, Chilcote RR, Coccia P, Exelby P, Kushner J, Siegel S \& Hammond D. Childhood non-Hodgkin's lymphoma. The results of a randomized therapeutic trial comparing a 4-drug regimen (COMP) with a 10-drug regimen (LSA2-L2). N Engl J Med 308:559-565, 1983.

Andersson A, Ritz C, Lindgren D, Eden P, Lassen C, Heldrup J, Olofsson T, Rade J, Fontes M, PorwitMacdonald A, Behrendtz M, Hoglund M, Johansson B \& Fioretos T. Microarray-based classification of a consecutive series of 121 childhood acute leukemias: prediction of leukemic and genetic subtype as well as of minimal residual disease status. Leukemia 21:1198-1203, 2007.

Annino L, Vegna ML, Camera A, Specchia G, Visani G, Fioritoni G, Ferrara F, Peta A, Ciolli S, Deplano W, Fabbiano F, Sica S, Di Raimondo F, Cascavilla N, Tabilio A, Leoni P, Invernizzi R, Baccarani M, Rotoli B, Amadori S \& Mandelli F. Treatment of adult acute lymphoblastic leukemia (ALL): long-term followup of the GIMEMA ALL 0288 randomized study. Blood 99:863-871, 2002.

Arico M, Baruchel A, Bertrand Y, Biondi A, Conter V, Eden T, Gadner H, Gaynon P, Horibe K, Hunger SP, Janka-Schaub G, Masera G, Nachman J, Pieters R, Schrappe M, Schmiegelow K, Valsecchi MG \& Pui $\mathrm{CH}$. The seventh international childhood acute lymphoblastic leukemia workshop report. Leukemia 19:1145-1152, 2005

Armstrong SA, Staunton JE, Silverman LB, Pieters R, den Boer ML, Minden MD, Sallan SE, Lander ES, Golub TR \& Korsmeyer SJ. MLL translocations specify a distinct gene expression profile that distinguishes a unique leukemia. Nat Genet 30:41-47, 2002.

Armstrong SA \& Look AT. Molecular genetics of acute lymphoblastic leukemia. J Clin Oncol 23:6306-6315, 2005.

Baak U, Gokbuget N, Orawa H, Schwartz S, Hoelzer D, Thiel E \& Burmeister T. Thymic adult T-cell acute lymphoblastic leukemia stratified in standard- and high-risk group by aberrant HOX11L2 expression: experience of the German multicenter ALL study group. Leukemia 22:1154-1160, 2008.

Baer R. TAL1, TAL2 and LYL1: a family of basic helix-loop-helix proteins implicated in T cell acute leukaemia. Semin Cancer Biol 4:341-347, 1993.

Balduzzi A, Valsecchi MG, Uderzo C, De Lorenzo P, Klingebiel T, Peters C, Stary J, Felice MS, Magyarosy E, Conter V, Reiter A, Messina C, Gadner H \& Schrappe M. Chemotherapy versus allogeneic transplantation for very-high-risk childhood acute lymphoblastic leukaemia in first complete remission: comparison by genetic randomisation in an international prospective study. Lancet 366:635642, 2005.

Balgobind BV, Van Vlierberghe P, van den Ouweland AM, Beverloo HB, Terlouw-Kromosoeto JN, van Wering ER, Reinhardt D, Horstmann M, Kaspers GJ, Pieters R, Zwaan CM, Van den Heuvel-Eibrink MM \& Meijerink JP. Leukemia-associated NF1 inactivation in patients with pediatric T-ALL and AML lacking evidence for neurofibromatosis. Blood 111:4322-4328, 2008.

Barrett MT, Scheffer A, Ben-Dor A, Sampas N, Lipson D, Kincaid R, Tsang P, Curry B, Baird K, Meltzer PS, Yakhini Z, Bruhn L \& Laderman S. Comparative genomic hybridization using oligonucleotide microarrays and total genomic DNA. Proc Natl Acad Sci USA 101:17765-17770, 2004.

Barry E, DeAngelo DJ, Neuberg D, Stevenson K, Loh ML, Asselin BL, Barr RD, Clavell LA, Hurwitz CA, Moghrabi A, Samson Y, Schorin M, Cohen HJ, Sallan SE \& Silverman LB. Favorable outcome for adolescents with acute lymphoblastic leukemia treated on Dana-Farber Cancer Institute Acute Lymphoblastic Leukemia Consortium Protocols. J Clin Oncol 25:813-819, 2007.

Bassan R, Spinelli O, Oldani E, Intermesoli T, Tosi M, Peruta B, Rossi G, Borlenghi E, Pogliani EM, Terruzzi E, Fabris P, Cassibba V, Lambertenghi-Deliliers G, Cortelezzi A, Bosi A, Gianfaldoni G, Ciceri F, Bernardi M, Gallamini A, Mattei D, Di Bona E, Romani C, Scattolin AM, Barbui T \& Rambaldi A. Improved risk classification for risk-specific therapy based on the molecular study of minimal residual disease (MRD) in adult acute lymphoblastic leukemia (ALL). Blood 113:4153-4162, 2009. 
Bennett JM, Catovsky D, Daniel MT, Flandrin G, Galton DA, Gralnick HR \& Sultan C. Proposals for the classification of the acute leukaemias. French-American-British (FAB) co-operative group. $\mathrm{Br} J$ Haematol 33:451-458, 1976.

Bennett JM, Catovsky D, Daniel MT, Flandrin G, Galton DA, Gralnick HR \& Sultan C. The morphological classification of acute lymphoblastic leukaemia: concordance among observers and clinical correlations. Br J Haematol 47:553-561, 1981.

Bertin R, Acquaviva C, Mirebeau D, Guidal-Giroux C, Vilmer E \& Cave H. CDKN2A, CDKN2B, and $M T A P$ gene dosage permits precise characterization of mono- and bi-allelic 9p21 deletions in childhood acute lymphoblastic leukemia. Genes Chromosomes Cancer 37:44-57, 2003.

Bhojwani D, Kang H, Menezes RX, Yang W, Sather H, Moskowitz NP, Min DJ, Potter JW, Harvey R, Hunger SP, Seibel N, Raetz EA, Pieters R, Horstmann MA, Relling MV, den Boer ML, Willman CL \& Carroll WL. Gene expression signatures predictive of early response and outcome in high-risk childhood acute lymphoblastic leukemia: A Children's Oncology Group Study. J Clin Oncol 26:43764384, 2008.

Biondi A, Cimino G, Pieters R \& Pui CH. Biological and therapeutic aspects of infant leukemia. Blood 96:24-33, 2000.

Biondi A, Rizzari C, Valsecchi MG, De Lorenzo P, Arico M, Basso G, Locatelli F, Lo Nigro L, De Rossi G \& Masera G. Role of treatment intensification in infants with acute lymphoblastic leukemia: results of two consecutive AIEOP studies. Haematologica 91:534-537, 2006.

Bleyer A. The adolescent and young adult gap in cancer care and outcome. Curr Probl Pediatr Adolesc Health Care 35:182-217, 2005.

Boissel N, Auclerc MF, Lheritier V, Perel Y, Thomas X, Leblanc T, Rousselot P, Cayuela JM, Gabert J, Fegueux N, Piguet C, Huguet-Rigal F, Berthou C, Boiron JM, Pautas C, Michel G, Fiere D, Leverger G, Dombret H \& Baruchel A. Should adolescents with acute lymphoblastic leukemia be treated as old children or young adults? Comparison of the French FRALLE-93 and LALA-94 trials. J Clin Oncol 21:774-780, 2003.

Borowitz MJ, Devidas M, Hunger SP, Bowman WP, Carroll AJ, Carroll WL, Linda S, Martin PL, Pullen DJ, Viswanatha D, Willman CL, Winick N \& Camitta BM. Clinical significance of minimal residual disease in childhood acute lymphoblastic leukemia and its relationship to other prognostic factors: a Children's Oncology Group study. Blood 111:5477-5485, 2008.

Bostrom BC, Sensel MR, Sather HN, Gaynon PS, La MK, Johnston K, Erdmann GR, Gold S, Heerema NA, Hutchinson RJ, Provisor AJ \& Trigg ME. Dexamethasone versus prednisone and daily oral versus weekly intravenous mercaptopurine for patients with standard-risk acute lymphoblastic leukemia: a report from the Children's Cancer Group. Blood 101:3809-3817, 2003.

Bruggemann M, Raff T, Flohr T, Gokbuget N, Nakao M, Droese J, Luschen S, Pott C, Ritgen M, Scheuring U, Horst HA, Thiel E, Hoelzer D, Bartram CR \& Kneba M. Clinical significance of minimal residual disease quantification in adult patients with standard-risk acute lymphoblastic leukemia. Blood 107:1116-1123, 2006.

Bungaro S, Dell'Orto MC, Zangrando A, Basso D, Gorletta T, Lo Nigro L, Leszl A, Young BD, Basso G, Bicciato S, Biondi A, te Kronnie G \& Cazzaniga G. Integration of genomic and gene expression data of childhood ALL without known aberrations identifies subgroups with specific genetic hallmarks. Genes Chromosomes Cancer 48:22-38, 2009.

Burke ME, Albritton K \& Marina N. Challenges in the recruitment of adolescents and young adults to cancer clinical trials. Cancer 110:2385-2393, 2007.

Campana D \& Pui CH. Detection of minimal residual disease in acute leukemia: methodologic advances and clinical significance. Blood 85:1416-1434, 1995.

Cario G, Stanulla M, Fine BM, Teuffel O, Neuhoff NV, Schrauder A, Flohr T, Schafer BW, Bartram CR, Welte K, Schlegelberger B \& Schrappe M. Distinct gene expression profiles determine molecular treatment response in childhood acute lymphoblastic leukemia. Blood 105:821-826, 2005.

Carvalho B, Ouwerkerk E, Meijer GA \& Ylstra B. High resolution microarray comparative genomic hybridisation analysis using spotted oligonucleotides. J Clin Pathol 57:644-646, 2004.

Caspersson T, Zech L, Johansson C \& Modest EJ. Identification of human chromosomes by DNA-binding fluorescent agents. Chromosoma 30:215-227, 1970. 
Cauwelier B, Dastugue N, Cools J, Poppe B, Herens C, De Paepe A, Hagemeijer A \& Speleman F. Molecular cytogenetic study of 126 unselected T-ALL cases reveals high incidence of TCRbeta locus rearrangements and putative new T-cell oncogenes. Leukemia 20:1238-1244, 2006.

Cave H, Cacheux V, Raynaud S, Brunie G, Bakkus M, Cochaux P, Preudhomme C, Lai JL, Vilmer E \& Grandchamp B. ETV6 is the target of chromosome 12p deletions in $\mathrm{t}(12 ; 21)$ childhood acute lymphocytic leukemia. Leukemia 11:1459-1464, 1997.

Cave H, van der Werff ten Bosch,J., Suciu S, Guidal C, Waterkeyn C, Otten J, Bakkus M, Thielemans K, Grandchamp B \& Vilmer E. Clinical significance of minimal residual disease in childhood acute lymphoblastic leukemia. N Engl J Med 339:591-598, 1998.

Chessells JM, Hall E, Prentice HG, Durrant J, Bailey CC \& Richards SM. The impact of age on outcome in lymphoblastic leukaemia; MRC UKALL X and XA compared: a report from the MRC Paediatric and Adult Working Parties. Leukemia 12:463-473, 1998.

Chessels JM, Swansbury GJ, Reeves B, Bailey CC \& Richards SM. Cytogenetics and prognosis in childhood lymphoblastic leukaemia: results of MRC UKALL X. Br J Haematol 99:93-100, 1997.

Chittenden T, Harrington EA, O'Connor R, Flemington C, Lutz RJ, Evan GI \& Guild BC. Induction of apoptosis by the Bcl-2 homologue Bak. Nature 374:733-736, 1995.

Conter V, Valsecchi MG, Silvestri D, Campbell M, Dibar E, Magyarosy E, Gadner H, Stary J, Benoit Y, Zimmermann M, Reiter A, Riehm H, Masera G \& Schrappe M. Pulses of vincristine and dexamethasone in addition to intensive chemotherapy for children with intermediate-risk acute lymphoblastic leukaemia: a multicentre randomised trial. Lancet 369:123-131, 2007.

Cornelissen JJ, van der Holt B, Verhoef GE, van't Veer MB, van Oers MH, Schouten HC, Ossenkoppele G, Sonneveld P, Maertens J, van Marwijk Kooy M, Schaafsma MR, Wijermans PW, Biesma DH, Wittebol S, Voogt PJ, Baars JW, Zachee P, Verdonck LF, Lowenberg B \& Dekker AW. Myeloablative allogeneic versus autologous stem cell transplantation in adult patients with acute lymphoblastic leukemia in first remission: a prospective sibling donor versus no-donor comparison. Blood 113:1375-1382, 2009.

Coustan-Smith E, Sancho J, Behm FG, Hancock ML, Razzouk BI, Ribeiro RC, Rivera GK, Rubnitz JE, Sandlund JT, Pui CH \& Campana D. Prognostic importance of measuring early clearance of leukemic cells by flow cytometry in childhood acute lymphoblastic leukemia. Blood 100:52-58, 2002.

Cremer T, Landegent J, Bruckner A, Scholl HP, Schardin M, Hager HD, Devilee P, Pearson P \& van der Ploeg M. Detection of chromosome aberrations in the human interphase nucleus by visualization of specific target DNAs with radioactive and non-radioactive in situ hybridization techniques: diagnosis of trisomy 18 with probe L1.84. Hum Genet 74:346-352, 1986.

Dahlke J, Kroger N, Zabelina T, Ayuk F, Fehse N, Wolschke C, Waschke O, Schieder H, Renges H, Kruger W, Kruell A, Hinke A, Erttmann R, Kabisch H \& Zander AR. Comparable results in patients with acute lymphoblastic leukemia after related and unrelated stem cell transplantation. Bone Marrow Transplant 37:155-163, 2006.

Davila M, Foster S, Kelsoe G \& Yang K. A role for secondary V(D)J recombination in oncogenic chromosomal translocations? Adv Cancer Res 81:61-92, 2001.

de Bont JM, Holt B, Dekker AW, van der Does-van den Berg,A., Sonneveld P \& Pieters R. Significant difference in outcome for adolescents with acute lymphoblastic leukemia treated on pediatric vs adult protocols in the Netherlands. Leukemia 18:2032-2035, 2004.

de Labarthe A, Rousselot P, Huguet-Rigal F, Delabesse E, Witz F, Maury S, Rea D, Cayuela JM, Vekemans MC, Reman O, Buzyn A, Pigneux A, Escoffre M, Chalandon Y, MacIntyre E, Lheritier V, Vernant JP, Thomas X, Ifrah N \& Dombret H. Imatinib combined with induction or consolidation chemotherapy in patients with de novo Philadelphia chromosome-positive acute lymphoblastic leukemia: results of the GRAAPH-2003 study. Blood 109:1408-1413, 2007.

DeAngelo DJ. The treatment of adolescents and young adults with acute lymphoblastic leukemia. Hematology 123-130, 2005.

Den Boer ML, van Slegtenhorst M, De Menezes RX, Cheok MH, Buijs-Gladdines JG, Peters ST, Van Zutven LJ, Beverloo HB, Van der Spek PJ, Escherich G, Horstmann MA, Janka-Schaub GE, Kamps WA, Evans WE \& Pieters R. A subtype of childhood acute lymphoblastic leukaemia with poor treatment outcome: a genome-wide classification study. Lancet Oncol 10:125-134, 2009. 
Dini G, Banov L \& Dini S. Where should adolescents with ALL be treated? Bone Marrow Transplant 42:S35-9, 2008.

Dupuy A \& Simon RM. Critical review of published microarray studies for cancer outcome and guidelines on statistical analysis and reporting. J Natl Cancer Inst 99:147-157, 2007.

Durrant IJ, Prentice HG \& Richards SM. Intensification of treatment for adults with acute lymphoblastic leukaemia: results of U.K. Br J Haematol 99:84-92, 1997.

Earl M. Incidence and management of asparaginase-associated adverse events in patients with acute lymphoblastic leukemia. Clin Adv Hematol Oncol 7:600-606, 2009.

Eden OB, Harrison G, Richards S, Lilleyman JS, Bailey CC, Chessells JM, Hann IM, Hill FG \& Gibson BE. Long-term follow-up of the United Kingdom Medical Research Council protocols for childhood acute lymphoblastic leukaemia, 1980-1997. Leukemia 14:2307-2320, 2000.

Eisen MB, Spellman PT, Brown PO \& Botstein D. Cluster analysis and display of genome-wide expression patterns. Proc Natl Acad Sci USA 95:14863-14868, 1998.

Ellisen LW, Bird J, West DC, Soreng AL, Reynolds TC, Smith SD \& Sklar J. TAN-1, the human homolog of the Drosophila notch gene, is broken by chromosomal translocations in T lymphoblastic neoplasms. Cell 66:649-661, 1991.

El-Rifai W, Ruutu T, Vettenranta K, Elonen E, Saarinen UM, Volin L \& Knuutila S. Follow-up of residual disease using metaphase-FISH in patients with acute lymphoblastic leukemia in remission. Leukemia 11:633-638, 1997.

Engholm G, Ferlay J, Christensen N, Bray F, Gjerstorff ML, Klint Å, Køtlum JE, Ólafsdóttir E, Pukkala E \& Storm HH. NORDCAN: Cancer Incidence, Mortality, Prevalence and Prediction in the Nordic Countries, Version 3.5. http://www.ancr.nu Danish Cancer Society, 2009.

Erikson J, Finger L, Sun L, ar-Rushdi A, Nishikura K, Minowada J, Finan J, Emanuel BS, Nowell PC \& Croce CM. Deregulation of c-myc by translocation of the alpha-locus of the T-cell receptor in T-cell leukemias. Science 232:884-886, 1986.

Faderl S, Jeha S \& Kantarjian HM. The biology and therapy of adult acute lymphoblastic leukemia. Cancer 98:1337-1354, 2003.

Farber S \& Diamond LK. Temporary remissions in acute leukemia in children produced by folic acid antagonist, 4-aminopteroyl-glutamic acid. N Engl J Med 238:787-793, 1948.

Fielding AK, Rowe JM, Richards SM, Buck G, Moorman AV, Durrant IJ, Marks DI, McMillan AK, Litzow MR, Lazarus HM, Foroni L, Dewald G, Franklin IM, Luger SM, Paietta E, Wiernik PH, Tallman MS \& Goldstone AH. Prospective outcome data on 267 unselected adult patients with Philadelphia chromosome-positive acute lymphoblastic leukemia confirms superiority of allogeneic transplantation over chemotherapy in the pre-imatinib era: results from the International ALL Trial MRC UKALLXII/ ECOG2993. Blood 113:4489-4496, 2009.

Flotho C, Coustan-Smith E, Pei D, Cheng C, Song G, Pui CH, Downing JR \& Campana D. A set of genes that regulate cell proliferation predicts treatment outcome in childhood acute lymphoblastic leukemia. Blood 110:1271-1277, 2007.

Forestier E \& Schmiegelow K. The incidence peaks of the childhood acute leukemias reflect specific cytogenetic aberrations. J Pediatr Hematol Oncol 28:486-495, 2006.

Fugmann SD, Lee AI, Shockett PE, Villey IJ \& Schatz DG. The RAG proteins and V(D)J recombination: complexes, ends, and transposition. Annu Rev Immunol 18:495-527, 2000.

Gale KB, Ford AM, Repp R, Borkhardt A, Keller C, Eden OB \& Greaves MF. Backtracking leukemia to birth: identification of clonotypic gene fusion sequences in neonatal blood spots. Proc Natl Acad Sci USA 94:13950-13954, 1997.

Garcia-Manero G, Daniel J, Smith TL, Kornblau SM, Lee MS, Kantarjian HM \& Issa JP. DNA methylation of multiple promoter-associated CpG islands in adult acute lymphocytic leukemia. Clin Cancer Res 8:2217-2224, 2002.

Garg R, Kantarjian H, Thomas D, Faderl S, Ravandi F, Lovshe D, Pierce S \& O'Brien S. Adults with acute lymphoblastic leukemia and translocation $(1 ; 19)$ abnormality have a favorable outcome with hyperfractionated cyclophosphamide, vincristine, doxorubicin, and dexamethasone alternating with methotrexate and high-dose cytarabine chemotherapy. Cancer 115:2147-2154, 2009. 
Gatta G, Corazziari I, Magnani C, Peris-Bonet R, Roazzi P \& Stiller C. Childhood cancer survival in Europe. Ann Oncol 14 Suppl 5:v119-127, 2003.

Gaynon PS, Trigg ME, Heerema NA, Sensel MG, Sather HN, Hammond GD \& Bleyer WA. Children's Cancer Group trials in childhood acute lymphoblastic leukemia: 1983-1995. Leukemia 14:2223-2233, 2000.

Gebhart E, Verdorfer I, Saul W, Trautmann U \& Brecevic L. Delimiting the use of comparative genomic hybridization in human myeloid neoplastic disorders. Int J Oncol 16:1099-1105, 2000.

Goldberg JM, Silverman LB, Levy DE, Dalton VK, Gelber RD, Lehmann L, Cohen HJ, Sallan SE \& Asselin BL. Childhood T-cell acute lymphoblastic leukemia: the Dana-Farber Cancer Institute acute lymphoblastic leukemia consortium experience. J Clin Oncol 21:3616-3622, 2003.

Goldstone AH, Richards SM, Lazarus HM, Tallman MS, Buck G, Fielding AK, Burnett AK, Chopra R, Wiernik PH, Foroni L, Paietta E, Litzow MR, Marks DI, Durrant J, McMillan A, Franklin IM, Luger $\mathrm{S}$, Ciobanu N \& Rowe JM. In adults with standard-risk acute lymphoblastic leukemia, the greatest benefit is achieved from a matched sibling allogeneic transplantation in first complete remission, and an autologous transplantation is less effective than conventional consolidation/maintenance chemotherapy in all patients: final results of the International ALL Trial (MRC UKALL XII/ECOG E2993). Blood 111:1827-1833, 2008.

Golub TR, Slonim DK, Tamayo P, Huard C, Gaasenbeek M, Mesirov JP, Coller H, Loh ML, Downing JR, Caligiuri MA, Bloomfield CD \& Lander ES. Molecular classification of cancer: class discovery and class prediction by gene expression monitoring. Science 286:531-537, 1999.

Grabher C, von Boehmer H \& Look AT. Notch 1 activation in the molecular pathogenesis of T-cell acute lymphoblastic leukaemia. Nat Rev Cancer 6:347-359, 2006.

Graux C, Cools J, Michaux L, Vandenberghe P \& Hagemeijer A. Cytogenetics and molecular genetics of T-cell acute lymphoblastic leukemia: from thymocyte to lymphoblast. Leukemia 20:1496-1510, 2006.

Greaves M. Pre-natal origins of childhood leukemia. Rev Clin Exp Hematol 7:233-245, 2003.

Greaves M. Infection, immune responses and the aetiology of childhood leukaemia. Nat Rev Cancer 6:193203, 2006.

Gupta V, Yi QL, Brandwein J, Minden MD, Schuh AC, Wells RA, Chun K, Kamel-Reid S, Tsang R, Daly A, Kiss T, Lipton JH \& Messner HA. The role of allogeneic bone marrow transplantation in adult patients below the age of 55 years with acute lymphoblastic leukemia in first complete remission: a donor vs no donor comparison. Bone Marrow Transplant 33:397-404, 2004.

Gustafsson G, Kreuger A, Clausen N, Garwicz S, Kristinsson J, Lie SO, Moe PJ, Perkkio M, Yssing M \& Saarinen-Pihkala UM. Intensified treatment of acute childhood lymphoblastic leukaemia has improved prognosis, especially in non-high-risk patients: the Nordic experience of 2648 patients diagnosed between 1981 and 1996. Acta Paediatr 87:1151-1161, 1998.

Gustafsson G, Schmiegelow K, Forestier E, Clausen N, Glomstein A, Jonmundsson G, Mellander L, Makipernaa A, Nygaard R \& Saarinen-Pihkala UM. Improving outcome through two decades in childhood ALL in the Nordic countries: the impact of high-dose methotrexate in the reduction of CNS irradiation. Leukemia 14:2267-2275, 2000.

Gutierrez MI, Siraj AK, Bhargava M, Ozbek U, Banavali S, Chaudhary MA, El Solh H \& Bhatia K. Concurrent methylation of multiple genes in childhood ALL: Correlation with phenotype and molecular subgroup. Leukemia 17:1845-1850, 2003.

Hallbook H, Simonsson B, Ahlgren T, Bjorkholm M, Carneskog J, Grimfors G, Hast R, Karlsson K, Kimby E, Lerner R, Linder O, Linderholm M, Lofvenberg E, Malm C, Nilsson PG, Paul C, Stenke L, Stockelberg D, Tidefelt U, Turesson I, Uden-Blome AM, Vilen L, Wahlin A, Winquist I \& Smedmyr B. High-dose cytarabine in upfront therapy for adult patients with acute lymphoblastic leukaemia. $\mathrm{Br} J$ Haematol 118:748-754, 2002.

Hallbook H, Gustafsson G, Smedmyr B, Soderhall S \& Heyman M. Treatment outcome in young adults and children $>10$ years of age with acute lymphoblastic leukemia in Sweden: a comparison between a pediatric protocol and an adult protocol. Cancer 107:1551-1561, 2006.

Hann I, Vora A, Richards S, Hill F, Gibson B, Lilleyman J, Kinsey S, Mitchell C \& Eden OB. Benefit of intensified treatment for all children with acute lymphoblastic leukaemia: results from MRC UKALL XI and MRC ALL97 randomised trials. Leukemia 14:356-363, 2000. 
Hannon GJ \& Beach D. p15 ${ }^{\mathrm{INK} 4 \mathrm{~B}}$ is a potential effector of TGF-beta-induced cell cycle arrest. Nature 371:257-261, 1994.

Harewood L, Robinson H, Harris R, Al-Obaidi MJ, Jalali GR, Martineau M, Moorman AV, Sumption N, Richards S, Mitchell C \& Harrison CJ. Amplification of AML1 on a duplicated chromosome 21 in acute lymphoblastic leukemia: a study of 20 cases. Leukemia 17:547-553, 2003.

Harms DO \& Janka-Schaub GE. Co-operative study group for childhood acute lymphoblastic leukemia (COALL): long-term follow-up of trials 82, 85, 89 and 92. Leukemia 14:2234-2239, 2000.

Harris MB, Shuster JJ, Carroll A, Look AT, Borowitz MJ, Crist WM, Nitschke R, Pullen J, Steuber CP \& Land VJ. Trisomy of leukemic cell chromosomes 4 and 10 identifies children with B-progenitor cell acute lymphoblastic leukemia with a very low risk of treatment failure: a Pediatric Oncology Group study. Blood 79:3316-3324, 1992.

Harris NL, Jaffe ES, Stein H, Banks PM, Chan JK, Cleary ML, Delsol G, De Wolf-Peeters C, Falini B \& Gatter KC. A revised European-American classification of lymphoid neoplasms: a proposal from the International Lymphoma Study Group. Blood 84:1361-1392, 1994.

Harrison CJ, Moorman AV, Barber KE, Broadfield ZJ, Cheung KL, Harris RL, Jalali GR, Robinson HM, Strefford JC, Stewart A, Wright S, Griffiths M, Ross FM, Harewood L \& Martineau M. Interphase molecular cytogenetic screening for chromosomal abnormalities of prognostic significance in childhood acute lymphoblastic leukaemia: a UK Cancer Cytogenetics Group Study. Br J Haematol 129:520-530, 2005.

Hastie T, Tibshirani R \& Friedman JThe Elements of Statistical Learning: Data Mining, Inference, and Prediction. New York, Springer. 2001.

Henze G, Langermann HJ, Bramswig J, Breu H, Gadner H, Schellong G, Welte K \& Riehm H. [The BFM 76/79 acute lymphoblastic leukemia therapy study (author's transl)]. Klin Padiatr 193:145-154, 1981.

Heyman M, Rasool O, Borgonovo Brandter L, Liu Y, Grander D, Soderhall S, Gustavsson G \& Einhorn S. Prognostic importance of p15INK4B and p16INK4 gene inactivation in childhood acute lymphocytic leukemia. J Clin Oncol 14:1512-1520, 1996.

Hilgers RA. Distribution-free confidence bounds for ROC curves. Methods Inf Med 30:96-101, 1991.

Hock H, Meade E, Medeiros S, Schindler JW, Valk PJ, Fujiwara Y \& Orkin SH. Tel/Etv6 is an essential and selective regulator of adult hematopoietic stem cell survival. Genes Dev 18:2336-2341, 2004.

Holleman A, Cheok MH, den Boer ML, Yang W, Veerman AJ, Kazemier KM, Pei D, Cheng C, Pui CH, Relling MV, Janka-Schaub GE, Pieters R \& Evans WE. Gene-expression patterns in drug-resistant acute lymphoblastic leukemia cells and response to treatment. N Engl J Med 351:533-542, 2004.

Hongeng S, Krance RA, Bowman LC, Srivastava DK, Cunningham JM, Horwitz EM, Brenner MK \& Heslop HE. Outcomes of transplantation with matched-sibling and unrelated-donor bone marrow in children with leukaemia. Lancet 350:767-771, 1997.

Huguet F, Leguay T, Raffoux E, Thomas X, Beldjord K, Delabesse E, Chevallier P, Buzyn A, Delannoy A, Chalandon Y, Vernant JP, Lafage-Pochitaloff M, Chassevent A, Lheritier V, Macintyre E, Bene MC, Ifrah N \& Dombret H. Pediatric-inspired therapy in adults with Philadelphia chromosome-negative acute lymphoblastic leukemia: the GRAALL-2003 study. J Clin Oncol 27:911-918, 2009.

Hurwitz CA, Silverman LB, Schorin MA, Clavell LA, Dalton VK, Glick KM, Gelber RD \& Sallan SE. Substituting dexamethasone for prednisone complicates remission induction in children with acute lymphoblastic leukemia. Cancer 88:1964-1969, 2000.

Hussein KK, Dahlberg S, Head D, Waddell CC, Dabich L, Weick JK, Morrison F, Saiki JH, Metz E \& Rivkin SE. Treatment of acute lymphoblastic leukemia in adults with intensive induction, consolidation, and maintenance chemotherapy. Blood 73:57-63, 1989.

Iacobucci I, Storlazzi CT, Cilloni D, Lonetti A, Ottaviani E, Soverini S, Astolfi A, Chiaretti S, Vitale A, Messa F, Impera L, Baldazzi C, D'Addabbo P, Papayannidis C, Lonoce A, Colarossi S, Vignetti M, Piccaluga PP, Paolini S, Russo D, Pane F, Saglio G, Baccarani M, Foa R \& Martinelli G. Identification and molecular characterization of recurrent genomic deletions on $7 \mathrm{p} 12$ in the IKZF1 gene in a large cohort of BCR-ABL1-positive acute lymphoblastic leukemia patients. Blood 114:2159-2167, 2009.

Isaacs D, Clarke JR, Tyrrell DA, Webster AD \& Valman HB. Deficient production of leucocyte interferon (interferon-alpha) in vitro and in vivo in children with recurrent respiratory tract infections. Lancet 2:950-952, 1981. 
Iyer L \& Ratain MJ. Pharmacogenetics and cancer chemotherapy. Eur J Cancer 34:1493-1499, 1998.

Jabber Al-Obaidi MS, Martineau M, Bennett CF, Franklin IM, Goldstone AH, Harewood L, Jalali GR, Prentice HG, Richards SM, Roberts K, Harrison CJ \& Medical Research Council Adult Leukaemia Working,Party. ETV6/AML1 fusion by FISH in adult acute lymphoblastic leukemia. Leukemia 16:669674,2002

Jeha S. Who should be treating adolescents and young adults with acute lymphoblastic leukaemia? Eur J Cancer 39:2579-2583, 2003.

Jin R, Huang J, Tan PH \& Bay BH. Clinicopathological significance of metallothioneins in breast cancer. Pathol Oncol Res 10:74-79, 2004.

Jones B, Freeman AI, Shuster JJ, Jacquillat C, Weil M, Pochedly C, Sinks L, Chevalier L, Maurer HM \& Koch K. Lower incidence of meningeal leukemia when prednisone is replaced by dexamethasone in the treatment of acute lymphocytic leukemia. Med Pediatr Oncol 19:269-275, 1991.

Kallioniemi A, Kallioniemi OP, Sudar D, Rutovitz D, Gray JW, Waldman F \& Pinkel D. Comparative genomic hybridization for molecular cytogenetic analysis of solid tumors. Science 258:818-821, 1992.

Kantarjian H, Thomas D, O'Brien S, Cortes J, Giles F, Jeha S, Bueso-Ramos CE, Pierce S, Shan J, Koller C, Beran M, Keating M \& Freireich EJ. Long-term follow-up results of hyperfractionated cyclophosphamide, vincristine, doxorubicin, and dexamethasone (Hyper-CVAD), a dose-intensive regimen, in adult acute lymphocytic leukemia. Cancer 101:2788-2801, 2004.

Kantarjian HM. Adult acute lymphocytic leukemia: critical review of current knowledge. Am J Med 97:176-184, 1994.

Kantarjian HM, O'Brien S, Smith TL, Cortes J, Giles FJ, Beran M, Pierce S, Huh Y, Andreeff M, Koller C, Ha CS, Keating MJ, Murphy S \& Freireich EJ. Results of treatment with hyper-CVAD, a dose-intensive regimen, in adult acute lymphocytic leukemia. J Clin Oncol 18:547-561, 2000.

Kaplan E \& Meier P. Nonparametric estimation from incomplete observations. Journal of the American Statistical Association 53:457-458-481, 1958.

Karrman K, Forestier E, Heyman M, Andersen MK, Autio K, Blennow E, Borgstrom G, Ehrencrona H, Golovleva I, Heim S, Heinonen K, Hovland R, Johannsson JH, Kerndrup G, Nordgren A, Palmqvist L \& Johansson B. Clinical and cytogenetic features of a population-based consecutive series of 285 pediatric T-cell acute lymphoblastic leukemias: rare T-cell receptor gene rearrangements are associated with poor outcome. Genes Chromosomes Cancer 48:795-805, 2009.

Kawamata N, Ogawa S, Zimmermann M, Kato M, Sanada M, Hemminki K, Yamatomo G, Nannya Y, Koehler R, Flohr T, Miller CW, Harbott J, Ludwig WD, Stanulla M, Schrappe M, Bartram CR \& Koeffler HP. Molecular allelokaryotyping of pediatric acute lymphoblastic leukemias by highresolution single nucleotide polymorphism oligonucleotide genomic microarray. Blood 111:776-784, 2008.

Kearney L. The impact of the new fish technologies on the cytogenetics of haematological malignancies. $\mathrm{Br}$ J Haematol 104:648-658, 1999.

Kiefer MC, Brauer MJ, Powers VC, Wu JJ, Umansky SR, Tomei LD \& Barr PJ. Modulation of apoptosis by the widely distributed Bcl-2 homologue Bak. Nature 374:736-739, 1995.

Kihslinger JE \& Godley LA. The use of hypomethylating agents in the treatment of hematologic malignancies. Leuk Lymphoma 48:1676-1695, 2007.

Kim M, Yim SH, Cho NS, Kang SH, Ko DH, Oh B, Kim TY, Min HJ, She CJ, Kang HJ, Shin HY, Ahn HS, Yoon SS, Kim BK, Shin HR, Han KS, Cho HI \& Lee DS. Homozygous deletion of CDKN2A (p16, p14) and $C D K N 2 B$ (p15) genes is a poor prognostic factor in adult but not in childhood B-lineage acute lymphoblastic leukemia: a comparative deletion and hypermethylation study. Cancer Genet Cytogenet 195:59-65, 2009.

Kitagawa Y, Inoue K, Sasaki S, Hayashi Y, Matsuo Y, Lieber MR, Mizoguchi H, Yokota J \& Kohno T. Prevalent involvement of illegitimate V(D)J recombination in chromosome 9p21 deletions in lymphoid leukemia. J Biol Chem 277:46289-46297, 2002.

Knudson AG,Jr. Mutation and cancer: statistical study of retinoblastoma. Proc Natl Acad Sci USA 68:820$823,1971$. 
Kohlmann A, Schoch C, Schnittger S, Dugas M, Hiddemann W, Kern W \& Haferlach T. Pediatric acute lymphoblastic leukemia (ALL) gene expression signatures classify an independent cohort of adult ALL patients. Leukemia 18:63-71, 2004.

Kuchinskaya E, Heyman M, Nordgren A, Schoumans J, Staaf J, Borg A, Soderhall S, Grander D, Nordenskjold M \& Blennow E. Array-CGH reveals hidden gene dose changes in children with acute lymphoblastic leukaemia and a normal or failed karyotype by G-banding. Br J Haematol 140:572-577, 2008.

Kuiper RP, Schoenmakers EF, van Reijmersdal SV, Hehir-Kwa JY, van Kessel AG, van Leeuwen FN \& Hoogerbrugge PM. High-resolution genomic profiling of childhood ALL reveals novel recurrent genetic lesions affecting pathways involved in lymphocyte differentiation and cell cycle progression. Leukemia 21:1258-1266, 2007.

Larson RA, Dodge RK, Burns CP, Lee EJ, Stone RM, Schulman P, Duggan D, Davey FR, Sobol RE \& Frankel SR. A five-drug remission induction regimen with intensive consolidation for adults with acute lymphoblastic leukemia: cancer and leukemia group B study 8811. Blood 85:2025-2037, 1995.

Larson RA, Dodge RK, Linker CA, Stone RM, Powell BL, Lee EJ, Schulman P, Davey FR, Frankel SR, Bloomfield CD, George SL \& Schiffer CA. A randomized controlled trial of filgrastim during remission induction and consolidation chemotherapy for adults with acute lymphoblastic leukemia: CALGB study 9111. Blood 92:1556-1564, 1998.

Leone G, Sears R, Huang E, Rempel R, Nuckolls F, Park CH, Giangrande P, Wu L, Saavedra HI, Field SJ, Thompson MA, Yang H, Fujiwara Y, Greenberg ME, Orkin S, Smith C \& Nevins JR. Myc requires distinct E2F activities to induce S phase and apoptosis. Mol Cell 8:105-113, 2001.

Li Z, Zhang W, Wu M, Zhu S, Gao C, Sun L, Zhang R, Qiao N, Xue H, Hu Y, Bao S, Zheng H \& Han JD. Gene expression-based classification and regulatory networks of pediatric acute lymphoblastic leukemia. Blood 224:4486-4493, 2009.

Lie SO \& Gustafsson G. Progress in the treatment of childhood leukaemias. Ann Med 24:319-323, 1992.

Linker C, Damon L, Ries C \& Navarro W. Intensified and shortened cyclical chemotherapy for adult acute lymphoblastic leukemia. J Clin Oncol 20:2464-2471, 2002.

Lowe EJ, Pui CH, Hancock ML, Geiger TL, Khan RB \& Sandlund JT. Early complications in children with acute lymphoblastic leukemia presenting with hyperleukocytosis. Pediatr Blood Cancer 45:10-15, 2005.

Lukas J, Parry D, Aagaard L, Mann DJ, Bartkova J, Strauss M, Peters G \& Bartek J. Retinoblastoma-proteindependent cell-cycle inhibition by the tumour suppressor p16. Nature 375:503-506, 1995.

Ma SK, Wan TS \& Chan LC. Cytogenetics and molecular genetics of childhood leukemia. Hematol Oncol 17:91-105, 1999.

Maciejewski JP, Tiu RV \& O'Keefe C. Application of array-based whole genome scanning technologies as a cytogenetic tool in haematological malignancies. Br J Haematol 146:479-488, 2009.

Maillard I, Fang T \& Pear WS. Regulation of lymphoid development, differentiation, and function by the Notch pathway. Annu Rev Immunol 23:945-974, 2005.

Maloney KW, Shuster JJ, Murphy S, Pullen J \& Camitta BA. Long-term results of treatment studies for childhood acute lymphoblastic leukemia: Pediatric Oncology Group studies from 1986-1994. Leukemia 14:2276-2285, 2000.

Mancini M, Scappaticci D, Cimino G, Nanni M, Derme V, Elia L, Tafuri A, Vignetti M, Vitale A, Cuneo A, Castoldi G, Saglio G, Pane F, Mecucci C, Camera A, Specchia G, Tedeschi A, Di Raimondo F, Fioritoni G, Fabbiano F, Marmont F, Ferrara F, Cascavilla N, Todeschini G, Nobile F, Kropp MG, Leoni P, Tabilio A, Luppi M, Annino L, Mandelli F \& Foa R. A comprehensive genetic classification of adult acute lymphoblastic leukemia (ALL): analysis of the GIMEMA 0496 protocol. Blood 105:3434-3441, 2005.

Marks DI, Perez WS, He W, Zhang MJ, Bishop MR, Bolwell BJ, Bredeson CN, Copelan EA, Gale RP, Gupta V, Hale GA, Isola LM, Jakubowski AA, Keating A, Klumpp TR, Lazarus HM, Liesveld JL, Maziarz RT, McCarthy PL, Sabloff M, Schiller G, Sierra J, Tallman MS, Waller EK, Wiernik PH \& Weisdorf DJ. Unrelated donor transplants in adults with Philadelphia-negative acute lymphoblastic leukemia in first complete remission. Blood 112:426-434, 2008.

Marks DI, Paietta EM, Moorman AV, Richards SM, Buck G, Dewald G, Ferrando A, Fielding AK, Goldstone AH, Ketterling RP, Litzow MR, Luger SM, McMillan AK, Mansour M, Rowe JM, Tallman MS \& Lazarus HM. T-cell acute lymphoblastic leukemia in adults: clinical features, immunophenotype, 
cytogenetics and outcome from the large randomised prospective trial (UKALL XII/ECOG 2993). Blood 114:5136-5145, 2009.

Martinelli G, Iacobucci I, Storlazzi CT, Vignetti M, Paoloni F, Cilloni D, Soverini S, Vitale A, Chiaretti S, Cimino G, Papayannidis C, Paolini S, Elia L, Fazi P, Meloni G, Amadori S, Saglio G, Pane F, Baccarani M \& Foa R. IKZF1 (Ikaros) deletions in BCR-ABL1-positive acute lymphoblastic leukemia are associated with short disease-free survival and high rate of cumulative incidence of relapse: a GIMEMA AL WP report. J Clin Oncol 27:5202-5207, 2009.

Mellentin JD, Smith SD \& Cleary ML. lyl-1, a novel gene altered by chromosomal translocation in T cell leukemia, codes for a protein with a helix-loop-helix DNA binding motif. Cell 58:77-83, 1989.

Melo JV. The diversity of BCR-ABL fusion proteins and their relationship to leukemia phenotype. Blood $88: 2375-2384,1996$.

Mertens F, Johansson B \& Mitelman F. Dichotomy of hyperdiploid acute lymphoblastic leukemia on the basis of the distribution of gained chromosomes. Cancer Genet Cytogenet 92:8-10, 1996.

Meyer C, Kowarz E, Hofmann J, Renneville A, Zuna J, Trka J, Ben Abdelali R, Macintyre E, De Braekeleer E, De Braekeleer M, Delabesse E, de Oliveira MP, Cave H, Clappier E, van Dongen JJ, Balgobind BV, van den Heuvel-Eibrink MM, Beverloo HB, Panzer-Grumayer R, Teigler-Schlegel A, Harbott J, Kjeldsen E, Schnittger S, Koehl U, Gruhn B, Heidenreich O, Chan LC, Yip SF, Krzywinski M, Eckert C, Moricke A, Schrappe M, Alonso CN, Schafer BW, Krauter J, Lee DA, Zur Stadt U, Te Kronnie G, Sutton R, Izraeli S, Trakhtenbrot L, Lo Nigro L, Tsaur G, Fechina L, Szczepanski T, Strehl S, Ilencikova D, Molkentin M, Burmeister T, Dingermann T, Klingebiel T \& Marschalek R. New insights to the MLL recombinome of acute leukemias. Leukemia 23:1490-1499, 2009.

Miller DR, Coccia PF, Bleyer WA, Lukens JN, Siegel SE, Sather HN \& Hammond GD. Early response to induction therapy as a predictor of disease-free survival and late recurrence of childhood acute lymphoblastic leukemia: a report from the Childrens Cancer Study Group. J Clin Oncol 7:1807-1815, 1989.

Mirebeau D, Acquaviva C, Suciu S, Bertin R, Dastugue N, Robert A, Boutard P, Mechinaud F, Plouvier E, Otten J, Vilmer E \& Cave H. The prognostic significance of CDKN2A, CDKN2B and MTAP inactivation in B-lineage acute lymphoblastic leukemia of childhood. Results of the EORTC studies 58881 and 58951. Haematologica 91:881-885, 2006.

Mitchell CD, Richards SM, Kinsey SE, Lilleyman J, Vora A \& Eden TO. Benefit of dexamethasone compared with prednisolone for childhood acute lymphoblastic leukaemia: results of the UK Medical Research Council ALL97 randomized trial. Br J Haematol 129:734-745, 2005.

Moghrabi A, Levy DE, Asselin B, Barr R, Clavell L, Hurwitz C, Samson Y, Schorin M, Dalton VK, Lipshultz SE, Neuberg DS, Gelber RD, Cohen HJ, Sallan SE \& Silverman LB. Results of the DanaFarber Cancer Institute ALL Consortium Protocol 95-01 for children with acute lymphoblastic leukemia. Blood 109:896-904, 2007.

Moorman AV, Harrison CJ, Buck GA, Richards SM, Secker-Walker LM, Martineau M, Vance GH, Cherry AM, Higgins RR, Fielding AK, Foroni L, Paietta E, Tallman MS, Litzow MR, Wiernik PH, Rowe JM, Goldstone AH \& Dewald GW. Karyotype is an independent prognostic factor in adult acute lymphoblastic leukemia (ALL): analysis of cytogenetic data from patients treated on the Medical Research Council (MRC) UKALLXII/Eastern Cooperative Oncology Group (ECOG) 2993 trial. Blood 109:3189-3197, 2007.

Moos PJ, Raetz EA, Carlson MA, Szabo A, Smith FE, Willman C, Wei Q, Hunger SP \& Carroll WL. Identification of gene expression profiles that segregate patients with childhood leukemia. Clin Cancer Res 8:3118-3130, 2002.

Moricke A, Reiter A, Zimmermann M, Gadner H, Stanulla M, Dordelmann M, Loning L, Beier R, Ludwig WD, Ratei R, Harbott J, Boos J, Mann G, Niggli F, Feldges A, Henze G, Welte K, Beck JD, Klingebiel T, Niemeyer C, Zintl F, Bode U, Urban C, Wehinger H, Niethammer D, Riehm H \& Schrappe M. Riskadjusted therapy of acute lymphoblastic leukemia can decrease treatment burden and improve survival: treatment results of 2169 unselected pediatric and adolescent patients enrolled in the trial ALL-BFM 95. Blood 111:4477-4489, 2008.

Mullighan CG, Goorha S, Radtke I, Miller CB, Coustan-Smith E, Dalton JD, Girtman K, Mathew S, Ma J, Pounds SB, Su X, Pui CH, Relling MV, Evans WE, Shurtleff SA \& Downing JR. Genome-wide analysis of genetic alterations in acute lymphoblastic leukaemia. Nature 446:758-764, 2007. 
Mullighan CG, Miller CB, Radtke I, Phillips LA, Dalton J, Ma J, White D, Hughes TP, Le Beau MM, Pui $\mathrm{CH}$, Relling MV, Shurtleff SA \& Downing JR. BCR-ABL1 lymphoblastic leukaemia is characterized by the deletion of Ikaros. Nature 453:110-114, 2008.

Mullighan CG \& Downing JR. Genome-wide profiling of genetic alterations in acute lymphoblastic leukemia: recent insights and future directions. Leukemia 23:1209-1218, 2009a.

Mullighan CG, Su X, Zhang J, Radtke I, Phillips LA, Miller CB, Ma J, Liu W, Cheng C, Schulman BA, Harvey RC, Chen IM, Clifford RJ, Carroll WL, Reaman G, Bowman WP, Devidas M, Gerhard DS, Yang W, Relling MV, Shurtleff SA, Campana D, Borowitz MJ, Pui CH, Smith M, Hunger SP, Willman CL \& Downing JR. Deletion of IKZF1 and prognosis in acute lymphoblastic leukemia. N Engl J Med 360:470480, 2009 b.

Murphy SB, Bowman WP, Abromowitch M, Mirro J, Ochs J, Rivera G, Pui CH, Fairclough D \& Berard CW. Results of treatment of advanced-stage Burkitt's lymphoma and B cell (SIg+) acute lymphoblastic leukemia with high-dose fractionated cyclophosphamide and coordinated high-dose methotrexate and cytarabine. J Clin Oncol 4:1732-1739, 1986.

Nachman J, Sather HN, Buckley JD, Gaynon PS, Steinherz PG, Tubergen DG, Lampkin BC \& Hammond GD. Young adults 16-21 years of age at diagnosis entered on Childrens Cancer Group acute lymphoblastic leukemia and acute myeloblastic leukemia protocols. Results of treatment. Cancer 71:3377-3385, 1993.

Nachman J. Clinical characteristics, biologic features and outcome for young adult patients with acute lymphoblastic leukaemia. Br J Haematol 130:166-173, 2005.

Nachman JB, La MK, Hunger SP, Heerema NA, Gaynon PS, Hastings C, Mattano LA,Jr, Sather H, Devidas M, Freyer DR, Steinherz PG \& Seibel NL. Young adults with acute lymphoblastic leukemia have an excellent outcome with chemotherapy alone and benefit from intensive postinduction treatment: a report from the children's oncology group. J Clin Oncol 27:5189-5194, 2009.

Novara F, Beri S, Bernardo ME, Bellazzi R, Malovini A, Ciccone R, Cometa AM, Locatelli F, Giorda R \& Zuffardi O. Different molecular mechanisms causing 9p21 deletions in acute lymphoblastic leukemia of childhood. Hum Genet 126:511-520, 2009.

Nowell PC \& Hungerford DA. Chromosome studies on normal and leukemic human leukocytes. J Natl Cancer Inst 25:85-109, 1960.

Nutt SL, Heavey B, Rolink AG \& Busslinger M. Commitment to the B-lymphoid lineage depends on the transcription factor Pax5. Nature 401:556-562, 1999.

Omura GA, Moffitt S, Vogler WR \& Salter MM. Combination chemotherapy of adult acute lymphoblastic leukemia with randomized central nervous system prophylaxis. Blood 55:199-204, 1980.

Osada H \& Takahashi T. MicroRNAs in biological processes and carcinogenesis. Carcinogenesis 28:2-12, 2007.

Paulsson K, Heidenblad M, Morse H, Borg A, Fioretos T \& Johansson B. Identification of cryptic aberrations and characterization of translocation breakpoints using array CGH in high hyperdiploid childhood acute lymphoblastic leukemia. Leukemia 20:2002-2007, 2006.

Paulsson K, Cazier JB, Macdougall F, Stevens J, Stasevich I, Vrcelj N, Chaplin T, Lillington DM, Lister TA \& Young BD. Microdeletions are a general feature of adult and adolescent acute lymphoblastic leukemia: Unexpected similarities with pediatric disease. Proc Natl Acad Sci USA 105:6708-6713, 2008.

Pearson OH \& Eliel LP. Use of pituitary adrenocorticotropic hormone (ACTH) and cortisone in lymphomas and leukemias. JAMA 144:1349-1353, 1950.

Perry A, Nobori T, Ru N, Anderl K, Borell TJ, Mohapatra G, Feuerstein BG, Jenkins RB \& Carson DA. Detection of p16 gene deletions in gliomas: a comparison of fluorescence in situ hybridization (FISH) versus quantitative PCR. J Neuropathol Exp Neurol 56:999-1008, 1997.

Peto R, Pike MC, Armitage P, Breslow NE, Cox DR, Howard SV, Mantel N, McPherson K, Peto J \& Smith PG. Design and analysis of randomized clinical trials requiring prolonged observation of each patient. II. Analysis and examples. Br J Cancer 35:1-39, 1977.

Pieters R, Schrappe M, De Lorenzo P, Hann I, De Rossi G, Felice M, Hovi L, LeBlanc T, Szczepanski T, Ferster A, Janka G, Rubnitz J, Silverman L, Stary J, Campbell M, Li CK, Mann G, Suppiah R, Biondi A, Vora A \& Valsecchi MG. A treatment protocol for infants younger than 1 year with acute lymphoblastic leukaemia (Interfant-99): an observational study and a multicentre randomised trial. Lancet 370:240-250, 2007. 
Pinkel D, Simone J, Hustu HO \& Aur RJ. Nine years' experience with "total therapy" of childhood acute lymphocytic leukemia. Pediatrics 50:246-251, 1972.

Pollack JR, Perou CM, Alizadeh AA, Eisen MB, Pergamenschikov A, Williams CF, Jeffrey SS, Botstein D \& Brown PO. Genome-wide analysis of DNA copy-number changes using cDNA microarrays. Nat Genet 23:41-46, 1999.

Propp S \& Lizzi FA. Philadelphia chromosome in acute lymphocytic leukemia. Blood 36:353-360, 1970.

Pui CH \& Evans WE. Acute lymphoblastic leukemia. N Engl J Med 339:605-615, 1998.

Pui CH, Boyett JM, Rivera GK, Hancock ML, Sandlund JT, Ribeiro RC, Rubnitz JE, Behm FG, Raimondi SC, Gajjar A, Razzouk B, Campana D, Kun LE, Relling MV \& Evans WE. Long-term results of Total Therapy studies 11, 12 and 13A for childhood acute lymphoblastic leukemia at St Jude Children's Research Hospital. Leukemia 14:2286-2294, 2000.

Pui CH, Cheng C, Leung W, Rai SN, Rivera GK, Sandlund JT, Ribeiro RC, Relling MV, Kun LE, Evans WE \& Hudson MM. Extended follow-up of long-term survivors of childhood acute lymphoblastic leukemia. N Engl J Med 349:640-649, 2003.

Pui CH, Sandlund JT, Pei D, Campana D, Rivera GK, Ribeiro RC, Rubnitz JE, Razzouk BI, Howard SC, Hudson MM, Cheng C, Kun LE, Raimondi SC, Behm FG, Downing JR, Relling MV \& Evans WE. Improved outcome for children with acute lymphoblastic leukemia: results of Total Therapy Study XIIIB at St Jude Children's Research Hospital. Blood 104:2690-2696, 2004.

Pui CH \& Evans WE. Treatment of acute lymphoblastic leukemia. N Engl J Med 354:166-178, 2006.

Pui CH, Robison LL \& Look AT. Acute lymphoblastic leukaemia. Lancet 371:1030-1043, 2008.

Pui CH, Campana D, Pei D, Bowman WP, Sandlund JT, Kaste SC, Ribeiro RC, Rubnitz JE, Raimondi SC, Onciu M, Coustan-Smith E, Kun LE, Jeha S, Cheng C, Howard SC, Simmons V, Bayles A, Metzger ML, Boyett JM, Leung W, Handgretinger R, Downing JR, Evans WE \& Relling MV. Treating childhood acute lymphoblastic leukemia without cranial irradiation. N Engl J Med 360:2730-2741, 2009.

Pullarkat V, Slovak ML, Kopecky KJ, Forman SJ \& Appelbaum FR. Impact of cytogenetics on the outcome of adult acute lymphoblastic leukemia: results of Southwest Oncology Group 9400 study. Blood 111:2563-2572, 2008.

Rabbitts TH. Chromosomal translocations in human cancer. Nature 372:143-149, 1994.

Rabin KR, Man TK, Yu A, Folsom MR, Zhao YJ, Rao PH, Plon SE \& Naeem RC. Clinical utility of array comparative genomic hybridization for detection of chromosomal abnormalities in pediatric acute lymphoblastic leukemia. Pediatr Blood Cancer 51:171-177, 2008.

Raff T, Gokbuget N, Luschen S, Reutzel R, Ritgen M, Irmer S, Bottcher S, Horst HA, Kneba M, Hoelzer D \& Bruggemann M. Molecular relapse in adult standard-risk ALL patients detected by prospective MRD monitoring during and after maintenance treatment: data from the GMALL 06/99 and 07/03 trials. Blood 109:910-915, 2007.

Raimondi SC. Current status of cytogenetic research in childhood acute lymphoblastic leukemia. Blood 81:2237-2251, 1993.

Ramanujachar R, Richards S, Hann I \& Webb D. Adolescents with acute lymphoblastic leukaemia: emerging from the shadow of paediatric and adult treatment protocols. Pediatr Blood Cancer 47:748756, 2006.

Ramanujachar R, Richards S, Hann I, Goldstone A, Mitchell C, Vora A, Rowe J \& Webb D. Adolescents with acute lymphoblastic leukaemia: outcome on UK national paediatric (ALL97) and adult (UKALLXII/E2993) trials. Pediatr Blood Cancer 48:254-261, 2007.

Reiter A, Schrappe M, Tiemann M, Ludwig WD, Yakisan E, Zimmermann M, Mann G, Chott A, Ebell W, Klingebiel T, Graf N, Kremens B, Muller-Weihrich S, Pluss HJ, Zintl F, Henze G \& Riehm H. Improved treatment results in childhood B-cell neoplasms with tailored intensification of therapy: A report of the Berlin-Frankfurt-Munster Group Trial NHL-BFM 90. Blood 94:3294-3306, 1999.

Rempel RE, Saenz-Robles MT, Storms R, Morham S, Ishida S, Engel A, Jakoi L, Melhem MF, Pipas JM, Smith C \& Nevins JR. Loss of E2F4 activity leads to abnormal development of multiple cellular lineages. Mol Cell 6:293-306, 2000.

Ren R. Mechanisms of $B C R-A B L$ in the pathogenesis of chronic myelogenous leukaemia. Nat Rev Cancer 5:172-183, 2005. 
Ribera JM, Oriol A, Bethencourt C, Parody R, Hernandez-Rivas JM, Moreno MJ, del Potro E, Torm M, Rivas C, Besalduch J, Sanz MA \& Ortega JJ. Comparison of intensive chemotherapy, allogeneic or autologous stem cell transplantation as post-remission treatment for adult patients with high-risk acute lymphoblastic leukemia. Results of the PETHEMA ALL-93 trial. Haematologica 90:1346-1356, 2005.

Ribera JM, Oriol A, Sanz MA, Tormo M, Fernandez-Abellan P, del Potro E, Abella E, Bueno J, Parody R, Bastida P, Grande C, Heras I, Bethencourt C, Feliu E \& Ortega JJ. Comparison of the results of the treatment of adolescents and young adults with standard-risk acute lymphoblastic leukemia with the Programa Espanol de Tratamiento en Hematologia pediatric-based protocol ALL-96. J Clin Oncol 26:1843-1849, 2008.

Ringden O, Pavletic SZ, Anasetti C, Barrett AJ, Wang T, Wang D, Antin JH, Di Bartolomeo P, Bolwell BJ, Bredeson C, Cairo MS, Gale RP, Gupta V, Hahn T, Hale GA, Halter J, Jagasia M, Litzow MR, Locatelli F, Marks DI, McCarthy PL, Cowan MJ, Petersdorf EW, Russell JA, Schiller GJ, Schouten H, Spellman S, Verdonck LF, Wingard JR, Horowitz MM \& Arora M. The graft-versus-leukemia effect using matched unrelated donors is not superior to HLA-identical siblings for hematopoietic stem cell transplantation. Blood 113:3110-3118, 2009.

Ringner M, Peterson C \& Khan J. Analyzing array data using supervised methods. Pharmacogenomics 3:403-415, 2002.

Robinson HM, Broadfield ZJ, Cheung KL, Harewood L, Harris RL, Jalali GR, Martineau M, Moorman AV, Taylor KE, Richards S, Mitchell C \& Harrison CJ. Amplification of AML1 in acute lymphoblastic leukemia is associated with a poor outcome. Leukemia 17:2249-2250, 2003.

Robinson HM, Harrison CJ, Moorman AV, Chudoba I \& Strefford JC. Intrachromosomal amplification of chromosome 21 (iAMP21) may arise from a breakage-fusion-bridge cycle. Genes Chromosomes Cancer 46:318-326, 2007.

Romana SP, Le Coniat M \& Berger R. t(12;21): a new recurrent translocation in acute lymphoblastic leukemia. Genes Chromosomes Cancer 9:186-191, 1994.

Roman-Gomez J, Jimenez-Velasco A, Castillejo JA, Agirre X, Barrios M, Navarro G, Molina FJ, Calasanz MJ, Prosper F, Heiniger A \& Torres A. Promoter hypermethylation of cancer-related genes: a strong independent prognostic factor in acute lymphoblastic leukemia. Blood 104:2492-2498, 2004.

Roman-Gomez J, Jimenez-Velasco A, Barrios M, Prosper F, Heiniger A, Torres A \& Agirre X. Poor prognosis in acute lymphoblastic leukemia may relate to promoter hypermethylation of cancer-related genes. Leuk Lymphoma 48:1269-1282, 2007.

Ross ME, Zhou X, Song G, Shurtleff SA, Girtman K, Williams WK, Liu HC, Mahfouz R, Raimondi SC, Lenny N, Patel A \& Downing JR. Classification of pediatric acute lymphoblastic leukemia by gene expression profiling. Blood 102:2951-2959, 2003.

Rowe JM, Buck G, Burnett AK, Chopra R, Wiernik PH, Richards SM, Lazarus HM, Franklin IM, Litzow MR, Ciobanu N, Prentice HG, Durrant J, Tallman MS \& Goldstone AH. Induction therapy for adults with acute lymphoblastic leukemia: results of more than 1500 patients from the international ALL trial: MRC UKALL XII/ECOG E2993. Blood 106:3760-3767, 2005.

Rubnitz JE, Downing JR, Pui CH, Shurtleff SA, Raimondi SC, Evans WE, Head DR, Crist WM, Rivera GK, Hancock ML, Boyett JM, Buijs A, Grosveld G \& Behm FG. TEL gene rearrangement in acute lymphoblastic leukemia: a new genetic marker with prognostic significance. J Clin Oncol 15:1150-1157, 1997.

Saarinen UM, Mellander L, Nysom K, Ringden O, Schroeder H, Glomstein A \& Gustafsson G. Allogeneic bone marrow transplantation in first remission for children with very high-risk acute lymphoblastic leukemia: a retrospective case-control study in the Nordic countries. Bone Marrow Transplant 17:357363, 1996.

Saarinen-Pihkala UM, Gustafsson G, Ringden O, Heilmann C, Glomstein A, Lonnerholm G, Abrahamsson J, Bekassy AN, Schroeder H, Mellander L \& Nordic Society of Pediatric Hematology and,Oncology. No disadvantage in outcome of using matched unrelated donors as compared with matched sibling donors for bone marrow transplantation in children with acute lymphoblastic leukemia in second remission. J Clin Oncol 19:3406-3414, 2001.

Saarinen-Pihkala UM, Gustafsson G, Carlsen N, Flaegstad T, Forestier E, Glomstein A, Kristinsson J, Lanning M, Schroeder H \& Mellander L. Outcome of children with high-risk acute lymphoblastic leukemia (HR-ALL): Nordic results on an intensive regimen with restricted central nervous system irradiation. Pediatr Blood Cancer 42:8-23, 2004. 
Saarinen-Pihkala UM, Heilmann C, Winiarski J, Glomstein A, Abrahamsson J, Arvidson J, Bekassy AN, Forestier E, Jonmundsson G, Schroeder H, Vettenranta K, Wesenberg F \& Gustafsson G. Pathways through relapses and deaths of children with acute lymphoblastic leukemia: role of allogeneic stem-cell transplantation in Nordic data. J Clin Oncol 24:5750-5762, 2006.

Saiki RK, Gelfand DH, Stoffel S, Scharf SJ, Higuchi R, Horn GT, Mullis KB \& Erlich HA. Primer-directed enzymatic amplification of DNA with a thermostable DNA polymerase. Science 239:487-491, 1988.

Sauerbrey A, Zintl F \& Volm M. Expression of metallothionein in initial and relapsed childhood acute lymphoblastic leukemia. Ann Hematol 69:111-115, 1994.

Savola S, Nardi F, Scotlandi K, Picci P \& Knuutila S. Microdeletions in 9p21.3 induce false negative results in CDKN2A FISH analysis of Ewing sarcoma. Cytogenet Genome Res 119:21-26, 2007.

Schena M, Shalon D, Davis RW \& Brown PO. Quantitative monitoring of gene expression patterns with a complementary DNA microarray. Science 270:467-470, 1995.

Schiffer CA. Differences in outcome in adolescents with acute lymphoblastic leukemia: a consequence of better regimens? Better doctors? Both? J Clin Oncol 21:760-761, 2003.

Schneider NR, Carroll AJ, Shuster JJ, Pullen DJ, Link MP, Borowitz MJ, Camitta BM, Katz JA \& Amylon MD. New recurring cytogenetic abnormalities and association of blast cell karyotypes with prognosis in childhood T-cell acute lymphoblastic leukemia: a pediatric oncology group report of 343 cases. Blood 96:2543-2549, 2000.

Schrappe M, Reiter A, Ludwig WD, Harbott J, Zimmermann M, Hiddemann W, Niemeyer C, Henze G, Feldges A, Zintl F, Kornhuber B, Ritter J, Welte K, Gadner H \& Riehm H. Improved outcome in childhood acute lymphoblastic leukemia despite reduced use of anthracyclines and cranial radiotherapy: results of trial ALL-BFM 90. Blood 95:3310-3322, 2000a.

Schrappe M, Reiter A, Zimmermann M, Harbott J, Ludwig WD, Henze G, Gadner H, Odenwald E \& Riehm H. Long-term results of four consecutive trials in childhood ALL performed by the ALL-BFM study group from 1981 to 1995. Leukemia 14:2205-2222, $2000 \mathrm{~b}$.

Schrauder A, Reiter A, Gadner H, Niethammer D, Klingebiel T, Kremens B, Peters C, Ebell W, Zimmermann M, Niggli F, Ludwig WD, Riehm H, Welte K \& Schrappe M. Superiority of allogeneic hematopoietic stem-cell transplantation compared with chemotherapy alone in high-risk childhood T-cell acute lymphoblastic leukemia: results from ALL-BFM 90 and 95. J Clin Oncol 24:5742-5749, 2006.

Schrauder A, von Stackelberg A, Schrappe M, Cornish J, Peters C, ALL-BFM Study G \& Ebmt Pd WP. Allogeneic hematopoietic SCT in children with ALL: current concepts of ongoing prospective SCT trials. Bone Marrow Transplant 41:S71-74, 2008.

Schultz KR, Bowman WP, Aledo A, Slayton WB, Sather H, Devidas M, Wang C, Davies SM, Gaynon PS, Trigg M, Rutledge R, Burden L, Jorstad D, Carroll A, Heerema NA, Winick N, Borowitz MJ, Hunger SP, Carroll WL \& Camitta B. Improved early event-free survival with imatinib in Philadelphia chromosome-positive acute lymphoblastic leukemia: a children's oncology group study. J Clin Oncol 27:5175-5181, 2009.

Seabright M. A rapid banding technique for human chromosomes. Lancet 2:971-972, 1971.

Secker-Walker LM, Lawler SD \& Hardisty RM. Prognostic implications of chromosomal findings in acute lymphoblastic leukaemia at diagnosis. Br Med J 2:1529-1530, 1978.

Seibel NL. Treatment of acute lymphoblastic leukemia in children and adolescents: peaks and pitfalls. Hematology 374-380, 2008.

Seibel NL, Steinherz PG, Sather HN, Nachman JB, Delaat C, Ettinger LJ, Freyer DR, Mattano LA,Jr, Hastings CA, Rubin CM, Bertolone K, Franklin JL, Heerema NA, Mitchell TL, Pyesmany AF, La MK, Edens C \& Gaynon PS. Early postinduction intensification therapy improves survival for children and adolescents with high-risk acute lymphoblastic leukemia: a report from the Children's Oncology Group. Blood 111:2548-2555, 2008.

Shaffer LG, Slovak ML \& Campbell LJISCN (2009): An International System for Human Cytogenetic Nomenclature. Basel, S. Karger. 2009.

Shendure J. The beginning of the end for microarrays? Nat Methods 5:585-587, 2008.

Shimoda R, Achanzar WE, Qu W, Nagamine T, Takagi H, Mori M \& Waalkes MP. Metallothionein is a potential negative regulator of apoptosis. Toxicol Sci 73:294-300, 2003. 
Sigvardsson M, O'Riordan M \& Grosschedl R. EBF and E47 collaborate to induce expression of the endogenous immunoglobulin surrogate light chain genes. Immunity 7:25-36, 1997.

Silverman LB, Declerck L, Gelber RD, Dalton VK, Asselin BL, Barr RD, Clavell LA, Hurwitz CA, Moghrabi A, Samson Y, Schorin MA, Lipton JM, Cohen HJ \& Sallan SE. Results of Dana-Farber Cancer Institute Consortium protocols for children with newly diagnosed acute lymphoblastic leukemia (1981-1995). Leukemia 14:2247-2256, 2000.

Silverman LB, Gelber RD, Dalton VK, Asselin BL, Barr RD, Clavell LA, Hurwitz CA, Moghrabi A, Samson Y, Schorin MA, Arkin S, Declerck L, Cohen HJ \& Sallan SE. Improved outcome for children with acute lymphoblastic leukemia: results of Dana-Farber Consortium Protocol 91-01. Blood 97:1211-1218, 2001.

Smith M, Arthur D, Camitta B, Carroll AJ, Crist W, Gaynon P, Gelber R, Heerema N, Korn EL, Link M, Murphy S, Pui CH, Pullen J, Reamon G, Sallan SE, Sather H, Shuster J, Simon R, Trigg M, Tubergen D, Uckun F \& Ungerleider R. Uniform approach to risk classification and treatment assignment for children with acute lymphoblastic leukemia. J Clin Oncol 14:18-24, 1996.

Solinas-Toldo S, Lampel S, Stilgenbauer S, Nickolenko J, Benner A, Dohner H, Cremer T \& Lichter P. Matrix-based comparative genomic hybridization: biochips to screen for genomic imbalances. Genes Chromosomes Cancer 20:399-407, 1997.

Speicher MR, Gwyn Ballard S \& Ward DC. Karyotyping human chromosomes by combinatorial multifluor FISH. Nat Genet 12:368-375, 1996.

Steinemann D, Cario G, Stanulla M, Karawajew L, Tauscher M, Weigmann A, Gohring G, Ludwig WD, Harbott J, Radlwimmer B, Bartram C, Lichter P, Schrappe M \& Schlegelberger B. Copy number alterations in childhood acute lymphoblastic leukemia and their association with minimal residual disease. Genes Chromosomes Cancer 47:471-480, 2008.

Stock W, La M, Sanford B, Bloomfield CD, Vardiman JW, Gaynon P, Larson RA \& Nachman J. What determines the outcomes for adolescents and young adults with acute lymphoblastic leukemia treated on cooperative group protocols? A comparison of Children's Cancer Group and Cancer and Leukemia Group B studies. Blood 112:1646-1654, 2008.

Stott FJ, Bates S, James MC, McConnell BB, Starborg M, Brookes S, Palmero I, Ryan K, Hara E, Vousden $\mathrm{KH} \&$ Peters $\mathrm{G}$. The alternative product from the human CDKN2A locus, p14(ARF), participates in a regulatory feedback loop with p53 and MDM2. EMBO J 17:5001-5014, 1998.

Strefford JC, van Delft FW, Robinson HM, Worley H, Yiannikouris O, Selzer R, Richmond T, Hann I, Bellotti T, Raghavan M, Young BD, Saha V \& Harrison CJ. Complex genomic alterations and gene expression in acute lymphoblastic leukemia with intrachromosomal amplification of chromosome 21. Proc Natl Acad Sci USA 103:8167-8172, 2006.

Strefford JC, Worley H, Barber K, Wright S, Stewart AR, Robinson HM, Bettney G, van Delft FW, Atherton MG, Davies T, Griffiths M, Hing S, Ross FM, Talley P, Saha V, Moorman AV \& Harrison CJ. Genome complexity in acute lymphoblastic leukemia is revealed by array-based comparative genomic hybridization. Oncogene 26:4306-4318, 2007.

Su XY, Della-Valle V, Andre-Schmutz I, Lemercier C, Radford-Weiss I, Ballerini P, Lessard M, LafagePochitaloff M, Mugneret F, Berger R, Romana SP, Bernard OA \& Penard-Lacronique V. HOX11L2/ TLX3 is transcriptionally activated through T-cell regulatory elements downstream of BCL11B as a result of the $\mathrm{t}(5 ; 14)(\mathrm{q} 35 ; \mathrm{q} 32)$. Blood 108:4198-4201, 2006.

Sulong S, Moorman AV, Irving JA, Strefford JC, Konn ZJ, Case MC, Minto L, Barber KE, Parker H, Wright SL, Stewart AR, Bailey S, Bown NP, Hall AG \& Harrison CJ. A comprehensive analysis of the CDKN2A gene in childhood acute lymphoblastic leukemia reveals genomic deletion, copy number neutral loss of heterozygosity, and association with specific cytogenetic subgroups. Blood 113:100-107, 2009.

Swets JA. Measuring the accuracy of diagnostic systems. Science 240:1285-1293, 1988.

Takaoka A, Hayakawa S, Yanai H, Stoiber D, Negishi H, Kikuchi H, Sasaki S, Imai K, Shibue T, Honda K \& Taniguchi T. Integration of interferon-alpha/beta signalling to $\mathrm{p} 53$ responses in tumour suppression and antiviral defence. Nature 424:516-523, 2003.

Teuffel O, Dettling M, Cario G, Stanulla M, Schrappe M, Buhlmann P, Niggli FK \& Schafer BW. Gene expression profiles and risk stratification in childhood acute lymphoblastic leukemia. Haematologica 89:801-808, 2004. 
Thomas DA, Faderl S, Cortes J, O'Brien S, Giles FJ, Kornblau SM, Garcia-Manero G, Keating MJ, Andreeff M, Jeha S, Beran M, Verstovsek S, Pierce S, Letvak L, Salvado A, Champlin R, Talpaz M \& Kantarjian $\mathrm{H}$. Treatment of Philadelphia chromosome-positive acute lymphocytic leukemia with hyper-CVAD and imatinib mesylate. Blood 103:4396-4407, 2004.

Thomas X, Danaila C, Le QH, Sebban C, Troncy J, Charrin C, Lheritier V, Michallet M, Magaud JP \& Fiere D. Long-term follow-up of patients with newly diagnosed adult acute lymphoblastic leukemia: a single institution experience of 378 consecutive patients over a 21-year period. Leukemia 15:1811-1822, 2001.

Thomas X, Boiron JM, Huguet F, Dombret H, Bradstock K, Vey N, Kovacsovics T, Delannoy A, Fegueux N, Fenaux P, Stamatoullas A, Vernant JP, Tournilhac O, Buzyn A, Reman O, Charrin C, Boucheix C, Gabert J, Lheritier V \& Fiere D. Outcome of treatment in adults with acute lymphoblastic leukemia: analysis of the LALA-94 trial. J Clin Oncol 22:4075-4086, 2004.

Ting AH, McGarvey KM \& Baylin SB. The cancer epigenome--components and functional correlates. Genes Dev 20:3215-3231, 2006.

Tjio JH \& Levan A. The chromosome number of man. Hereditas 42:1-6, 1956.

Tjio JH \& Whang J. Chromosome preparations of bone marrow cells without prior in vitro culture or in vivo colchicine administration. Stain Technol 37:17-20, 1962.

Tsuchida M, Ikuta K, Hanada R, Saito T, Isoyama K, Sugita K, Toyoda Y, Manabe A, Koike K, Kinoshita A, Maeda M, Ishimoto K, Sato T, Okimoto Y, Kaneko T, Kajiwara M, Sotomatsu M, Hayashi Y, Yabe H, Hosoya R, Hoshi Y, Ohira M, Bessho F, Tsunematsu Y, Tsukimoto I \& Nakazawa S. Long-term followup of childhood acute lymphoblastic leukemia in Tokyo Children's Cancer Study Group 1981-1995. Leukemia 14:2295-2306, 2000.

Tyybakinoja A, Elonen E, Vauhkonen H, Saarela J \& Knuutila S. Single nucleotide polymorphism microarray analysis of karyotypically normal acute myeloid leukemia reveals frequent copy number neutral loss of heterozygosity. Haematologica 93:631-632, 2008.

Uckun FM, Sensel MG, Sather HN, Gaynon PS, Arthur DC, Lange BJ, Steinherz PG, Kraft P, Hutchinson $\mathrm{R}$, Nachman JB, Reaman GH \& Heerema NA. Clinical significance of translocation $t(1 ; 19)$ in childhood acute lymphoblastic leukemia in the context of contemporary therapies: a report from the Children's Cancer Group. J Clin Oncol 16:527-535, 1998.

Uckun FM, Pallisgaard N, Hokland P, Navara C, Narla R, Gaynon PS, Sather H \& Heerema N. Expression of TEL-AML1 fusion transcripts and response to induction therapy in standard risk acute lymphoblastic leukemia. Leuk Lymphoma 42:41-56, 2001.

van Dongen JJ, Seriu T, Panzer-Grumayer ER, Biondi A, Pongers-Willemse MJ, Corral L, Stolz F, Schrappe M, Masera G, Kamps WA, Gadner H, van Wering ER, Ludwig WD, Basso G, de Bruijn MA, Cazzaniga G, Hettinger K, van der Does-van den Berg,A., Hop WC, Riehm H \& Bartram CR. Prognostic value of minimal residual disease in acute lymphoblastic leukaemia in childhood. Lancet 352:1731-1738, 1998.

van Zutven LJ, van Drunen E, de Bont JM, Wattel MM, Den Boer ML, Pieters R, Hagemeijer A, Slater RM \& Beverloo HB. CDKN2 deletions have no prognostic value in childhood precursor-B acute lymphoblastic leukaemia. Leukemia 19:1281-1284, 2005.

Wassmann B, Pfeifer H, Stadler M, Bornhauser M, Bug G, Scheuring UJ, Bruck P, Stelljes M, Schwerdtfeger R, Basara N, Perz J, Bunjes D, Ledderose G, Mahlberg R, Binckebanck A, Gschaidmeier H, Hoelzer D \& Ottmann OG. Early molecular response to posttransplantation imatinib determines outcome in MRD+ Philadelphia-positive acute lymphoblastic leukemia (Ph+ ALL). Blood 106:458-463, 2005.

Weber HO, Samuel T, Rauch P \& Funk JO. Human p14(ARF)-mediated cell cycle arrest strictly depends on intact p53 signaling pathways. Oncogene 21:3207-3212, 2002.

Weng AP, Ferrando AA, Lee W, Morris JP,4th, Silverman LB, Sanchez-Irizarry C, Blacklow SC, Look AT \& Aster JC. Activating mutations of NOTCH1 in human T cell acute lymphoblastic leukemia. Science 306:269-271, 2004.

Wheeler KA, Richards SM, Bailey CC, Gibson B, Hann IM, Hill FG \& Chessells JM. Bone marrow transplantation versus chemotherapy in the treatment of very high-risk childhood acute lymphoblastic leukemia in first remission: results from Medical Research Council UKALL X and XI. Blood 96:24122418, 2000.

Wiemels JL, Cazzaniga G, Daniotti M, Eden OB, Addison GM, Masera G, Saha V, Biondi A \& Greaves MF. Prenatal origin of acute lymphoblastic leukaemia in children. Lancet 354:1499-1503, 1999. 
Xia Y, Brown L, Yang CY, Tsan JT, Siciliano MJ, Espinosa R,3rd, Le Beau MM \& Baer RJ. TAL2, a helixloop-helix gene activated by the $(7 ; 9)(\mathrm{q} 34 ; \mathrm{q} 32)$ translocation in human T-cell leukemia. Proc Natl Acad Sci USA 88:11416-11420, 1991.

Yang JJ, Bhojwani D, Yang W, Cai X, Stocco G, Crews K, Wang J, Morrison D, Devidas M, Hunger SP, Willman CL, Raetz EA, Pui CH, Evans WE, Relling MV \& Carroll WL. Genome-wide copy number profiling reveals molecular evolution from diagnosis to relapse in childhood acute lymphoblastic leukemia. Blood 112:4178-4183, 2008.

Yeoh EJ, Ross ME, Shurtleff SA, Williams WK, Patel D, Mahfouz R, Behm FG, Raimondi SC, Relling MV, Patel A, Cheng C, Campana D, Wilkins D, Zhou X, Li J, Liu H, Pui CH, Evans WE, Naeve C, Wong L \& Downing JR. Classification, subtype discovery, and prediction of outcome in pediatric acute lymphoblastic leukemia by gene expression profiling. Cancer Cell 1:133-143, 2002.

zur Stadt U, Harms DO, Schluter S, Schrappe M, Goebel U, Spaar H, Janka G \& Kabisch H. MRD at the end of induction therapy in childhood acute lymphoblastic leukemia: outcome prediction strongly depends on the therapeutic regimen. Leukemia 15:283-285, 2001. 